\title{
New drugs are not enough-drug repositioning in oncology: An update
}

\author{
ROMINA GABRIELA ARMANDO, DIEGO LUIS MENGUAL GÓMEZ and DANIEL EDUARDO GOMEZ
}

\author{
Laboratory of Molecular Oncology, Science and Technology Department, \\ National University of Quilmes, Bernal B1876, Argentina
}

Received August 15, 2019; Accepted December 16, 2019

DOI: $10.3892 /$ ijo.2020.4966

\begin{abstract}
Drug repositioning refers to the concept of discovering novel clinical benefits of drugs that are already known for use treating other diseases. The advantages of this are that several important drug characteristics are already established (including efficacy, pharmacokinetics, pharmacodynamics and toxicity), making the process of research for a putative drug quicker and less costly. Drug repositioning in oncology has received extensive focus. The present review summarizes the most prominent examples of drug repositioning for the treatment of cancer, taking into consideration their primary use, proposed anticancer mechanisms and current development status.
\end{abstract}

\section{Contents}
1. Introduction
2. Artesunate
3. Auranofin
4. Benzimidazole derivatives
5. Chloroquine
6. Chlorpromazine
7. Clomipramine
8. Desmopressin
9. Digoxin
10. Disulfiram
11. Doxycycline
12. Fenofibrate
13. HIV protease inhibitors
14. Itraconazole
15. Ivermectin
16. Leflunomide

Correspondence to: Dr Daniel Eduardo Gomez, Laboratory of Molecular Oncology, Science and Technology Department, National University of Quilmes, Roque Saenz Peña 352, Bernal B1876, Argentina

E-mail:degomez@unq.edu.ar

Key words: drug, repositioning, repurposing, oncology

\author{
17. Lithium \\ 18. Metformin \\ 19. Niclosamide \\ 20. Nitroxoline \\ 21. Nonsteroidal anti-inflammatory drugs \\ 22. Phosphodiesterase-5 inhibitors \\ 23. Pimozide \\ 24. Propranolol \\ 25. Riluzole \\ 26. Statins \\ 27. Thalidomide \\ 28. Valproic acid \\ 29. Verapamil \\ 30. Zidovudine \\ 31. Concluding remarks
}

\section{Introduction}

In previous decades, a considerable amount of work has been conducted in search of novel oncological therapies; however, cancer remains one of the leading causes of death globally. The creation of novel drugs requires large volumes of capital, alongside extensive experimentation and testing, comprising the pioneer identification of identifiable targets and corroboration, the establishment of the lead compound, and subsequent studies into efficacy, pharmacokinetics and toxicity. After this arduous process, a minimal number of possible oncology drugs reach clinical trials, a fraction that is considered to be $\sim 5 \%$ (1). Then, if the three phases of clinical trials are successful, the new compound can be authorized for use in therapeutic settings. The traditional method of developing new anticancer drugs is a pervasive, stringent and expensive procedure $(1,2)$. Paul et al $(3,4)$ estimated that the time of development of a new drug from beginning to end was 11.4-13.5 years, and Adams et al $(3,4)$ analyzed that the costs range between 161-1,800 million dollars per pharmaceutical product.

Despite the enormous quantities of money invested in drug discovery, the number of novel molecules introduced into the clinic has not increased significantly. An alternative method in drug development is the consideration of approved known molecules used in non-oncological situations (5). This strategy has previously been termed drug repositioning, drug repurposing, drug reprofiling, therapeutic switching or indication 
switching, of which, drug repositioning is the most frequently used. The significant advantage of this strategy is that various characteristics of these drugs, such as their pharmacokinetics, pharmacodynamics and toxicity, are already well known in animals and humans (6). Due to the basis of repurposing, new candidates could be ready for clinical trials faster, and if successfully approved by regulatory authorities, their integration into medical practice could be more agile. Repurposed drugs are generally approved quicker (3-12 years) and at a reduced cost (50-60\% compared with novel compounds) (7). Also, while $\sim 10 \%$ of new drug applications gain market approval, $\sim 30 \%$ of repurposed drugs are approved, giving companies a market-driven incentive to repurpose existing assets (8).

Research into repurposing drugs in oncology has been growing in the past years (9). One example is the Repurposing Drugs in Oncology project, an international collaboration initiated by several researchers, clinicians and patient advocates working in the non-profit sector (10). It is out of the sphere of this article to discuss the strategies for identifying repurposing opportunities (knowledge mining, in silico approaches, high-throughput screening). For the analysis of those strategies, the review of Xue et al (11) is recommended. At present, $>270$ drugs are being analyzed for potential antitumor activity; of these, $\sim 29 \%$ are on the World Health Organization Essential Medicines List (12). Furthermore, $75 \%$ of these drugs are off-patent, and $\sim 57 \%$ exhibited antitumor activity in human clinical trials (11). The purpose and significance of this review is to summarize updated information concerning the most promising drugs for repurposing in oncology, and combining analysis of their structures, the tumors that are affected by them, their diverse mechanisms of action and novel information regarding the clinical trials currently being conducted.

\section{Artesunate (ART)}

ART is a semi-synthetic byproduct of artemisinin, a sesquiterpene compound isolated from the plant Artemisia annиa used to treat malaria, generally in combination with other drugs (13). Malaria is caused by Plasmodium falciparum, which mostly resides in red blood cells and contains iron-rich heme-groups (14). The proposed mechanism of action for its treatment involves the cleavage of endoperoxide bridges by iron, producing free radicals which damage biological macromolecules, causing oxidative stress in the cells of the parasite (15). Several published case reports and pilot phase I/II trials indicate clinical anticancer activity of this compound in a variety of solid tumors, such as Kaposi's sarcoma, non-small cell lung cancer (NSCLC), and colon, melanoma, breast, ovarian, prostate and renal cancers (16-28). Cases of hepatotoxicity were found when artemisinin was combined with other drugs (29).

The mechanism of action of ART in cancer remains a matter of debate. The cellular response of cancer cells to ART may be due to toxic free radicals generated by an endoperoxide moiety, cell cycle arrest, induction of apoptosis or inhibition of tumor angiogenesis (30). Multiple studies revealed that the inhibitory effect of ART on cancer cells is iron-dependent, and iron-triggered ART radicals are more likely to alkylate cellular proteins covalently $(17,31,32)$. Thus, Zhou et al (31) concluded that three modes could be involved in ART alkylation. One of them involves the molecule binding in a specific and noncovalent manner, following which a covalent bond is formed by heme activation. Additionally, ART may non-specifically bind to the surface of proteins, primarily high abundance proteins, with covalent bonds formed by heme activation. The last model proposed involves the drug alkylating heme-containing proteins through heme or amino acid residues nearby. There is no clear consensus on the topic. Currently, five clinical trials are actively recruiting (clinical trial nos. NCT02633098, NCT03093129, NCT03792516, NCT03100045 and NCT02786589).

\section{Auranofin (AUF)}

Rheumatoid arthritis is defined by persistent inflammation and joint swelling, leading to functional disability (33). AUF is an $\mathrm{Au}(\mathrm{I})$ complex containing an $\mathrm{Au}-\mathrm{S}$ bond that is maintained by a triethyl phosphine group (34). AUF is prescribed for the treatment of rheumatoid arthritis, as it can slow disease progression by inhibiting inflammation and stimulating cell-mediated immunity (35). Also, AUF inhibits phagocytosis by macrophages, as well as the release of lysosomal enzymes and antibodies involved in cytotoxicity (36). The use of AUF is rare today due to the emergence of novel antirheumatic medications. AUF's anticancer properties were observed in a wide range of cancers, such as melanoma, leukemia, gastrointestinal stromal tumor (GIST) and NSCLC, among others (37-39). This organogold compound was also used in combination with other drugs; for instance, AUF enhanced the toxicity of tumor suppressor candidate 2 (TUSC2)/erlotinib synergistically (40). In the presence of AUF, several cancer cell lines exhibited increased susceptibility to the TUSC2/erlotinib combination, undergoing apoptosis.

Furthermore, it was found that those patients with rheumatoid arthritis treated with AUF had lower malignancy rates than those not treated (41). The antineoplastic antitumor effect is attributed mainly to the interaction of AUF with a selenocysteine residue within the redox-active domain of mitochondrial thioredoxin reductase, blocking its activity, and leading to increases in reactive oxygen species (ROS) levels and apoptosis (36). The second primary mechanism is due to the inhibition of the ubiquitin-proteasome pathway. This pathway is required for targeted degradation of proteins within cells, which is upregulated in various cancers (36). A number of the drugs undergoing repositioning affect the PI3K/Akt and mTOR signaling pathways, two pathways which are so interconnected that they could be regarded as a single pathway crucial to numerous aspects of cell growth and survival (42). Disruptions in the Akt-regulated pathways are associated with cancer, and Akt has become a valuable therapeutic target (43). Li et al (39) proposed that AUF inhibits the PI3K/Akt/mTOR axis, inducing potent anticancer activity. Currently, one clinical trial is recruiting in order to analyze the combination of AUF and Sirulimus in lung cancer (clinical trial no. NCT01737502).

\section{Benzimidazole derivatives (BZMs)}

BZMs are heterocyclic organic compounds with structural analogy to nucleotides. They are used as a significant scaffold 
for the development of a variety of drugs $(44,45)$. BZM-based compounds are broadly used as anthelmintic drugs with low mammalian toxicity and high effectivity against a wide range of helminth species (46). The mechanism of action of BZMs is based on its specific binding to tubulin, resulting in the disruption of microtubule structure and function, interfering with the microtubule-mediated transport of secretory vesicles in the absorptive tissues of helminths whilst also affecting their structure in tumor cells (47). Additionally, BZMs inhibit glucose uptake, deplete glycogen stores and decrease the formation of ATP, leading to the death of the parasites (48). Certain BZM-based compounds have shown antitumor activity. Including albendazole (ABZ), flubendazole (FLU), mebendazole (MBZ) and omeprazole (OMP).

$A B Z$. ABZ is a medication used for the treatment of a variety of helminth infestations (49). The antiproliferative effect of ABZ has been observed in vitro in hepatocellular carcinoma (HCC) and colorectal carcinoma (CRC) cells, as well as in vivo in a xenograft model of peritoneal carcinomatosis (50). ABZ was also active in cells resistant to other microtubule drugs, such as leukemia and ovarian cancer cells $(51,52)$. Its antitumor mechanism of action appears to depend on its ability to interfere with microtubules (53). Another mechanism of antitumor action has been proposed for ABZ; it inhibited vascular endothelial growth factor (VEGF) production and tumor angiogenesis in mice bearing peritoneal ovarian tumors (54). Currently, one clinical trial is recruiting to investigate $\mathrm{ABZ}$ in cancer (clinical trial no. NCT02366884).

$F L U$. FLU is mainly used in veterinary medicine for the treatment of intestinal parasites (55). FLU exhibits antiproliferative effects in leukemia, multiple myeloma (MM), melanoma and breast cancer cells (56). FLU alters microtubule structure, induces apoptosis, inhibits angiogenesis, induces cell differentiation, inhibits cell migration and induces ROS activating autophagy $(57,58)$. In a study of a panel of 26 cancer cell lines, neuroblastoma was identified as a highly FLU-sensitive malignancy (59). The antineuroblastoma activity of FLU involved the mouse double minute homolog 2 inhibitor and p53 activator nutlin-3 (59). In combined regimens, FLU enhanced the cytotoxicity of fluorouracil, doxorubicin, vinblastine and vincristine (56). At present, no clinical studies into the effects of FLU on human malignancies have been conducted (60).

$M B Z$. MBZ is used to treat several helminths infestations (49). Two different glioblastoma multiforme (GBM) animal models showed a survival benefit of treatment with MBZ (61). Additionally, growth inhibition was found in lung cancer cells (62). Growth inhibition involves the prevention of the polymerization of tubulin (63). MBZ was found to interact with several protein kinases, including inhibiting BCR-ABL (64). Furthermore, MBZ induces apoptosis in melanoma cell lines through phosphorylation of $\mathrm{Bcl} 2$ and decreased levels of the $\mathrm{X}$-linked inhibitor of apoptosis (65). Treatment with MBZ was as effective as temozolomide in a human melanoma xenograft model, and displayed strong therapeutic efficacy in animal models of both glioma and medulloblastoma, reaching therapeutically effective concentrations in the brain $(65,66)$. Currently, six actively recruiting clinical trials are ongoing, testing MBZ in different types of tumors either as a single drug or in combination with other compounds (clinical trial nos. NCT03925662, NCT03628079, NCT02644291, NCT02366884, NCT03774472, NCT01837862).

$O M P$. OMP is a widely used medication for peptide ulcers and other gastrointestinal diseases, and is a selective proton pump inhibitor (PPI) that inhibits acid secretion via specific inhibition of the $\mathrm{H}^{+} / \mathrm{K}^{+}$-ATPase system found in the parietal cells of the stomach. Jin et al (67) found that the OMP inhibits the invasion of breast and pancreatic cancer cells through inhibition of chemokine receptor type 4 transcription. Also, it was found that when it is given as an adjuvant drug for relieving common side effects of chemotherapy, OMP has a synergetic effect in improving chemoradiotherapy efficacy and decreasing rectal cancer recurrence (68). As preliminary laboratory studies have found that PPIs inhibit human fatty acid synthase and breast cancer cell survival, currently, a phase II clinical trial is actively recruiting (clinical trial no. NCT02595372) (69).

\section{Chloroquine (CLQ)}

CLQ and hydroxyCLQ (HCLQ) are 4-aminoquinolines used to treat malaria and autoimmune disorders, including lupus, rheumatoid arthritis and amebiasis (70,71). CLQ inhibits the enzyme heme polymerase, which converts toxic heme into non-toxic hemozoin. Against rheumatoid arthritis, CLQ mainly inhibits lymphoproliferation and phospholipase A2 (72,73). It also inhibits thiamine uptake (74). A vast body of experimental evidence has demonstrated the efficacy of these two drugs against a variety of malignant tumors (75). Such robust data allow the development of clinical trials for both molecules, suggesting that CLQ may be more efficacious than HCLQ (75). Although the vast majority of clinical data was found in patients with GBM and brain metastases, and in patients with BRAF mutations that block vemurafenib sensitivity, good results have also been found in clinical trials for sarcoma, MM and lung cancer (76-79). Inhibition of autophagic flux is the most studied anticancer effect of CLQ; however, other studies reported CLQ-induced cell death via inhibition of cholesterol biosynthesis $(80,81)$. Additionally, these drugs affect Toll-like receptor 9, p53 and CXC chemokine receptor 4-CXC ligand 12 pathways in cancer cells (82). In the tumor stroma, CLQ was shown to affect the tumor vasculature, cancer-associated fibroblasts and the immunological system (75). Currently, two actively recruiting clinical trials are ongoing, testing CLQ in GBM in combination with other compounds (clinical trial nos. NCT03243461 and NCT02378532).

Mefloquine (MFQ), another member of the quinoline family, has shown cytotoxicity and antiproliferative effects against several types of cancer cells. MFQ also exhibits good in vivo tumor growth inhibition as a single agent and effectively synergizes with primary cancer chemotherapeutics in arresting tumor growth (83). The mechanism of action of MFQ includes the inhibition of autophagy, lysosomal disruption, inhibition of various signaling pathways and inhibition of P-glycoprotein (P-gp), a plasma membrane ATP-binding cassette transporter that extrudes cytotoxic drugs (83). Currently, there is one active clinical trial studying MFQ in GBM (clinical trial no. NCT01430351). 


\section{Chlorpromazine (CPZ)}

$\mathrm{CPZ}$ is an antipsychotic agent clinically used for the control of psychosis symptoms (84). CPZ is a phenothiazine, and an antagonist of D2 dopamine receptors in cortical and limbic areas of the brain, and the chemical trigger zone (85). CPZ has antiproliferative activity in primary brain cultures, neuroblastomas and glioma cells (86). The antiproliferative effect of CPZ is due to cell cycle arrest at the G2/M phase. Shin et al (87) demonstrated that CPZ modulates the p21 promoter, a regulator of cell cycle progression, via the activation of the tumor-suppressor early growth response 1 independently of p53. CPZ is also able to induce apoptosis-independent autophagic cell death through the inhibition of cell cycle progression via the Beclin-1 dependent pathway and modulation of the Akt/mTOR pathway (88). The reported cytotoxic effects of $\mathrm{CPZ}$ were selective to dividing cells, with tumor cells more sensitive than non-tumor cells (89). CPZ can cross the blood-brain barrier and accumulate in the brain, two characteristics which make it an attractive adjuvant in human gliomas possessing genetic alterations such as $\mathrm{p} 53$ mutation or PTEN deletion (90). Furthermore, CPZ can circumvent multidrug resistance in cancer cells (91). It has also been reported that $\mathrm{CPZ}$ can promote apoptosis in leukemia and lymphoma cells, and enhances the cytotoxic effect of tamoxifen in tamoxifen-resistant human breast cancer cells $(92,93)$. Moreover, it has been proposed as an antitumor drug in CRC via the inhibition of sirtuin-1 (94). Additionally, CPZ was able to inhibit the growth of orthotopic liver tumors and, in combination with the antiparasitic agent pentamidine, produce synergistic inhibitory effects on tumor growth $(93,95,96)$.

\section{Clomipramine (CMP)}

CMP is a tricyclic drug; its mechanism of action is due to mixed inhibition of norepinephrine and serotonin uptake, as well as acting as an antagonist of certain G-protein coupled receptors (97). It is used in depression and other psychiatric disorders (98). Previous studies demonstrated that CMP had a selective cytotoxic effect on all tested brain tumors, probably as it crosses the blood-brain barrier and is retained in the brain for extended periods (99-102). In vitro treatment of human leukemia cell lines with CMP produces apoptosis due to a rapid increase in the production of ROS (103). Mechanistically, it has been shown that CMP exerts its antineoplastic effect vi inhibition of mitochondrial complex III, leading to decreased oxygen consumption and subsequent induction of apoptosis via caspase activation (104). CMP has also been proven to be useful in combination with other drugs, such as imatinib in glioma cells, VRP in drug-resistant tumors and dexamethasone in astrocytoma $(101,105,106)$.

\section{Desmopressin (dDAVP)}

dDAVP is a synthetic version of vasopressin; it is a medication used to treat central diabetes insipidus as a replacement for endogenous antidiuretic hormone when this molecule is insufficient or non-existent (107). dDAVP limits the amount of water eliminated in the urine, functioning at the renal collecting duct (108). It binds to vasopression receptor 2 (V2R), which signals for the translocation of aquaporin channels, causing increased water reabsorption from the urine (109). This water becomes passively redistributed from the nephron to the circulation by way of basolateral membrane channels (110). As dDAVP also stimulates the release of von Willebrand factor from endothelial cells, by acting on V2R, it is used to treat patients with mild-to-moderate cases of moderate hemophilia A and von Willebrand disease (111). The FDA authorized dDAVP for the treatment of bedwetting in 2017 (112).

The presence of vasopressin receptors has been documented in various human malignancies, including CRC, breast and small cell neuroendocrine tumors (NETs) (113). Alonso et al (114) proposed the use of dDAVP in surgical oncology, reporting that dDAVP was capable of inhibiting lung colonization by blood-borne tumor cells in preclinical mouse models of aggressive breast cancer. In a model of subcutaneous tumor manipulation and surgical excision, they found that tumor manipulation produced dissemination to the axillary nodes, increasing the number of metastasis in the lungs by up to 6 -fold; perioperative treatment with dDAVP decreased regional metastasis. The percentage of lymph node involvement in manipulated animals was $12 \%$ with dDAVP and $87 \%$ without treatment (115). Similar outcomes were reported for colon cancer (116). Regarding melanoma, an antimetastatic effect was also observed in a model overexpressing tissue inhibitor of metalloproteinases-1 (TIMP-1) (117). Additionally, perioperative administration of dDAVP significantly prolonged survival in a clinical veterinary trial in dogs with locally advanced mammary cancer (118). It has also found that Ddavp may impair the aggressiveness of residual mammary tumors during chemotherapy (116).

Summarized evidence on mechanisms of action that account for the antitumor activity of dDAVP includes direct cytostatic effects, stimulation of microenvironmental production of angiostatin and endothelial release of von Willebrand factor, a key element in resistance to metastasis (119-121). It was suggested that dDAVP disrupts cooperative interactions between the tumor and endothelial cells during early metastatic progression (120). A phase II dose-escalation trial in patients with breast carcinoma explored the safety and potential utility of perioperative administration of dDAVP in humans (clinical trial no. NCT01606072) (121). At the highest dose level evaluated $(2 \mu \mathrm{g} / \mathrm{kg}), \mathrm{dDAVP}$ appeared safe when administered in two slow infusions, before and after surgery. Notably, treatment with dDVAP was associated with reduced intraoperative bleeding and a rapid postoperative drop in circulating tumor cells, as determined via quantitative PCR of cytokeratin-19 transcripts. A trial in patients with rectal bleeding due to CRC is ongoing (clinical trial no. NCT01623206). Another research group reported enhanced efficacy of docetaxel-based therapy in combination with dDAVP for the treatment of castration-resistant prostate cancer in an orthotopic model $(122,123)$. The perioperative period is an attractive window of opportunity to reduce the risk of metastatic disease; in this context, dDAVP has emerged as a potential surgical adjuvant in oncology (124).

\section{Digoxin (DGX)}

DGX is a cardiac glycoside with a long history of use in the treatment of heart failure and arrhythmia (125). DGX acts 
by inhibiting the $\mathrm{Na}^{+} / \mathrm{K}^{+}$ATPase; such inhibition produces an increase in intracellular sodium levels, and subsequently decreased activity of the $\mathrm{Na}^{+} / \mathrm{Ca}^{2+}$ exchanger (126). This produces an increase in the intracellular calcium concentration in myocardiocytes, thereby exerting a beneficial effect in the hearts of patients with heart failure or arrhythmia (127). It was previously reported owed that DGX decreases breast cancer recurrence and aggressiveness (128). However, subsequent research found evidence that the use of DGX increased breast cancer incidence among females in Denmark, which was explained by the fact that DGX is a phytoestrogen (129). Taking this into account, a large cohort study with long-term follow-up reported that DGX reduced the incidence of prostate cancer by $25 \%$ in males (130). Also, males who used DGX for $>10$ years presented a $\sim 46 \%$ decrease in the incidence of prostate cancer. These data led to a phase II clinical trial for recurrent prostate cancer (clinical trial no. NCT01162135) (131). Estrogens diminish the levels of androgen, inhibiting prostate cancer (132).

Another mechanism proposed is the inhibition of hypoxia-inducible factor (HIF)-1 $\alpha$ synthesis and its target genes, such as VEGF (133). Additionally, the binding of cardiac glycosides to $\mathrm{Na}^{+} / \mathrm{K}^{+}$-ATPase activates proto-oncogene tyrosine-protein kinase, epidermal growth factor receptor (EGFR) and ERK1/2 phosphorylation, leading to an accumulation of p21/CIPI, consequently inducing cell cycle arrest in cancer cells (134). Frankel et al (135) conducted a phase IB clinical trial of DGX + trametinib, reporting good tolerance and high rate of disease control in BRAF wild-type metastatic melanoma. Xia et al (136) found that DGX inhibits the growth of chordoma, a rare, slow-growing malignant tumor arising from remnants of the fetal notochord, potentially by inducing the apoptosis of tumor cells via a mitochondrial pathway involving cytochrome c and caspases-3/8. Currently, 21 clinical trials using DGX (either alone or in combination with other drugs) are analyzing its antitumor properties in a variety of tumors.

\section{Disulfiram (DSF)}

DSF has been used as an alcohol deterrent for $>60$ years by inhibiting the enzyme acetaldehyde dehydrogenase; it functions by breaking down the acetaldehyde generated from enzymatic degradation of alcohol, producing an intense discomfort to alcohol consumers (137). DSF has received particular attention for its antineoplastic effects, both as a single agent and in combination (138). Some of the cytotoxic effects are due to its binding to divalent cations, interfering with copper- and zinc-dependent processes such as angiogenesis and apoptosis (139). Furthermore, it was reported that DSF suppresses the proteasome and $\mathrm{NF}-\kappa \mathrm{B}$ pathways, specifically suppressing ubiquitin E3 ligase activity $(140,141)$. DSF also affects epigenetic pathways.

DSF contains thiol-reactive functional groups; this chemistry is effective in blocking the active site of certain enzymes. In prostate cancer, DSF can act as a DNA demethylating agent via inhibition of DNA methyltransferase 1 (142). Furthermore, in primary GBM cells treated with DSF in vitro, the expression of kinases such as Polo-like kinase 1 was reduced at both the protein and mRNA levels (143). In ovarian cancer cells, DSF administration produced apoptosis via copper-dependent induction of heat-shock proteins (144). DSF was reported to stabilize a family of inhibitors called I $\kappa$ Bs, the main inhibitors of NF- $\kappa \mathrm{B}$, which is dysregulated in cancer (140). Stabilization of $\mathrm{I} \kappa \mathrm{B}$ has been found to re-sensitize gemcitabine-resistant breast and colon cancer to treatment (145). Similarly, DSF resensitized treatment-resistant GBM cell lines (146). Skrott et al (147) found that the molecular target of DSF's tumor-suppressive effects was nuclear protein localization protein 4 (Npl4), a substrate-recruiting cofactor of the cell division cycle (Cdc)48p-Npl4p-ubiquitin fusion degradation protein $1 \mathrm{p}$ segregase, which is essential for the turnover of proteins involved in multiple regulatory and stress-response pathways in cells. Cong et al (148) proposed a chemoradiation regimen targeting stem and non-stem pancreatic cancer cells with the addition of DSF. Triscott et al (149) stated that DSF kills cancer stem cells (CSCs) of a variety of cancer types and propose its use in gliomas. Based on these promising preclinical studies, a randomized phase II clinical study compared the effects of cisplatin alone or in combination with DSF, but no difference was found between treated and control groups (150). Furthermore, a clinical dose-escalation trial of DSF in patients with recurrent prostate cancer did not suggest any clinical benefits (151). However, $>15$ clinical trials are underway at present for breast, prostate, pancreatic and liver cancers, as well as melanoma and GBM, among other malignant tumors. Currently, seven actively recruiting clinical trials are ongoing testing DSF in GBM alone or in combination with other compounds, plus studies in breast and pancreatic cancers (clinical trial nos. NCT03323346, NCT02671890, NCT03950830, NCT03363659, NCT02678975, NCT03151772 and NCT02715609).

\section{Doxycycline (DXC)}

DXC is a broad-spectrum bacteriostatic antibiotic commonly used for the treatment of various bacterial infections (152). DXC inhibits translation by binding to the 16S rRNA portion of the ribosome, preventing binding of tRNA to the $30 \mathrm{~S}$ bacterial ribosomal subunit, which is necessary for the delivery of amino acids for protein synthesis. As a result of these actions, the initiation of protein synthesis by polyribosome formation is blocked (153). This antibiotic has a long half-life and is currently used successfully for the long-term treatment of acne (154). In addition to its antibiotic effects, DXC possesses various non-antimicrobial activities, including its ability to inhibit the activities of various matrix metalloproteinases (MMPs), as well as its inhibition of MMP gene expression (155). MMPs are zinc-dependent enzymes reported to be involved in the initial stages of invasion and metastasis of various tumor cells (156). Lamb et al (157) proposed a novel method for the treatment of early cancerous lesions and advanced metastatic disease by selectively targeting CSCs responsible for tumor initiation, maintenance and metastasis. DXC is known to inhibit mitochondrial biogenesis (158). The authors found a strict dependence on mitochondrial biogenesis for the clonal expansion and survival of CSCs (157). Then, the authors tested the ability of DXC to inhibit tumor-sphere formation in a broad panel of cancer cell lines derived from eight different tumor types (breast, ductal carcinoma, ovarian, prostate, lung, pancreatic, melanoma and GBM) and reported inhibitory effects of DXC on all of them (157). 
DXC can induce apoptosis in diffuse large B-cell lymphoma cell lines (159). Also, it has been used in human tumor xenografts and other animal models to reduce tumor burden and metastatic cancer cell growth. For example, in pancreatic tumor xenografts, DXC treatment reduced tumor growth by $\sim 80 \%$ (160). In a model of breast cancer bone metastasis, DXC reduced bone and bone-associated soft tissue tumor mass by $\sim 60$ and $\sim 80 \%$, respectively (161). Wan et al (162) showed that DXC, in combination with acetylsalicylic acid (AAS), lysine and mifepristone, can prevent and treat cancer metastasis. Qin et al (163) reported that DXC suppressed the proliferation and metastasis of lung cancer cells.

Regarding the mechanism of action of DXC in tumor reduction, one of the strongest $\mathrm{DXC}$ targets identified via quantitative proteomic analysis was DNA-dependent protein kinase (DNA-PKcs), which is required for proper non-homologous end-joining DNA in the maintenance of mitochondrial DNA integrity and copy number repair (164). DXC confers resistance to radiosensitivity in tumor-initiating cells (165). DNA-PKcs directly interacts with lymphoid enhancer-binding factor 1 , which acts downstream in WNT signaling (166). Alexander-Savino et al (167) analysed the gene expression profiles of compounds targeting NF- $\kappa \mathrm{B}$, and discovered that DXC is an inhibitor of the $\mathrm{NF}-\kappa \mathrm{B}$ pathway in a dose-dependent manner. DXC inhibits tumor necrosis factor (TNF)-induced $N F-\kappa B$ activation and reduces the expression of $\mathrm{NF}-\kappa \mathrm{B}$-dependent antiapoptotic proteins, including $\mathrm{Bcl} 2 \alpha$ (167). DXC induces cell death through the activation of caspase- 8 and release of cytochrome C, suggesting the involvement of both extracellular and intracellular pathways in apoptosis; through the inhibition of NF- $\mathrm{B}, \mathrm{DXC}$ increased ROS in CTCL cells and triggered apoptosis that could be reversed through treatment with antioxidants (167). At present, $>40$ clinical trials are ongoing, of which six trials are actively recruiting, testing the effects of DXC on lymphoma, breast, uterine and lung cancer, as well as in malignant pleural effusions (clinical trial nos. NCT02874430, NCT02201381, NCT01411202, NCT03465774, NCT02583282 and NCT02341209).

\section{Fenofibrate (FNF)}

FNF, a peroxisome proliferator-activated receptor $\alpha$ (PPAR- $\alpha$ ) agonist, has been used for decades to treat hypertriglyceridemia and mixed dyslipidemia (168). Multiple studies showed that it may exhibit antitumor effects in B-cell lymphoma, prostate cancer, GBM, mantle cell lymphoma, squamous cell carcinoma, HCC, glioma, melanoma, fibrosarcoma, medulloblastoma, and lung, breast and endometrial cancers (169-171). However, its antitumor mechanisms remain unclear. Li et al (169) described the induction of apoptosis in triple negative breast cancer (TNBC) cells via activation of the $N F-\kappa B$ pathway in a PPAR- $\alpha$-independent manner. Cytoprotective pathways, such as Akt1 and Erk1/2, may also be involved in the antitumor effects of FNF; inhibition of Akt and Erk1/2 pathways led to apoptosis and cell cycle arrest.

One hypothesis in oral cancer suggests targeting mitochondrial metabolism to trigger cell death through decreasing energy production from the Warburg effect (172). Jan et al (173) demonstrated that FNF delayed oral tumor development via the reprogramming of metabolic processes. FNF induced cytotoxicity by decreasing oxygen consumption rates, increasing extracellular acidification rates and reducing ATP content (173). Moreover, FNF caused changes in the protein expressions of hexokinase II pyruvate kinase, pyruvate dehydrogenase, and voltage-dependent anion channels (VDACs), all associated with the Warburg effect (174-176). Furthermore, FNF reprogrammed metabolic pathways by interrupting the binding of hexokinase II to VDAC. FBF administration suppressed the incidence rate of tongue lesions, reduced tumor sizes, decreased tumor multiplicity, and reduced the immunoreactivities of VDAC and mTOR. The molecular mechanisms involved in the capacity of FNF to retard tumor growth included downregulation of mTOR via tuberous sclerosis protein (TSC)1/2-dependent signaling through activation of AMPK and suppression of Akt, or via a TSC1/2-independent pathway through direct suppression of raptor (173). Currently, four actively recruiting clinical trials are ongoing, testing FNF in medulloblastoma, and breast and lung cancers (clinical trial nos. NCT01356290, NCT03631706, NCT02751710 and NCT03390686).

\section{HIV protease inhibitors (HPIs)}

HPIs mimic endogenous peptides and inhibit the active site of HIV aspartyl protease, a viral enzyme responsible for cleaving the Gag-Pol polyprotein (177). This class of drug has been very effective in controlling the effects of HIV in patients, and additionally has been shown to possess antitumor properties, specially nelfinavir (NLV) and ritonavir (RTV). NLV has undergone several preclinical studies in NSCLC, MM, liposarcoma, Kaposi's sarcoma, GBM, prostate cancer, breast cancer, melanoma and thyroid cancer cells with positive results (178). Also, a phase II clinical trial of NLV in combination with chemoradiation for advanced unresectable pancreatic cancer reported acceptable toxicity and promising survival (179). Another trial using NLV in recurrent adenoid cystic cancer of the head and neck showed promising results (180). An extensive number of mechanisms underlying its antitumor activity have been proposed. First, NLV inhibits the PI3K/Akt pathway and cyclin-dependent kinase 2 activity via the degradation of Cdc25A phosphatase $(181,182)$. Another mechanism involves NLV as an inhibitor of heat shock protein 90 (HSP90), suppressing its interaction with Akt (183). Also, the induction of endoplasmic reticulum (ER) stress and autophagy have been implicated (184). Furthermore, NLV was examined as an inhibitor of angiogenesis through the downregulation of HIF-1 $\alpha$ (185). Additionally, NLV has been reported to exhibit antiviral activity against specific HPV-transformed cervical carcinoma cells, potentially via the inhibition of E6-mediated proteasomal degradation of mutant p53 (186). There are numerous other possible effects that may explain the anticancer effects described, including MMP-9 and MMP-2 inhibition, increasing radiosensitivity, inhibition of NF- $\kappa \mathrm{B}$, blocking of interleukin (IL)-6, stimulated phosphorylation of signal transducer and activator of transcription 3 (STAT3), decreases in ATP levels, androgen receptors (ARs) and cell survival, upregulation of TRAIL receptor and death receptor 5, Bax upregulation, inhibition of EGFR and insulin growth factor receptor 1, and increased 
fatty acid synthase levels (187-194). At present, seven clinical trials are actively recruiting testing the effects of NLV on MM, medulloblastoma, Kaposi's sarcoma, and breast and lung cancers (clinical trial nos. NCT02363829, NCT02024009, NCT01925378, NCT03256916, NCT03829020, NCT02207439 and NCT03077451).

Concerning the antitumor activity of RTV, it was determined that it reduces proliferation and viability, and increases chemosensitivity in MM cell lines (195). Also, it was found that RTV has cytostatic and cytotoxic effects on GBM cells by inhibiting the chymotrypsin-like activity of the proteasome (196). Another study suggested that RTV, via its inhibition of glucose transporter (GLUT)4, decreases glucose consumption, lactate production, and the proliferation of GBM and MM cells in vitro (195). Also, RTV may interfere with HSP90 in GBM cells and exert IL-18-inhibiting activities (197). Ikezoe et al (198) reported that RTV induces growth arrest and differentiation of human myeloid leukemia cells, and enhances the ability of all-trans retinoic acid to decrease the proliferation and increase the differentiation of these cells. It was also found that RTV induced growth arrest and apoptosis of human MM via downregulation of the antiapoptotic protein myeloid cell leukemia 1 (Mcl-1) in these cells. Furthermore, other studies have shown that RTV blocked IL-6-induced activation of STAT3 and ERK signaling in MM cells by inducing growth arrest and apoptosis (198-200).

Clinically, MM responds to standard drug treatment; however, it may acquire drug resistance, subsequently losing its responsiveness to previously effective treatments (201). Drug resistance may be due to the overexpression of P-gp. Another potential cause of drug resistance involves cytochrome $\mathrm{P} 450$ 3A4 (CYP3A4), which is associated with the metabolism of chemotherapeutic agents. RTV inhibits P-gp and CYP3A4 activity (198). Future studies are required to determine whether RTV can overcome the drug resistance of MM cells in patients. At present, $>90 \%$ of chronic cases are caused by a chromosomal abnormality that produces the so-called Philadelphia chromosome; this aberration is a consequence of a fusion between the Abl tyrosine kinase gene at chromosome 9 and the Bcr gene at chromosome 22, resulting in a chimeric oncogene, Bcr-Abl, that is responsible for the production of the active Bcr-Abl tyrosine kinase implicated in the pathogenesis of chronic myeloid leukemia (CML) (202). Compounds have been developed to inhibit this aberrant tyrosine kinase, such as imatinib; however, despite impressive results with imatinib, a subset of patients treated with imatinib will develop resistance (203). A total of 6 out of 9 cases of advanced-stage CML with imatinib resistance carried a rare mutation called T315I that caused the substitution of threonine for isoleucine at codon 315 of the Abl protein (204). In 2017, Xu et al (205) virtually screened the FDA-approved drug database to identify novel inhibitors for the wild-type and T315I gatekeeper mutant Abl1, finding that RTV could inhibit the T315I mutant Abl1. The only clinical trial so far with published results is a phase II trial of RTV/lopinavir in cases of progressive or recurrent high-grade gliomas that showed no survival benefit (206). However, such results must be revisited, as RTV passes poorly through the blood-brain barrier. RTV must be administered with caution in patients due to interactions with various drugs (207). Careful selection of patients for clinical trials regarding medicine consumption is essential. For example, two drugs mentioned in this review have negative interactions: DSF decreases the metabolism of RTV and statins (STs), increasing the risk of rhabdomyolysis $(208,209)$. At present, three clinical trials are openly recruiting in breast and prostate cancer (clinical trial nos. NCT03890744, NCT04028388 and NCT03066154).

\section{Itraconazole (ITZ)}

ITZ was developed in 1980 as a triazole antifungal drug (210). In contrast to human cells (which present cholesterol in its cell membrane), fungi contain ergosterol, a product obtained by the demethylation of lanosterol; the mechanism of action of ITZ involves the inhibition of CYP450-dependent $14 \alpha$-demethylation of lanosterol, which interferes with the fungal ergosterol biosynthesis pathway (211). Its anticancer activity was reported for the first time by Chong et al (212), who reported that $14 \alpha$-demethylase was central for endothelial cell proliferation. Inhibition of $\mathrm{WNT} / \beta$-catenin signaling was observed in basal cells and examined in melanoma cells. Additionally, ITZ inhibits VEGF- and basic fibroblast growth factor (bFGF)-dependent angiogenesis in vivo (212). Concomitantly, ITZ inhibits VEGF receptor 2 (VEGFR2) glycosylation, trafficking and signaling in endothelial cells, leading to the inhibition of migration and tube formation in human vascular endothelial cells (213). Furthermore, in vivo experiments demonstrated that ITZ, alone or in combination with pemetrexed, exhibits anticancer activity in NSCLC, basal cell carcinoma and medulloblastoma (214).

$\mathrm{Xu}$ et al (215) demonstrated that ITZ inhibits cholesterol trafficking in human endothelial cells, leading to inhibition of mTOR. Additionally, Kim et al (216) reported that ITZ inhibits the Hedgehog signaling pathway. In GBM cells, the decrease of cholesterol in the cell membrane leads to decreased Aktl activity, resulting in inhibition of mTOR and subsequent apoptosis (217). Furthermore, the in vivo growth of two Hedgehog-dependent tumor models, a medulloblastoma and a basal cell carcinoma, was reduced in animals receiving the antifungal drug (216). The same results were obtained in another study using pleural mesothelioma cells (218).

Another possible mechanism of action involves the effect of ITZ on P-gp expression (219). Positive results in phase II clinical trials for the treatment of lung cancer, prostate cancer and basal carcinoma showed good tolerance and type I toxicity $(220,221)$. Other studies conducted in breast, lung, ovarian or pancreatic cancers also showed promising results (221-224). More clinical trials are currently actively recruiting for different types of tumors using ITZ alone or in combination (clinical trial no. NCT03513211, NCT02749513, NCT03664115, NCT03994211, NCT04018872 and NCT03972748). Cautiousness should be exerted, as there is some evidence that the use of antifungal drugs may interfere with the actions of other anticancer agents, in particular, with rituximab (225).

\section{Ivermectin (IVM)}

IVM is an antiparasitic drug used to treat numerous types of parasitic infestations, belonging to the avermectin family of medications. It works by causing the parasite's cell membrane to increase its permeability, resulting in paralysis 
and death. The avermectins are 16-membered macrocyclic lactone derivatives generated as fermentation products by Streptomyces avermitilis. IVM has shown some preliminary antitumor activity (226-229). Jiang et al (230) found that IVM reversed the resistance of tumor cells to chemotherapeutic drugs. Mechanistically, IVM exerts these effects mainly by reducing the expression of P-gp via inhibition of the EGFR. IVM binds to the extracellular domain of EGFR, inhibiting its activation and the downstream ERK/Akt/NF- $\mathrm{KB}$ signaling cascade. The inhibition of NF- $\mathrm{KB}$ leads to reduced P-gp transcription. IVM also inhibits yes-associated protein 1 (YAP1), which acts by activating the transcription of genes involved in cell proliferation and apoptotic suppression (231). An exploration of drugs targeting YAP1 showed that IVM has antitumor properties (232). Also, IVM exhibits karyopherin $\beta 1$ (KPNB1)-dependent antitumor properties against ovarian cancer (233). KPNB1 encodes nuclear transport factors, and in ovarian cancer cells, IVM was found to block KPNB1 function, causing apoptosis and cell cycle arrest (233). In vivo use of IVM with paclitaxel produces a synergistic antitumor effect (233).

IVM was identified as an effective inhibitor of the canonical WNT pathway that acts on a transcriptional factor of the TCF family, blocking colon and lung cancer proliferation; such findings were validated in CRC preclinical models of tumor growth with cell lines and patient-derived primary tumors (234). Kwon et al (235) found that treatment with IVM led to transcriptional modulation of genes associated with the epithelial-mesenchymal transition and maintenance of a CSC phenotype in TNBC, resulting in an impairment of clonogenic self-renewal in vitro, and inhibition of tumor growth and metastasis in vivo. Beyond the aforementioned examples, IVM exerts its antitumor effects in different types of cancer using a wide variety of mechanisms. IVM interacts with several targets, including the multidrug resistance (MDR) protein, the Akt/mTOR pathways, purinergic receptors, p21-activated kinase-1, cancer-related epigenetic dysregulators such as SIN3A and SIN3B, RNA helicase and chloride channel receptors (226).

\section{Leflunomide (LFN)}

LFN is an inhibitor of the mitochondrial enzyme dihydroorotate dehydrogenase, which plays a central role in the de novo pyrimidine synthesis pathway. Therefore, LFN inhibits the duplication of rapidly dividing cells, especially lymphocytes (236). The FDA approved it as an immunomodulatory drug for the treatment of patients with rheumatoid arthritis (237). A number of studies reported that LFN inhibits the growth of several different cell types, including human MM, prostate cancer, NETs, breast cancer and neuroblastoma cells (238-241). Hanson et al (242) showed that LFN exhibits potential therapeutic value in treating melanoma. They demonstrated that LFN reduced cell viability in three melanoma cell lines harboring the BRAFV600E mutation. Additionally, they found that LFN affects melanoma cells that do not harbor BRAF mutations, showing that the treatment of LFN with targeted therapies that block components of the proproliferative mitogen-activated protein kinase (MAPK) pathway, such as BRAF (inhibited by vemurafenib) and MAPK kinase
(MEK; inhibited by selumetinib), exhibit synergistic antitumor activity in melanoma (242). Caution should be exerted when using LFN in combination, since the concomitant use of LFN and methotrexate (MTX) could produce lethal liver-damage or hepatotoxicity (243).

Beyond the aforementioned immunosuppressive effects of LFN, other mechanisms of action have been described. For example, LFN can induce G1 cell cycle arrest via modulation of cyclin D2 and retinoblastoma protein (pRb) expression, and decreasing the phosphorylation of Akt, p70 S6 kinas, and eukaryotic translation initiation factor 4E-binding protein-1 (238). As Ephrins and their receptors (Eph) have been identified as critical regulators of angiogenesis, Chu and Zhang (244) found that LFN has antiangiogenic effects on breast cancer cells via the inhibition of the angiogenic soluble Ephrin-A1/EphA2 system. In supernatants of breast cancer cell lines co-cultured with endothelial cells, soluble Ephrin-A1 was released from breast cancer cells; the co-culture supernatants containing soluble Ephrin-A1 caused the internalization and downregulation of EphA2 on endothelial cells, and activation of human umbilical vein endothelial cells (HUVECs). The soluble Ephrin-A1/EphA2 system functions regulating angiogenesis in breast cancer, but similar results were found in a bladder carcinogenesis model via inhibition of the soluble Ephrin-A1/EphA2 system; Ephrin-A1 overexpression could partially reverse LFN-induced suppression of angiogenesis and subsequent tumor growth inhibition (244). Cook et al (240) showed that LFN and its natural metabolites suppress Achaete-scute homolog 1, both at the protein and mRNA level, via a mechanism that is predominately dependent upon the Raf-1/MEK/ERK1/2 pathway. Other mechanisms of action have also been considered, as described by Zhang and Chu (245). Currently, a phase I/II trial of LFN in females with previously treated metastatic TNBC is actively recruiting (clinical trial no. NCT03709446).

\section{Lithium (LTH)}

LTH has traditionally been used for the treatment of bipolar disorders (BPD). LTH affects all neurotransmitter pathways through highly complex networks. Therefore, it is hypothesized to restore the balance among aberrant signaling pathways in critical regions of the brain (246). It has been shown that the actions of LTH on signal transduction [phosphoinositide hydrolysis, adenylyl cyclase, $\mathrm{G}$ protein, glycogen synthase kinase (GSK)-3 $\beta$, protein kinase $\mathrm{C}$ and its substrate, myristoylated alanine-rich $\mathrm{C}$ kinase substrate] trigger long-term changes in neuronal signaling patterns that account for the protective properties of LTH in the treatment of BPD $(247,248)$. Through its effects on GSK- $3 \beta$ and protein kinase C, LTH may also modify the level of phosphorylation of cytoskeletal proteins, which leads to neuroplastic changes associated with mood stabilization (248). Chronic LTH regulates transcriptional factors, which in turn may modulate the expression of a variety of genes that compensate for aberrant signaling associated with the pathophysiology of BPD $(248,249)$.

LTH effects on cancer cells have been attributed to the inhibition of GSK3, which impacts multiple cell functions (250). GSK3 inactivates glycogen synthase, a negative regulator of WNT signaling (251). LTH induces anti-invasive, 
antimigratory and antiproliferative effects through the inhibition of GSK-3; knockdown of either GSK-3 $\alpha$ or GSK-3 $\beta$ produced suppression (252). Additionally, LTH changes the release of neurotransmitters, modulates the activity of several phosphoproteins and directly inhibits inositol monophosphatase (253). A study showed inhibitory effects of LTH on proliferation and growth in prostate cancer cell lines and tumor xenografts via GSK3 inhibition, due to reduced interactions between the transcription factor E2F and DNA that induce S-phase gene expression (254). LTH has also been shown to increase the effect of doxorubicin and etoposide, acting on the cell cycle in prostate cancer cell lines (255). In colon cancer cells, it was suggested that LTH could prevent metastasis through inhibition of lymphangiogenesis, as the inactivation of GSK-3 downregulates Smad3, which reduced expression levels of TGF $\beta$-induced protein, a key mediator of lymphangiogenesis in colon cancer (256). Long-term use of LTH has been associated with nephropathy, and some links between LTH and cancer development have been established (257). However, this fact remains a matter of debate. In a Danish study, overall CRC risk was not affected by the use of LTH, although a slight overall risk for distal colon tumors was seen (258). LTH is accumulated in GBM cells faster and in greater quantities than in neuroblastoma cells, and its levels further increase with chronic exposure (259). Other studies revealed the anti-invasive potential of LTH in GBM cell lines $(252,253,259,260)$. Currently, two actively recruiting clinical trials are ongoing, testing LTH in osteosarcoma, CRC and esophageal cancer (clinical trial nos. NCT03153280 and NCT01669369) (261).

\section{Metformin (MET)}

MET is a biguanide, widely used for the treatment of type 2 diabetes. Although MET has been used for $>50$ years, the exact molecular mechanisms of its therapeutic action remain a matter of debate (262). MET induces its antihyperglycemic effects mainly through the blockage of gluconeogenesis. The site of drug action is at the mitochondrial level, mediated by transient and specific inhibition of the respiratory-chain complex 1, inducing a drop in cellular energy charge (263). As a consequence, cellular ATP concentrations fall, and the increase in both ADP/ATP and AMP/ATP ratios triggers AMPK. AMPK coordinates a wide array of compensatory, protective, and energy-sparing responses, ultimately leading to a reduction in hepatic glucose output $(264,265)$. Additional studies are required to understand how MET modulates the respiratory-chain complex 1 (266). Evans et al (267) presented evidence that individuals with diabetes treated with MET presented a substantially lower cancer burden than individuals with diabetes treated with other agents, and other studies reached similar conclusions (267-272). The studied populations were patients with type 2 diabetes; therefore, its conclusions may not qualify for nondiabetic subjects. Additionally, these studies were based on retrospective reviews of medical records, and are thus potentially subject to a variety of biases (273). Therefore, the utility of MET in oncology is based on pharmacoepidemiologic data that are considered controversial (274), including studies into prostate cancer risk and MM outcomes $(275,276)$. Despite encouraging in vitro and epidemiological data for diverse tumor types, available results from randomized clinical trials on MET are mostly disappointing (277).

The indirect effects of MET on cancer have been described. The proposed mechanisms of action of MET in oncology can be divided into two broad, non-mutually exclusive categories: Indirect and direct (278). Indirectly, MET acts on the liver to inhibit glucose production, producing changes in the metabolic and endocrine circuits that could affect various cellular and molecular processes that influence cancer biology. The most notable change of oncologic relevance is the reduction of hyperinsulinemia, given prior evidence that high insulin levels can stimulate the proliferation of a subset of common cancers (279). MET also influences adipokine levels in cancer biology in vivo, but clinical data are needed (280). Previous studies suggested that the immunological or anti-inflammatory modulatory actions of MET are relevant in cancer treatment; however, again there are no clinical data to support or refute these observations $(281,282)$.

Regarding the direct effects of MET on cancer, dozens of in vivo and in vitro studies have reported direct antineoplastic activity of MET in model systems without providing relevant data for clinical applications $(264,278)$. One study provided evidence regarding the role of AMPK; experiments showed that activation of AMPK is essential in the action of biguanides by showing that the direct AMPK activator A-769662 has antineoplastic activity in vivo (283). Other findings suggest the relevance of inhibition of respiratory-chain complex $1(263,284)$. Modification in the metabolism of cancer cells in a manner that is influenced by mutations in exposed cancer cells are important consequences of the MET-induced reduction of oxidative phosphorylation, suggesting that rational drug combinations may be a useful approach $(285,286)$. An excellent work published by Pollak (278) demonstrated a rationale for combining biguanides with inhibitors of kinases that control glycolysis. Cancer cells may have a requirement to increase oxidative phosphorylation to counterbalance the diminished glycolysis that appears as a consequence of oncogenic kinase inhibition. With the use of MET, the compensatory increase is attenuated, resulting in the enhanced antineoplastic activity of the kinase inhibitor (287). Another study found that a direct action of MET on cancer cells inhibits growth in vitro in association with AMPK activation and inhibition of mTOR, as a consequence of MET-induced energetic stress (288). Other mechanisms have also been proposed, showing contradictory results; it remains to be determined if AMPK activation in cancer cells, due either to the inhibition of oxidative phosphorylation by MET or the direct activation by specific pharmacological activators has antiproliferative or prosurvival consequences (289). Cancer cells functionally deficient in AMPK are less likely to reduce energy consumption in the face of a biguanide-induced reduction on ATP generation, and are therefore more likely to experience a lethal energetic crisis (290). Mutations in genes encoding respiratory-chain complex 1 in cancer cells have also been shown to be hypersensitive to biguanides $(284,291)$. There are two completed trials on multi-histology solid tumors assessing the dose-limiting toxicity of various treatments that include MET with promising results $(292,293)$. Thus, enthusiasm remains for understanding the role of MET in cancer through ongoing clinical research (294). At the moment, $>80$ 
actively recruiting clinical trials are open; details can be found in Saraei et al (271).

\section{Niclosamide (NCS)}

NCS is a medication used to treat tapeworm infestations by inhibiting glucose uptake, oxidative phosphorylation and anaerobic metabolism produced in the parasite (295). Mounting evidence indicates that NCS is a noteworthy multifunctional drug with a wide variety of pharmacological activities, due to its capacity to uncouple mitochondrial phosphorylation and modulate a selection of signaling pathways associated with tumor suppression (296). In adrenocortical carcinoma, it was found that NCS inhibits cell proliferation, which was associated with apoptosis, reduction of epithelial-to-mesenchymal transition, $\beta$-catenin levels and mitochondrial uncoupling activity (297).

In breast cancer, Fonseca et al (298) reported that NCS inhibits mTOR complex 1 (mTORC1) signaling in a breast cancer cell line. A mechanistic study indicated that NCS lowers the cytoplasmic $\mathrm{pH}$ and may indirectly lead to inhibition of mTORC1 signaling (299). Wang et al (300) found that NCS inhibited the formation of breast cancer spheroids and induced apoptosis. Karakas et al (301) reported that NCS enhanced the antitumor activity of the palladium(II) saccharinate complex, leading to enhanced cytotoxic activity in breast CSCs. In TNBC, it was found that NCS alone or in combination with cisplatin suppresses the growth of xenografts of cisplatin-resistant cells (302). Mechanistically NCS reversed the epithelial-mesenchymal transition phenotype, inhibited Akt, ERK and Src signaling pathways, and inhibited the proliferation of both cisplatin-sensitive and cisplatin-resistant TNBC (302).

NCS inhibited the growth of colon cancer cells from human patients both in vitro and in vivo, regardless of mutations in adenomatous polyposis coli (APC) (303). It was found that NCS inhibited colon cell migration, invasion, proliferation and colony formation in vitro, and also reduced liver metastasis in a mouse model (304). Suliman et al (305) measured growth inhibition and the apoptosis of three colon cancer cell lines after treatment with NCS, observing that NCS is associated with inhibition of the Notch signaling pathway and increased expression of the tumor suppressor microRNA-200 family. Other studies identified NCS as a selective inhibitor of GBM cell viability, revealing that NCS suppressed WNT, Notch, mTOR and NF-кB signaling pathways $(296,305,306)$. Pre-exposure to NCS significantly diminished the malignant potential of glioma cells in vivo (307). Additionally, it was reported that inhibition of STAT3 signaling led to inhibited growth of head and neck cancer cells both in vitro and in vivo, and enhanced the antitumor effect of erlotinib (308).

The Notch signaling pathway is essential in the generation of hematopoietic stem cells, and activated Notch receptors are cleaved to release the Notch intracellular domain, which moves to the nucleus and binds to transcription factors such as CBF1 to alter gene expression (309). NCS was identified as an inhibitor of endogenous Notch signaling in acute myeloid leukemia (AML) cells (300). Additionally, it was determined that NCS increased the levels of ROS in AML cells. NCS was synergistic with the chemotherapeutic agents cytarabine, etoposide and daunorubicin in vitro, and inhibited the growth of AML cells in nude mice (310).
It is estimated that $20 \%$ of patients with NSCLC harbor mutations in the EGFR gene, which promotes cancer cell growth (311). EGFR inhibitors (such as erlotinib) are used, but drug resistance is present in certain cases. It was found that NCS treatment overcomes erlotinib resistance, as NCS in combination with erlotinib potently suppressed the growth of erlotinib-resistant lung cancer cells and increased apoptosis in tumors (312). Additionally, NCS is effective in reducing the radioresistance of human lung cancers in vitro and in vivo; the mechanism involves inhibition of JAK2-STAT3 activity induced by radiation (313). One study determined that NCS enhanced the suppression of STAT3 in a cell line of NSCLC (314). Another study found that NCS reactivated the tumor suppressor protein phosphatase $2 \mathrm{~A}$ in NSCLC cells (315). NCS inhibited cell proliferation, colony formation, tumor sphere formation and induced mitochondrial dysfunction by increasing mitochondrial ROS production (315).

It has been reported that NCS can effectively inhibit osteosarcoma cell proliferation, migration, and survival (316). This inhibitory effect is associated with decreased expression of c-Fos, c-Jun, E2F1 and c-Myc. NCS also inhibits osteosarcoma tumor growth in a mouse xenograft tumor model (316). Additionally, NCS produces growth inhibition of ovarian tumor-initiating cells. Subsequently, NCS was found to inhibit ovarian tumor-initiating cells in vitro and in vivo through alterations of metabolic pathways in ovarian cancer cells (317). King et al (318) found that NCS decreased $\beta$-catenin transcriptional activity and reduced cell viability in ovarian carcinoma; NCS inhibited tumor growth and the progression of human ovarian cancers in xenograft animal models.

Enzalutamide is a novel antiandrogen for the treatment of metastatic, castration-resistant prostate cancer (319). Resistance to enzalutamide therapy was reported to be associated with the expression of AR splice variants, including the AR-V7 isoform; it was found that NCS downregulated AR-V7 expression and inhibited AR-V7 transcription (320). Treatment of NCS + enzalutamide in prostate cancer cells resulted in inhibition of colony formation and growth arrest (321). Furthermore, NCS was reported to have the ability to inhibit mitochondrial function, which is associated with acidic pH in prostate NET cells (322). NCS exhibits $\mathrm{pH}$-dependent toxicity in a castration-resistant prostate NET cell line (322). Additionally, NCS inhibits proliferation and anchorage-independent colony formation in two renal cell carcinoma cell lines, and synergizes with cisplatin and sorafenib both in vivo and in vitro (323). Recently, the effects of NCS alone and in combination with paclitaxel in cervical cancer were found experimentally (324). NCS significantly inhibited proliferation and induced apoptosis in a panel of cervical cancer cell lines, and inhibited tumor growth in a cervical cancer xenograft mouse model, with it demonstrated that NCS induced mitochondrial dysfunctions by inhibiting mitochondrial respiration, complex I activity and ATP generation, which led to oxidative stress (324). Currently, four clinical trials are actively recruiting for colon and prostate cancer (clinical trial nos. NCT02687009, NCT02687009, NCT03123978 and NCT02807805).

\section{Nitroxoline (NTX)}

NTX is a widely used antibiotic that is particularly useful for the treatment of urinary tract infections. NTX has gained 
considerable attention due to its anticancer properties. These properties have been associated with angiogenesis inhibition by targeting methionine aminopeptidase 2 and sirtuin $1 / 2$, arresting the migration and invasion of cancer cells by affecting cathepsin B, and directly inducing apoptosis (325-327).

NTX demonstrated potent anticancer activity against various types of cancer cells, including lymphoma, leukemia, glioma, and bladder, breast, pancreatic and ovarian cancer cells in a dose-dependent manner (327). Furthermore, NTX effectively and dose-dependently inhibited the growth of urological tumors in orthotopic mouse models (327). Additionally, it was found that NTX sulfate, one of the most common metabolites of NTX, may inhibit the proliferation of T24 cells and HUVECs (327). The results provide evidence for the repurposing of NTX for clinical anticancer applications, particularly for bladder cancer treatment (327). These results, in addition to the known safety profile of NTX and well-defined pharmacokinetic properties, successfully advanced NTX repurposing into a phase II clinical trial in China for non-muscle invasive bladder cancer treatment (clinical trial no. CTR20131716) (327). In another study, Mao et al (328) found that NTX induced apoptosis in $>40 \%$ MM cells within $24 \mathrm{~h}$, which was induced by activation of caspase-3 and inactivation of poly(ADP-ribose) polymerase, an essential enzyme in DNA damage repair. NTX also suppressed prosurvival proteins Bcl-xL and Mcl-1. Moreover, NTX suppressed the growth of MM xenografts in nude mice models. Mechanistically, NTX was found to downregulate tripartite motif-containing protein 25 and upregulate p53 (328).

\section{Nonsteroidal anti-inflammatory drugs (NSAIDs)}

NSAIDs are a family of drugs used to treat inflammation, mild-to-moderate pain and fever. Probably the best known NSAID is AAS, used since 1897 as an analgesic, antipyretic, and inhibitor of platelet aggregation (329). AAS acts as an acetylating agent that covalently attaches an acetyl group to serine residue $\mathrm{S} 530$ in the active site of cyclooxygenase (COX), leading to the inhibition of prostaglandins which are the precursors of thromboxanes (330). A substantial body of evidence has established that AAS has antineoplastic effects in vitro (331). Those studies established a close link between inflammation and cancer, suggesting that the anti-inflammatory properties are the central mechanism of action (332). As such, numerous clinical trials have been conducted (333). Cole et al (334) performed a meta-analysis of four extensive studies, the Aspirin/Folate Polyp Prevention Study, the Colorectal Adenoma Prevention Study (Cancer and Leukemia Group B), the United Kingdom Colorectal Adenoma Prevention Study and the Association pour la Prevention par l'Aspirine du Cancer Colorectal, concluding that AAS is an active chemopreventive agent in CRC. Additionally, several combinations of AAS with other chemopreventive agents have been evaluated for the prevention of CRC, in addition to clinical studies investigating the use of AAS in treating the dissemination of CRC that leads to liver metastases (clinical trial no. NCT03326791) (333).

In patients diagnosed with Lynch syndrome, which leads to a higher-than-average chance of developing CRC or endometrial cancer, the anticancer efficacy of AAS was determined (clinical trial no. NCT02497820) (333). Additionally, AAS may reduce the risk of metastases and death in patients with lung, prostate, endometrial and breast cancers (335). Another meta-analysis found a decreasing risk of glioma following NSAID treatment, including non-AAS-NSAIDs and AAS; the authors concluded that NSAID use was significantly associated with a lower risk of central nervous system tumors (336). Beyond inhibiting the synthesis of prostaglandin E2 (PGE2), AAS is associated with increased expression of 15-hydroxyprostaglandin dehydrogenase (15-HPGD), leading to the inactivation of PGE2 by another pathway (337). Furthermore, AAS can block PGE2-induced secretion of the C-C motif chemokine ligand 2 and thus the activation of myeloid-derived suppressor cells, thereby causing immune suppression (338).

Immune function is also influenced by AAS, which increases COX-dependent production of resolvin. Resolvins are byproducts of $\omega-3$ fatty acids, which have an essential role in promoting the restoration of normal cell function following inflammation (339). As AASs also decrease platelet aggregation, they could modulate immune function because activated platelets suppress the natural killer cell-mediated lysis of tumor cells (340). It was also demonstrated that AAS activates the NF- $\kappa \mathrm{B}$ signaling pathway, inducing apoptosis in models of human cancer (341). At present, $>40$ clinical trials are actively recruiting using AAS alone or in combination to evaluate its efficacy in cancer treatment (261).

Beyond AAS, there are other NSAIDs, such as celecoxib (CXB), diclofenac (DCF), +-ibuprofen (IBP), ketorolac (KTL), naproxen (NPX), piroxicam (PXM) and sulindac (SLD). Various studies have been conducted using NSAIDs alone or in combination with other drugs for the treatment of cancer (342-344). It is important to note that NSAIDs reduce blood flow to the kidneys, decreasing the elimination of MTX and therefore increasing its blood concentration, what could increase its side effects (345).

CXB is a selective COX-2 inhibitor that was approved by the FDA for the treatment of familial adenomatous polyposis to prevent the formation and growth of colon polyps (261). CXB blocks COX-2 but has little effect on COX-1, and is therefore further classified as a selective COX-2 inhibitor (346). It was found to be useful in the prevention of colon adenomas in a randomized clinical trial, but caused potential cardiovascular events, which limited its advancement (347). It was reported that patients receiving $\mathrm{CXB}$ exhibited chemopreventive effects. As determined by a decreased cumulative incidence of advanced adenomas over 5 years (348). Also, preclinical evidence suggests that $\mathrm{CXB}$ may provide chemopreventive activity against breast cancer. Clinical trials also showed positive results; two case-control studies illustrated that a standard dose intake of $\mathrm{CXB}$ significantly reduced the risk of breast cancer $(349,350)$. CXB inhibits the WNT/ $\beta$-catenin signaling pathway and its gene products, including survivin and cyclin D1, exhibiting chemopreventive effects against colon cancer $(351,352)$. It is hypothesized that CXB induces several potential antitumor mechanisms, including inhibition of proliferation, induction of apoptosis, immunoregulation, regulation of the tumor microenvironment, antiangiogenic effects, and resensitization of other antitumor drugs (353). Recently, Yu et al (354) proposed that the effects of CXB may be due to regulation of tumor autophagy. Currently, 23 actively recruiting clinical trials at different stages are 
studying the safety and effectiveness of CXB in a variety of tumor types (355).

Leidgens et al (356) demonstrated that DCF induced c-myc inhibition followed by decreased gene expression of GLUT1, as well as decreased lactate dehydrogenase A and lactate secretion, leading to decreased lactate-mediated immunosuppression in a murine glioma model. Another study from the same research group demonstrated that DCF inhibits STAT3 phosphorylation and lactate formation, induces cell cycle arrest at $\mathrm{G} 2 / \mathrm{M}$, and delays tumor growth in an in vivo animal model (356). It has also exhibited antitumor activity in a variety of malignant cell lines in vitro (357). Arisan et al (358) hypothesized that DCF-mediated apoptosis is associated with inhibition of the PI3K/Akt/MAPK signaling axis. DCF also regulates mitochondrial adenine nucleotide transferase and the oxidative phosphorylation complex $\mathrm{V}$, leading to decoupling of oxidative phosphorylation and subsequent reduced ATP generation and cell proliferation (359). In neuroblastoma, DCF enhanced chemotherapy-induced apoptosis via upregulation of p53 (360).

IBP, the most commonly used over-the-counter NSAID, was efficient at decreasing the mitosis rate and inhibited the proliferation of glioma, neuroblastoma, CRC, bladder, breast, lung, pancreatic and gastric cancer cells $(361,362)$. In particular, this drug showed superior effectiveness compared with other NSAIDs in suppressing the proliferation and inducing the apoptosis of human prostate cancer cells at clinically relevant concentrations (361). In vitro experiments demonstrated that IBP induces antiangiogenic effects, apoptosis, reduction of cell proliferation, and altered expression of Akt, p53, proliferating cell nuclear antigen, Bax and Blc2 (261).

KTL was proposed to treat oral cancer via inhibition of the ATP-dependent RNA helicase DDX3X (363). Also, KTL salt has shown to suppress early breast cancer relapse (364). KTL is a chiral molecule administered as a 1:1 racemic mixture of the S- and R-enantiomers; the S-enantiomer is considered the active component in pain management with selective activity against COX enzymes (365). The R-enantiomer exhibits activity as an inhibitor of Rac1 and Cdc42. KTL differs from other NSAIDs by functioning as two distinct pharmacologic entities due to the independent actions of each enantiomer. In a recent review, Hudson et al (365) summarized the evidence supporting the benefits of KTL administration for patients with ovarian cancer, also discussing how simultaneous inhibition of these two distinct classes of targets (COX enzymes and Rac1/Cdc42 by S-KTL and R-KTL, respectively) may each contribute to anticancer activity.

NPX induced significant inhibition of the effects of the carcinogen azoxymethane, an inducer of colon adenocarcinoma multiplicity in rats (344). Chaudhary et al (366) conducted a study using a Ptch1 $1^{+-} / \mathrm{SKH}-1$ hairless mouse model, which is highly sensitive to ultraviolet-B (UVB) radiation; they found that NPX also works by reversibly inhibiting both COX-1 and COX-2. It has been demonstrated that NPX reduces tumors developed following chronic UVB irradiation of these animals in both basal and squamous cell carcinoma. The mechanism of action of NPX remains a matter of debate. A phase I clinical study is underway to determine the adverse effects and optimal dose of NPX in preventing DNA mismatch-repair-deficient $\mathrm{CRC}$ in patients with Lynch syndrome (clinical trial no. NCT02052908) (333).
PXM blocks ornithine decarboxylase induction, inhibiting polyamine production involved in non-melanoma skin carcinogenesis (367). PXM can induce tumor cell apoptosis and suppress MMP-2 activity (368). Actinic keratosis (AK) is a chronic progressive disease that may develop into skin cancer; damage to the skin is multifactorial, but UVB radiation is the paramount factor related to AK pathogenesis (369). Local application of PXM inhibits COX, resulting in blockade of the biosynthesis of PGs and an increase in 15-HPGD expression. Also, the treatment leads to a reduction of proliferation, tumor progression and angiogenesis, as well as an increase in apoptosis (370). Campione et al $(367,371)$ found that after topical treatment of AK with PXM, typical epidermal architecture was restored. The efficacy of PXM is related to its activity on both COX enzymes. In a preliminary open-label trial, researchers evaluated the efficacy and tolerability of PXM 1\% gel in the treatment of patients affected by AKs; they observed improvement either in the typical features of the AKs or in the perilesional area, observing a healing response in $>50 \%$ in AKs with the use of PXM (367,371).

Palmerini et al (372) analyzed, in a preclinical model of human colon cancer, the action of PXM on cancer progression in Mlh1 $1^{+/ /} / \mathrm{APC} 1638^{\mathrm{N} /+}$ mice. PXM diminished the total number of tumors per mice by $80 \%$ in the small intestine. Conversely, PXM augmented tumor incidence, multiplicity and volume in the colon. Apoptosis was increased in the epithelium of the large intestine; accordingly, tumors were decreased at this site. In the cecum, PXM increased tumorigenesis, but apoptosis was not diminished, therefore suggesting that other mechanisms play a role in the differential organ-specific effects of PXM on tumorigenesis (372). Further studies are required to elucidate the precise antitumor mechanism of action of PXM.

SLD induces apoptosis and inhibits tumor growth in vivo in patients with head and neck tumors (373). Additionally, a substantial reduction was observed in colonic adenomas in patients with familial polyposis (373). Giardiello et al (374) reported that SLD decreases the number of adenomas, and Takayama et al (375) showed that SLD significantly suppresses the number of aberrant crypt foci in a randomized trial. Sulindac and its metabolites also appear to induce apoptosis in colonic adenomas in vivo (375). One clinical trial is actively recruiting to analyze the combination of eflornithine, a medication used to treat African trypanosomiasis, and SLD in reducing the incidence of adenomas and second primary CRCs in patients previously treated for stage 0-III CRC (clinical trial no. NCT01349881).

\section{Phosphodiesterase-5 inhibitors (PDE5Is)}

Three PDE5Is, sildenafil (SLD), tadalafil (TLD) and vardenafil (VLD), are approved for the treatment of erectile dysfunction (ED) (376). SLD and TLD are also approved for the treatment of pulmonary arterial hypertension (377). Additionally, there is some evidence of beneficial effects in a variety of clinical conditions, including female sexual arousal disorder, overactive bladder, incontinence, Raynaud's disease, heart failure and stroke (378). Regarding the mechanism of action, it should be stressed that the superfamily of mammalian cyclic nucleotide PDEs constitute a complex family of hydrolases 
that catalyze the hydrolytic breakdown of cyclic adenosine monophosphate (cAMP) and cyclic guanosine monophosphate (cGMP) into their biologically inactive counterparts 5'-AMP and 5'-GMP, respectively (379). Inhibition of the breakdown of cGMP, which regulates blood flow in the penis, promotes amelioration of the symptoms of ED. Inhibition of PDE5 activity is emerging as a promising approach via apoptosis and restoration of normal intracellular cGMP levels, thereby resulting in the activation of various downstream molecules to inhibit proliferation, motility and invasion (380).

There are reports in different tumor cell types of increased ROS production and apoptosis following treatment with PDE5Is (381). SLD and VLD induced caspase-dependent apoptosis of B-cell chronic lymphocytic leukemia cells (382). Also, PDE5Is were shown to alter the tumor microenvironment by reducing myeloid-derived suppressor cell function and thus augmenting endogenous antitumor immunity (383). Enhanced tumor suppression and apoptotic activity were seen in a NSCLC cancer orthotopic tumor model following SLD-docetaxel combination treatment (384), as well as with a SLD-capecitabine combination in breast cancer (385) and the combination of SLD-doxorubicin in in vivo models of prostate cancer (386). High levels of PDE5 have been described in several types of cancer, such as prostate, lung and breast cancers, CRC and melanoma (387). It was previously demonstrated that PDE5/cGMP/protein kinase G signaling targets the Hippo/tafazzin pathway to maintain the stemness of prostate cancer stem cells, evidencing a new role of PDE5 in governing stem cell features (388). TLD also attenuated TGF $\beta 1$-induced fibroblast-myofibroblast trans-differentiation, suggesting a potential role for PDE5Is in preventing stromal enlargement (389).

A retrospective analysis of 4,974 males showed that the prolonged use of PDE5I was associated with a lower incidence rate of prostate cancer (390). The apoptotic and growth-inhibitory activities of PDE5Is have been demonstrated in numerous lung cancer cell lines (391-393). VLD significantly increases the accumulation and enhances the antitumor activity of trastuzumab in a xenograft mouse model of lung cancer (394). Another study showed that SLD was able to enhance the antitumor effects of pemetrexed in NSCLCs, and this effect was further enhanced in vivo via co-treatment with the mTOR inhibitor temsirolimus (380). Increased PDE5 expression has been reported in various cell lines deriving from breast cancer (395-397). It was demonstrated that PDE5Is could act as chemopreventive agents due to their ability to suppress 1-methyl-1-nitrosourea-induced mammary carcinogenesis (398). It was reported that SUC metabolites inhibit the MEK/ERK signaling cascade in CRC cell lines, indicating an additional molecular mechanism via which SUC inhibits tumor cell growth (399). Additionally, the treatment of human CRC cells with SLD resulted in cell proliferation inhibition, cell cycle arrest and apoptosis along with increased intracellular ROS levels in vitro, causing the reduction of xenograft tumor growth in nude mice (400).

It has been demonstrated that SLD suppresses polyp formation in mice treated with azoxymethane/dextran sulfate sodium (401), highlighting the chemopreventive role of PDE5Is. In both neuroblastoma and hybrid neuroblastoma-glioma cells, both the presence and regulation of PDE5 mRNA during cell differentiation was observed (402). In medulloblastoma cells, PDE5Is interacted with vincristine/etoposide/cisplatin to cause cell death (403). PDE5I promoted autophagy and enhanced chemotherapy-induced DNA damage in a nitric oxide (NO) synthase-dependent manner (404). Oral administration of SLD and VLD selectively improved tumor capillary permeability in gliosarcoma-bearing rats, without changes in normal capillaries (405). Notably, tumor-bearing rats treated with adriamycin in combination with VLD exhibited significantly longer survival than rats treated with adriamycin alone (405). PDE5I enhanced transport and therapeutic efficacy of trastuzumab in hard-to-treat brain metastases from different primary tumors (406). TLD can also enhance the treatment efficacy of the chimeric anti-CD20 monoclonal antibody rituximab by improving the microvascular permeability in an intracranial brain lymphoma mice model (407). In thyroid cancer cells in vitro, SLD and TLD diminished proliferation, and at lower doses, they were also able to reduce cellular migration (408). The role of PDE5 in melanoma remains controversial. In a cohort study, males who used SLD for ED exhibited a significantly elevated risk of developing melanoma (394). A case-control study showed that the use of PDE5Is was associated with a modest but significantly increased risk of melanoma (409). Later, a large study failed to find evidence of a positive association between PDE5I exposure and melanoma risk (410). Recently, a meta-analysis revealed an increased risk of malignant melanoma in users of PDE5I (411); however, the inherent limitations of observational studies should be considered. Further studies are needed to evaluate this association properly.

\section{Pimozide (PMZ)}

PMZ is a neuroleptic drug that selectively blocks dopamine receptor D2, and is used to treat several mental and mood disorders, such as chronic schizophrenia, as it reduces dopamine activity (412). PMZ has been studied as a putative anticancer treatment, showing satisfactory results in melanoma, central nervous system tumors, osteosarcoma, neuroblastoma, myeloproliferative neoplasms, CRC, breast, lung, prostate, ovarian and pancreatic cancers, and HCC (412-423). There are several proposed mechanisms of action. PMZ was previously shown to inhibit the proliferation of the human breast cancer-derived cell line MCF-7 in vitro by blocking estradiol-induced growth (418). Additionally, a previous study demonstrated that PMZ is a potential inhibitor of Ran GTPase (Ran), which belongs to the Ras superfamily of small GTPases, and is involved in various aspects of nuclear structure and function, cell cycle regulation, nuclear transport and cell transformation (424). By decreasing Ran mRNA expression, $\mathrm{PMZ}$ also reduces the expression of Akt and phosphorylation of VEGFR2 in breast cancer cell lines and HUVECs, leading to increased caspase-3 activation and apoptotic cell death. PMZ also causes a reduction in cell proliferation, migration and invasion in vitro, and lung metastasis in vivo (424). This may be due to PMZ-induced downregulation of MMPs-1, -2 and -14 (413). In myelogenous leukemia cells, PMZ has gained attention as anticancer agent by acting as STAT5 inhibitor, as well as an inhibitor of the STAT3 signaling pathway in HCC and suppressing cancer stem-like cell maintenance (413). 
Also, it has been demonstrated that PMZ inhibited the growth of HCC cells by disrupting the WNT/ $\beta$-catenin signaling pathway and reducing epithelial cell adhesion molecule expression (422). Furthermore, it has been reported that PMZ affects CSCs by inhibiting ubiquitin-specific protease and WD repeat-containing protein 48 , which are proteins responsible for inhibiting differentiation and maintaining the cell in an undifferentiated state (421). Also, it is of importance to note that PMZ induces ROS generation by suppressing catalase expression (414). Recently, it has been demonstrated that PMZ inhibits P-gp, increasing apoptosis, as well as the expression of pRB and phosphorylated H2AX in KBV20 cells (425). Finally, Chen et al (426) reported that PMZ induces a reversible inhibition of proliferation in liver cancer and has an additive activity with sorafenib, which indicates the potential of pimozide as an adjuvant anticancer therapy.

\section{Propranolol (PPL)}

PPL is a competitive antagonist of the cardiac $\beta 1$-adrenergic receptor. It competes with sympathomimetic neurotransmitters to bind to receptors, which inhibits sympathetic stimulation of the heart. Block of neurotransmitter binding to $\beta 1$ receptors on cardiac myocytes suppress activation of adenylate cyclase, inhibiting cAMP synthesis and reducing protein kinase A activation (427). This results in less calcium influx to cardiac myocytes through voltage-gated L-type calcium channels, meaning there is a diminished sympathetic action on cardiac cells, which produces a decrease in heart rate and arterial blood pressure (428). In 2014, PPL was approved by the FDA to treat infantile hemangioma $(\mathrm{IH})$, providing improved treatment outcomes than previous treatments with corticosteroids, interferon, vincristine or cyclophosphamide (429). IH is a common benign tumor of childhood that is potentially disfiguring or life-threatening (430). It is interesting to analyze the mechanism of actions of PPL on IH, as it is an excellent example of all the mechanisms of action of PPL working in an integrated form. Early on, PPL causes vasoconstriction through the inhibition of NO synthesis and release; $\sim 3$ days after the beginning of therapy, PPL inhibits the vasodilation mediated by adrenalin, leading to vasoconstriction. At $\sim 1$ week later, PPL induces downregulation of angiogenic factors, such as VEGF and bFGF, and promotes remodeling of the extracellular matrix by inhibiting MMP-2 and MMP-9, which are vital for the process of angiogenesis, producing an abundance of TIMPs $(155,431)$. This action, together with the inhibition of the proangiogenic ERK/MAPK cascade, causes the inhibition of angiogenesis. The long-term effects of PPL are characterized by the induction of apoptosis in proliferating endothelial cells, producing tumor regression (432).

Based on its therapeutic actions against IH, PPL is currently being studied for applications in more malignant vascular sarcomas (433). A clinical study found that patients treated for $>1$ year with PPL exhibit a reduced risk of progression of malignant melanomas and decreased breast cancer mortality $(434,435)$. Currently, in vitro studies have found an antiproliferative effect of PPL in several types of cancer, such as breast, pancreatic and brain cancers (436-438).

Although PPL is by itself effective in cancer treatment, its use in combination with radiotherapy or with standard chemotherapy is auspicious. Several malignant tumors have limited sensitivity to radiotherapy. In these cases, a radiosensitizer is required to overcome this problem. Several studies have shown that antagonists of VEGF, COX-2 and EGFR expression can act as radiosensitizers (439-441). Rico et al (442) showed that PPL reduced cell viability and migration in a panel of breast cancer cell lines, and that the effect was increased when combined with MET. Furthermore, the combination reduced tumor growth in two immunocompetent models of TNBC, thereby improving survival. Treatment also reduced metastatic growth, with evidence that PPL reduced colonization in the lungs. Another group retrospectively assessed the impact of selective and non-selective $\beta$-blockers on tumor proliferation as measured by Ki67 expression (443). Results showed that non-selective $\beta$-blockade reduced tumor proliferation by $66 \%$ in early-stage breast cancer. Cell line data showed that PPL dose-dependently reduced tumor cell viability. Data from a phase I clinical trial prospectively treated with PPL for 3 weeks showed that Ki67 staining was reduced by $23 \%$ (clinical trial no. NCT00502684) (444).

Endothelial cells are very complex cells expressing a variety of molecules and playing an essential role in several functions, including vascular permeability, hemodynamic sensors endothelium-induced vasodilation, and chemical changes (445). Antiangiogenic agents combined with radiation therapy increase treatment effectiveness, killing both cancer and endothelial cells (446). Regarding chemotherapy, when PPL is used in combination with vincristine, its antimitochondrial and antimitotic effects in neuroblastoma cells are increased; the same results were found in an in vivo study using a neuroblastoma mouse model (447). A number of preclinical studies combining PPL with chemotherapeutic agents in different tumor cell lines have been conducted, including gemcitabine in pancreatic cancer cells, imatinib in glioma cells, and PTX in TNBC (448). Due to the very advanced stage of the study, it is essential to mention the phase III clinical trials combining PPL and the COX-2 inhibitor Etodolac for the prevention of CRC recurrence and distant metastatic disease (2). As $\beta$-blockers have demonstrated their antitumor properties, it has been suggested that $\alpha 1$-blockers such as terazosin, doxazosin and prazosin may also present potential antitumor activity (449). At present, $>15$ clinical trials using PPL are ongoing.

\section{Riluzole (RZL)}

RLZ is used in the treatment of amyotrophic lateral sclerosis by reducing glutamate (GLT) release. RLZ preferentially blocks the tetrodotoxin-sensitive voltage-gated sodium channel $(450,451)$; however, the action of RLZ on GLT receptors has been controversial. The close relationship between the cystine/glutamate transporter (xCT) and GLT release has been well-established (452). The xCT system is an amino acid antiporter or exchanger that typically mediates the exchange of extracellular L-cystine and intracellular L-GLT across the cellular plasma membrane (453).

Aside from its original uses, RLZ has been shown to have antitumor effects. The release of GLT in human cancer is well established; for instance, glioma cells show a more aggressive phenotype when releasing an excess of GLT, inducing neurotoxicity in surrounding neurons (454). Similarly, breast 
and prostate cancer cells release an excess of GLT, conferring on them a growth advantage (455). Additionally, inhibition of GLT release by RLZ suppresses the proliferation of GLT receptor 1-positive tumor cells in vitro and tumor progression in vivo (456). For gliomas and other neuronal cancers, inhibition of $\mathrm{xCT}$ reduces the invasiveness of glioma xenografts, likely due to a decrease in GLT release to the extracellular space, resulting in reduced excitotoxic death of neurons via excess GLT (457). In the prostate, AR drives prostate cancer; however, inhibiting AR or androgen biosynthesis induces remission for a short time, following which patients acquire a more aggressive castration-resistant condition with reactivated AR-dependent signaling. Downregulating AR expression has been considered as a potential treatment for prostate cancer (458). Wadosky et al (458) demonstrated that RLZ downregulates AR-full length, mutant ARs and AR-V7 expression by protein degradation through the ER stress pathway and selective autophagy.

RLZ has also been studied in melanoma. Once transformed, melanoma cells release excess GLT (459). Following $\mathrm{xCT}$ transport, cystine is reduced into two molecules of cysteine (460). In melanocytes, transport of cystine by $\mathrm{xCT}$ is used for cell growth, glutathione production and protection of cells from oxidative stress (453). In the absence of xCT, RLZ's GLT release-inhibitory activity is reduced, producing a decrease in RLZ-mediated antiproliferative effects in metabotropic GLT receptor (GRM1)-expressing tumor cells $(457,461)$. In normal melanocytes, the equilibrium between proliferation and differentiation is tightly regulated (462). However, in melanomas, released GLT is used either for increasing proliferation or promoting antiapoptotic responses resulting from mutations in GRM1, 3 and 5, or ionotropic GLT receptors. There is a direct and proportional association between xCT levels and cell proliferation in vitro/tumor progression in vivo (463). As a rapid increase in intracellular GLT induces cell death in PC12 cells due to an increase of ROS, RLZ-mediated increases in intracellular GLT may lead to similar consequences to melanoma cells (464). As a response to a rapid increase in GLT-mediated oxidative stress, melanoma cells quickly upregulate xCT expression (457). Melanoma cells under oxidative stress due to serum starvation promptly upregulate $\mathrm{xCT}$ protein expression within 2-3 h. Some melanoma cells may survive and acquire resistance to RLZ (465). Therefore, these cells can reduce their dependence on $\mathrm{xCT}$, as shown in RLZ-resistant melanoma cell lines (457). Currently, eight clinical trials are ongoing for different types of tumors.

\section{Statins (STs)}

STs are drugs used to treat lipid disorders due to their effectiveness in preventing the development of cardiovascular diseases (466). STs inhibit the rate-limiting enzyme 3-hydroxy-3-methylglutaryl-coenzyme A reductase (HMG-CoA) and thus the mevalonate pathway that constitutes the initial step in cholesterol biosynthesis (467). Importantly, data suggest that inhibition of the HMG-CoA may underlie protective effects against cancer, as the mevalonate pathway provides geranylgeranyl pyrophosphate and farnesyl pyrophosphate (468). These compounds are used for the prenylation of proteins, a process critical for directing these proteins to the cell membrane $(467,469-471)$. Interference with this process may be disruptive to cell cycle progression and cell proliferation, thereby mediating antineoplastic effects (472).

One study reported the antitumor properties of lovastatin (LVS) on F3II sarcomatoid mammary carcinoma, a highly invasive and metastatic murine tumor model (473). In female mice, treatment increased tumor latency, and decreased tumor formation and metastatic dissemination to the lungs. The antitumor properties of LVS were strongly associated with inhibition of tumor cell attachment and migration; these actions were prevented by the presence of mevalonate. Incubation of F3II cells with LVS produced a rounded-cell phenotype, lacking cortical actin organization, microtubule disruption and inhibition of integrin-mediated focal contacts in LVS-treated cells. LVS decreases membrane localization of Rho, a signaling molecule that requires geranylation for membrane association and activation (474). Also, LVS induces dose-dependent inhibition of the secretion of urokinase, a key proteolytic enzyme during tumor invasion and metastasis, and a significant increase of tissue-type plasminogen activator, a marker of good prognosis in mammary cancer (475).

STs affect the small GTPase Rho, which requires attachment to cell membranes for proper signaling activity. Chimaerins are GTPase-activating proteins (GAPs) that accelerate GTP hydrolysis from Rac, another GTPase of the same family (476). F3II cells transfected with the $\beta 2$-chimaerin GAP domain exhibiting low intracellular levels of active Rac-GTP were exposed in vitro to a panel of STs. Transfected cells were more sensitive to the cytostatic effects of LVS, simvastatin, atorvastatin and rosuvastatin than untransfected controls with high Rac-GTP levels. Transfected tumor cells also showed a higher capacity for detachment from the substrate and apoptosis after ST exposure (477). STs may affect gliomas by altering the mevalonate pathway, with subsequent modulations on the RAS-RAF-MEK-ERK or Akt signaling pathways (478). Combination treatment of STs with azathioprine, a compound that specifically blocks Rac1 activation, demonstrated an enhanced growth-inhibitory effect on F3II cells (477). Observational studies and meta-analyses have investigated the relationship between cancer incidence and ST use $(479,480)$. Studies of all cancer types, as well as specific cancers, are inconsistent, although several studies suggest a positive association with reduced incidence of gastrointestinal cancers. One meta-analysis, including 7,611 patients with gastric cancer in 26 randomized controlled trials and eight observational studies, found a $27 \%$ risk reduction associated with ST use (481). Similarly, other meta-analyses have reported that statin use is associated with a reduced risk of esophageal cancer, HCC and other prevalent cancer types, including breast cancer and CRC (482-484). However, other cohorts and case-control studies, as well as meta-analyses, have reported only weak or no significant correlation between reduced cancer risk and statin use $(485,486)$. In summary, studies published up to this point have reported conflicting results, and are overall inconclusive. It should be emphasized that most clinical trials that have been analyzed have endpoints relating to cardiovascular disease. A possible role for STs in cancer prevention can only be determined through carefully designed clinical trials with a sufficiently long follow-up and cancer incidence as a primary endpoint. At present, $\sim 160$ 
clinical trials are evaluating the effect of STs in cancer, both as a therapy and as a biomarker regarding the association between ST use and cancer incidence.

\section{Thalidomide (THL)}

THL is a classic example of drug repositioning in oncology (487). It was developed and commercialized as a sedative, and shortly after it was prescribed to mitigate nausea and vomiting in pregnancy. It was launched to the market in 1957, and soon after its popularization, it was observed that thousands of newborns presented severe limb defects such as amelia and phocomelia. As a consequence, it was banned in $1961(488,489)$. Currently, it is known that the reason for these limb malformations is the binding of THL to cereblon, a protein required in normal morphogenesis (490). Such binding promotes the recruitment of the DNA-binding protein Ikaros and zinc-finger protein Aiolos to the E3 complex, leading to substrate ubiquitination and degradation (490).

Starting in the 1990s with the research of D'Amato et al (491), it was found that THL possesses anticancer properties. Subsequently, a clinical trial in patients with MM was carried out with positive results, ending in the approval of its use by the FDA in combination with dexamethasone in newly diagnosed MM patients (492). At present, it is known that THL inhibits the production of TNF $\alpha$, altering the mechanisms of intracellular transduction by inhibiting NF- $\mathrm{KB}$ activation and the synthesis of IL-6, affecting cell proliferation, inflammation, angiogenesis and apoptosis (493). Furthermore, THL affects VEGF levels by downregulating its expression (494). After FDA approval, new analogs of THL with fewer side effects and increased potency were developed and assayed, including lenalidomide (LDM), and pomalidomide (PLM), all belonging to the class of drugs known as immunomodulatory drugs (IMiDs) (495).

In 2003, the FDA granted fast-track status to LDM for the treatment of relapsed or refractory MM. It has been shown that LDM has antitumor activity in a variety of types of lymphoma and leukemia (496). LDM in combination with dexamethasone possesses even higher activity, and the addition of a monoclonal antibody appears to improve efficacy even further (497). Then, in 2015 and 2016, four different combinations of LDM, dexamethasone plus a third drug were approved for relapsed/refractory MM, with carfilzomib, ixazomib, elotuzumab and daratumumab as the third compound (498). Fan et al (499) have described the mechanism of action of LDM-the combination of LDM and cereblon recruits new substrates (Ikaros, Aiolas and glutamine synthetase) that bind to the cereblon-CRL4 complex, leading to increased ubiquitination and proteasome-dependent degradation, thus resulting in anti-MM activity.

PLM was approved in 2013 as a treatment for relapsed and refractory multiple MM; however, patients treated with IMiDs should be monitored for the risk of infections (500). The possibility of cardiovascular and thrombotic complications should also be considered. However, Bringhen et al (501) analyzed 1,146 individual patient data to assess toxic deaths during induction treatment with first-generation novel agents THL, LDM and bortezomib, finding a significant reduction in toxicity-related mortality compared with conventional chemotherapy. At present, $>60$ clinical trials into different types of tumor or clinical settings are being conducted using these compounds (502).

\section{Valproic acid (VPA)}

VPA is a drug used as an anticonvulsant, and is also utilized in bipolar disorder and the prevention of migraine headaches (503). Although the mechanism is not entirely understood, it is hypothesized that its anticonvulsant action is due to the blockade of voltage-gated sodium channels and augmented levels of $\gamma$-aminobutyric acid (504).

Histone acetylation and deacetylation are processes via which the lysine residues at the N-terminal tail of the histone of the nucleosome are acetylated or deacetylated as a critical process of gene regulation (505). The reactions are catalyzed by the enzymes histone acetyltransferase (HAT) or histone deacetylase (HDAC), respectively (506). VPA is an HDAC inhibitor, and histone deacetylation is associated with gene silencing (507). Deacetylation allows the histones to wrap DNA tightly, preventing access to transcription factors, leading to transcriptional repression (506,508-510). The overexpression and increased activity of HDACs are characteristic of tumorigenesis and metastasis, suggesting an important regulatory role of histone deacetylation on oncogene expression (511). VPA has been shown to have antitumor activity (512).

The nature of the association between HDAC-mediated epigenetic regulation, and autophagy induction or suppression remains mostly unknown. It was found in lymphoma cells that HDAC inhibition by VPA is indispensable for the autophagy-enhancing effects demonstrated when used in combination with the mTOR inhibitor temsirolimus (513). Also, patients who have AML benefit from the apoptotic induction in tumor cells using VPA (514). Additionally, VPA suppresses prostatic tumor growth by increasing androgen sensitivity and augmenting cellular prostatic acid phosphatase via histone acetylation, leading to dephosphorylation of ErbB-2 (515). Moreover, studies showed that VPA induces the expression of cyclin D2, a crucial cell cycle regulatory gene that is mostly absent in prostate cancer (516). VPA has also been tested in head and neck squamous cell carcinoma, where it was demonstrated to increase p21, thus affecting cancer cell viability, differentiation marker expression and growth (517).

Studies combining VPA with MTF have demonstrated their synergistic anticancer effect, likely due to the p53 signaling pathway, which induces cancer cell apoptosis (518). Another synergetic combination of VPA and ellipticine (a topoisomerase II inhibitor) induces apoptosis in neuroblastoma cells, due to increasing histone $\mathrm{H} 3$ and $\mathrm{H} 4$ acetylation (519). VPA also exhibited its anticancer effects on bladder cancer in combination with melatonin, demonstrating a synergetic effect by activating apoptotic, necrotic and autophagy-associated genes (520). Another combination study has shown that VPA increases thymidine phosphorylase levels in breast cancer cells, thus synergizing the effects of capecitabine (521). Effects of VPA on pancreatic and colon cancer were associated with reduced levels of amyloid precursor protein (APP); lowering the levels of APP was associated with the activation of the chaperone GRP78 in cancer cells (521). DNA damage and apoptosis through ROS production have been proposed as additional mechanisms of VPA in pancreatic and cervical 
cancer (522). Abdelaleem et al (523) summarizes the evidence concerning the antitumor effects of VPA on gliomas. At present, $>14$ clinical trials are investigating the effectiveness of VPA in a wide variety of malignant tumors, such as pancreatic, bladder, cervix, thyroid and prostate cancers (412).

\section{Verapamil (VRP)}

VRP, an L-type calcium channel blocker, is used for the treatment of high blood pressure, angina and supraventricular tachycardia by blocking voltage-dependent calcium $\left(\mathrm{Ca}_{\mathrm{v}}\right)$ channels. There is compelling evidence that $\mathrm{Ca}_{\mathrm{V}}$ channels are expressed in various cancers at the gene and protein levels (524). Sun et al (525) reported that $\mathrm{LNCaP}$ prostate cancer cells displayed $\mathrm{Ca}^{2+}$ transients following stimulation with $5 \alpha$-DHT, which were inhibited by VRP. VRP has been shown to induce growth inhibition in meningioma cell cultures, as well as in a mouse xenograft model (526). Additionally, VRP combined with hydroxyurea or RU486 increased meningioma growth inhibition in vitro by inducing apoptosis and G1 cell cycle arrest, and in vivo by affecting microvascular density (527). Hajighasemi et al (528) found that VRP downregulated the production of VEGF in human peripheral blood mononuclear cells. VRP has exhibited antiproliferative effects on breast cancer cells in a mouse model (529). In a prospective study of 99 patients with anthracycline-resistant metastatic breast carcinoma, VRP showed positive survival effects. In advanced NSCLC, VRP improved the survival of patients when administered alongside vindesine and ifosfamide (530). However, there are controversial results concerning the anticancer properties of $\operatorname{VRP}(531,532)$.

As mentioned previously, tumor cells develop a form of drug resistance known as MDR, which is linked to the expression of P-gp. VRP is also an inhibitor of P-gp that, when combined with chemotherapeutics, can help to induce intracellular drug accumulation (533). Another reported mechanism involves autophagy. Autophagy is a natural, highly regulated process that involves orderly degradation and recycling of cellular materials (232). It has been debated as to whether autophagy acts as a tumor suppressor or as a factor that helps the survival of malignant cells. However, it has been shown that autophagy is more likely to act as a tumor suppressor, according to several models (534). VRP led to an accumulation of autophagy-like structures (535). VRP stimulates autophagy, involving a switch toward aerobic glycolysis and enhanced lactate production (535). VRP can reduce intracellular glucose levels with a reduction of lactate products (535). These produce two effects in the cancer cell; first, depriving the cells of substrates for anaerobic glycosylation, and secondly, producing a reduction of lactate products that maintain an acidic $\mathrm{pH}$ and facilitate tumor growth (536). Other mechanisms also play a role in the antitumor effects of VRP, such as reduced angiogenesis (535-538). Further investigation is needed. Currently, one clinical trial is open and actively recruiting analyzing the effect of brentuximab, dedotin, cyclosporine and VRP in patients with relapsed or refractory Hodgkin Lymphoma (clinical trial no. NCT03013933).

\section{Zidovudine (AZT)}

AZT is an analog of thymidine synthesized in 1964 as a potential anticancer agent, but which failed at that time to have positive results (539). In 1983, a retrovirus known as HIV was identified as the cause of AIDS. AZT proved to be a potent inhibitor of retroviruses, and following several studies, was approved for the treatment of HIV (540). AZT blocks the replication of HIV-1 by inhibiting reverse transcriptase (RT); AZT is phosphorylated intracellularly to AZT-triphosphate (AZT-TP) by thymidine kinase, and then is integrated into viral DNA, blocking chain elongation (541). Telomeres are the extremes of the chromosomes; their DNA consists of repetitive sequences, protecting the chromosomal ends. In each cell division, every chromosome is duplicated, but DNA polymerases cannot copy all bases in the $3^{\prime}$ end after primer removal, which results in the loss of a certain number of telomeric sequences in every cycle. Then, telomeres shorten progressively; when telomere length is critical, the cell enters into senescence and apoptosis (542). In the case of germinal or stem cells, they do not have an incomplete replication process; to solve this issue, the vast majority of organisms use a specific mechanism to maintain telomere length, executed by a specialized holoenzyme called telomerase (543). Telomerase is also an RT (structurally similar to HIV RT) comprised of a main catalytic subunit (hTERT) and an RNA (hTR) that acts as a template for the addition of telomeric sequences at the DNA $3^{\prime}$ end. Telomerase is inactive in most somatic cells; however, it is active in $85-90 \%$ of human tumors (544). The fact that hTERT is a functional catalytic RT led to a study concerning the possibility of inhibiting this enzyme in cancer cells using viral RT inhibitors such as AZT. It was demonstrated that AZT was preferentially incorporated into telomeric DNA rather than non-telomeric DNA and, for the first time, that telomere shortening caused by AZT was irreversible (545,546). Numerous other studies observed similar results (541,547-550). Synergistic interactions were seen, with AZT promoting the effects of cisplatin, paclitaxel and 5-fluorouracil (551-553).

In 2001, the effects of chronic in vitro AZT exposure on a mouse mammary carcinoma cell line were investigated (554). Treatment with AZT for $\geq 30$ passages completely inhibited telomerase activity, inducing progressive telomere shortening that led to cell senescence and apoptosis. Regarding the antitumor mechanism, AZT-TP is also incorporated into eukaryotic DNA in place of thymidine, having low affinity for DNA polymerases $\alpha, \beta$ and $\gamma$, and high affinity for RT (555). Several non-telomeric telomerase functions have been described, such as transcriptional modulation of the WNT/ $\beta$-catenin signaling pathway and RNA-dependent RNA polymerase activity; it was concluded that the inhibition produced by AZT was a mix of effects between canonical and non-canonical functions $(556,557)$. Recently, Song et al (558) demonstrated that AZT decreased angiogenesis by reducing receptor tyrosine kinase signaling in endothelial cells.

Currently, AZT is employed in the treatment of numerous virus-associated human cancers, including Epstein-Barr-associated lymphoma, AIDS-related Kaposi sarcoma, primary central nervous system lymphoma, Kaposi sarcoma-associated primary effusion lymphoma and adult $\mathrm{T}$ cell leukemia (559). As of 2019,>20 clinical trials are ongoing studying AZT in the treatment of Kaposi's sarcoma, lymphoma, leukemia and other tumors in patients with AIDS. AZT has been tested in phase I and II clinical trials for other types of tumor, either alone or in combination, showing some tumor regression (560-564). In 2012, it was demonstrated that AZT was effective against two 
Table I. Drug repositioning in oncology.

\begin{tabular}{lccc}
\hline $\begin{array}{l}\text { Drug name } \\
\text { (class of drug) }\end{array}$ & Primary use & $\begin{array}{c}\text { Potential anticancer } \\
\text { treatment applications }\end{array}$ & $\begin{array}{c}\text { Clinical trial } \\
\text { identifier }\end{array}$ \\
\hline
\end{tabular}

\begin{tabular}{ll}
\hline Artesunate & Malaria \\
Auranofin & Rheumatoid arthritis \\
Albendazole (BZM) & Helminths infestation \\
Flubendazole (BZM) & Intestinal parasites \\
Mebendazole (BZM) & $\begin{array}{l}\text { Helminths infestation } \\
\text { Omeprazole (BZM) }\end{array}$ \\
$\begin{array}{l}\text { Gastrointestinal disease } \\
\text { Chloroquine }\end{array}$ & $\begin{array}{l}\text { Malaria, lupus, amebiosis, } \\
\text { rheumatoid arthritis } \\
\text { Psychosis }\end{array}$ \\
\hline Chlorpromazine &
\end{tabular}
psychiatric disorders

Desmopressin

Central diabetes insipidus

Digoxin

Disulfiram

Doxycycline

Fenofibrate

Nelfinavir (HPI)

Ritonavir (HPI)
Hearth failure and arrhythmia

Alcohol deterrent

Bacterial infestation

Hypertriglyceridemia and mixed dyslipidemia AIDS

AIDS
Kaposi's sarcoma, NSCLC, melanoma, breast, ovarian, prostate and renal cancers

Melanoma, leukemia, gastrointestinal stromal tumor, NSCLC

CRC, leukemia, liver and ovarian cancers

Leukemia, melanoma, myeloma, neuroblastoma, breast cancer

GBM, melanoma, glioma, medulloblastoma

$\mathrm{CRC}$, breast and pancreatic cancers

GBM, NSCLC, pancreatic and breast cancers

Glioma, neuroblastoma, leukemia, lymphoma, CRC, breast and liver cancers

Glioma, astrocytoma

NCT02633098

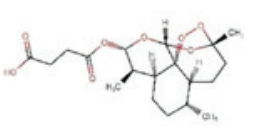

NCT01737502

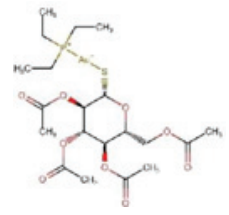

NCT02366884
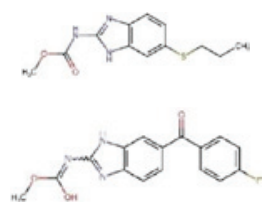

NCT03925662

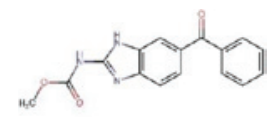

NCT02595372

NCT03243461

NCT03021486
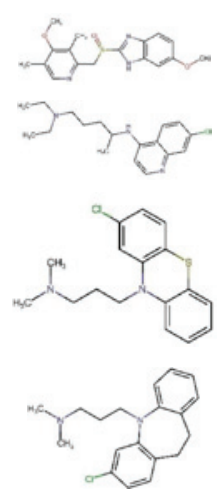

CRC, lung and breast cancers

NCT01623206

Breast, prostate, and head and neck cancers

NCT01763931
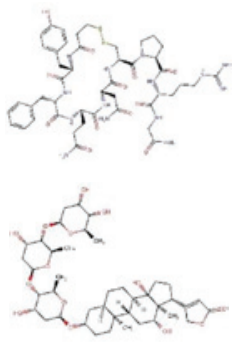

GBM, CRC, melanoma, prostate, ovarian, breast, pancreatic and liver cancers

NCT03323346

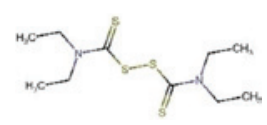
GBM, melanoma, breast, pancreatic cancers

Medulloblastoma, breast and lung cancers

Myeloma, sarcoma, GBM, melanoma, head and neck, pancreatic, breast, lung, thyroid and prostate cancers MM, glioma, breast cancer, chronic myeloid leukemia
NCT02775695

NCT01356290
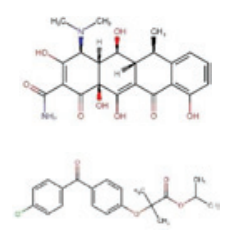

NCT01065844

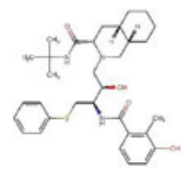

NCT01009437 
Table I. Continued.

\begin{tabular}{lccc}
\hline $\begin{array}{l}\text { Drug name } \\
\text { (class of drug) }\end{array}$ & Primary use & $\begin{array}{c}\text { Potential anticancer } \\
\text { treatment applications }\end{array}$ & $\begin{array}{c}\text { Clinical trial } \\
\text { identifier }\end{array}$ \\
\hline
\end{tabular}

\begin{tabular}{ll}
\hline Itraconazole & Antifungal \\
& NSCLC, GBM, medulloblastoma, \\
& basal cell carcinoma, breast, lung, \\
& prostate, ovarian and pancreatic \\
& cancers
\end{tabular}

Ivermectin Parasitic infestation

Leflunomide

Lithium

Metformin

Niclosamide

Nitroxoline

Acetylsalicylic acid

(NSAID)

Celecoxib (NSAID) Familial adenomatous polyposis

Diclofenac (NSAID) Antipyretic, anti-inflammatory, analgesic

Ibuprofen (NSAID) Antipyretic, anti-inflammatory, analgesic

Ketorolac (NSAID) Antipyretic, anti-inflammatory, analgesic

Naproxen (NSAID) Antipyretic, anti-inflammatory, analgesic
TNBC, CRC, lung and ovarian cancers

Myeloma, melanoma, NET, TNBC, neuroblastoma, prostate, bladder and breast cancers

Osteosarcoma, leukemia, CRC, GBM, prostate, thyroid, lung, stomach, esophageal brain, and head and neck cancers

CRC, NSCLC, breast, bladder, endometrial, lung, prostate and pancreatic cancers

NET, NSCLC, TNBC, acute myeloid leukemia, osteosarcoma, adrenocortical carcinoma, glioma, ovarian, prostate, lung, and head and neck cancers

Non-muscle invasive bladder cancer

CRC and CRC liver metastases

CRC, lung, breast, prostate, bladder, and head and neck cancers

Glioma, skin cancer

Glioma, neuroblastoma, CRC, prostate, bladder, breast, lung and gastric cancers

Oral, head and neck, and breast cancers

CRC, basal and squamous cell carcinoma
NCT04091022

NCT00769600

NCT02366884

NCT03709446

NCT02285855<smiles>CN(O)C(=N)NC(=N)N</smiles>

NCT02807805

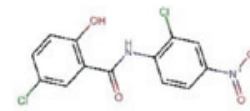

CTR20131716<smiles>C=C(C)C(=O)c1ccc(C)c2ccccc12</smiles>

NCT03326791<smiles>O=C(O)Cc1ccccc1C(=O)O</smiles>

NCT02429427

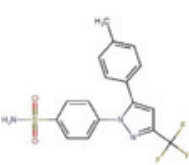

NCT02141139
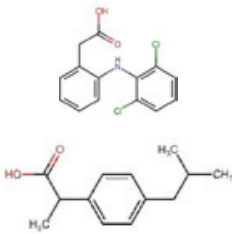

NCT02470299

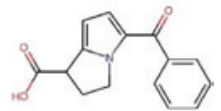

NCT02052908

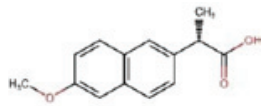


Table I. Continued.

\begin{tabular}{|c|c|c|c|}
\hline $\begin{array}{l}\text { Drug name } \\
\text { (class of drug) }\end{array}$ & Primary use & $\begin{array}{l}\text { Potential anticancer } \\
\text { treatment applications }\end{array}$ & $\begin{array}{l}\text { Clinical trial } \\
\text { identifier }\end{array}$ \\
\hline
\end{tabular}

Piroxicam (NSAID) Antipyretic, anti-inflammatory, Skin cancer analgesic

Sulindac (NSAID) Antipyretic, anti-inflammatory, Colorectal neoplasms

NCT01349881

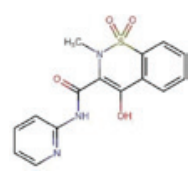

\author{
analgesic
}

Sildenafil (PDE5I) Erectile dysfunction

NSCLC

NCT00752115

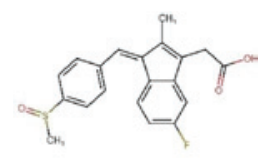

Tadalafil (PDE5I) Erectile dysfunction

HCC, metastatic pancreatic

NCT03785210 cancer

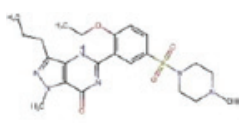

(1)

Vardenafil (PDE5I) Erectile dysfunction

Gliomas and brain metastases

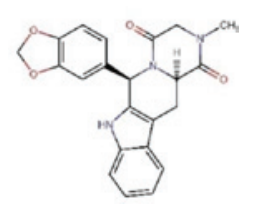

Pimozide

Several mental $/$ mood disorders

Breast, lung, prostate, ovarian and pancreatic cancers, CRC, $\mathrm{HCC}$

Breast cancer, CRC

Melanoma, breast and prostate cancerc

HCC, CRC, prostate cancer

Prostate cancer, lymphoma, leukemia, MM Nausea an
pregnancy

Valproic acid

Anticonvulsant, bipolar disorder, migraine headaches

Verapamil

High blood pressure, angina, tachycardia

Lymphoma, myeloid leukemia, CRC, glioma, thyroid, cervical, bladder, head and neck, prostate and pancreatic cancers

NSCLC, meningioma, breast cancer

Lymphoma, MM, breast cancer
AIDS
Zidovudine
NCT02279992

NCT00888797

NCT02796755

NCT04026230

NCT00450008
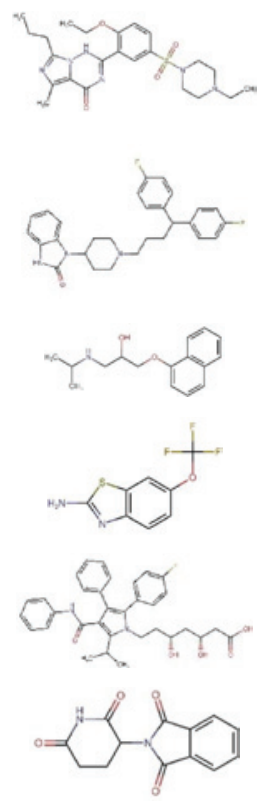

NCT00670046<smiles>O=C(O)C(CCO)CCO</smiles>

NCT00706810

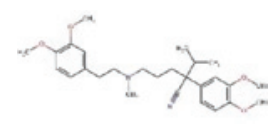

NCT00854581

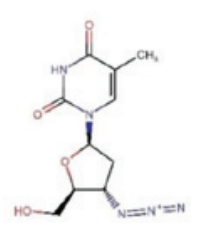

One example of a notable clinical trial is provided for each drug. BZM, benzimidazole derivative; HPI, HIV protease inhibitor; NSAID, nonsteroidal anti-inflammatory drug; PDE5I, phospodiesterase-5 inhibitor; CRC, colorectal carcinoma; HCC, hepatocellular carcinoma; GBM, glioblastoma multiforme; MM, multiple myeloma; NET, neuroendocrine tumors; NSCLC, non-small cell lung cancer; TNBC, triple negative breast cancer. 
human MM cell lines in vitro in a dose- and time-dependent manner, promoting cell cycle arrest in S phase. AZT is extremely promising. However, additional clinical studies are required to search for the full potential of AZT in a clinical setting (565).

\section{Concluding remarks}

Developing more effective cancer treatments requires not only the classical design of new molecules, but also intelligent searches for new antitumor medications by repurposing old drugs already approved for other uses. Such an approach has certain advantages; the development of a new drug is costly and timely, whereas drugs that are already approved have defined safety and pharmacological profiles. A drug with a long clinical history in humans has properly defined pharmacokinetic and pharmacodynamics data, including target identification, toxicity profiles, recommended dosage schemes and the consistent recognition of adverse effects, often meaning that development for an oncological indication can begin at a later stage, such as phase IIA. Furthermore, repositioned molecules often are approved quicker with reduced cost. However, there are some hurdles in the path, mainly the interests of companies and the costly remaining phases of the clinical trials prior to final approval. This review underlines the most promising drugs for repurposing, which are summarized in Table I, and although more research is needed, repositioning could pave the way to new, improved and more effective treatments for patients with cancer.

\section{Acknowledgements}

Not applicable.

\section{Funding}

The present study was funded by Quilmes National University (grant no. PUNQ 1398/15) and the Cancer National Institute of Argentina (grant no. EXPTE 756/16). The study was also supported by CONICET.

\section{Availability of data and materials}

Not applicable.

\section{Authors' contributions}

All authors contributed intellectually to the research, drafting and editing of the manuscript, and approved the final version of the manuscript to be published.

\section{Ethics approval and consent to participate}

Not applicable.

\section{Patient consent for publication}

Not applicable.

\section{Competing interests}

The authors declare that they have no competing interests.

\section{References}

1. Gupta SC, Sung B, Prasad S, Webb LJ and Aggarwal BB: Cancer drug discovery by repurposing: Teaching new tricks to old dogs. Trends Pharmacol Sci 34: 508-517, 2013.

2. Hanusova V, Skalova L, Kralova V and Matouskova P: Potential anti-cancer drugs commonly used for other indications. Curr Cancer Drug Targets 15: 35-52, 2015.

3. Paul SM, Mytelka DS, Dunwiddie CT, Persinger CC, Munos BH, Lindborg SR and Schacht AL: How to improve R\&D productivity: The pharmaceutical industry's grand challenge. Nat Rev Drug Discov 9: 203-214, 2010.

4. Adams CP and Brantner VV: Estimating the cost of new drug development: Is it really 802 million dollars? Health Aff (Millwood) 25: 420-428, 2006.

5. Nowak-Sliwinska P, Scapozza L and Ruiz IAA: Drug repurposing in oncology: Compounds, pathways, phenotypes and computational approaches for colorectal cancer. Biochim Biophys Acta Rev Cancer 1871: 434-454, 2019.

6. Bertolini F, Sukhatme VP and Bouche G: Drug repurposing in oncology-patient and health systems opportunities. Nat Rev Clin Oncol 12: 732-742, 2015.

7. Chong CR and Sullivan DJ Jr: New uses for old drugs. Nature 448: 645-646, 2007.

8. Ashburn TT and Thor KB: Drug repositioning: Identifying and developing new uses for existing drugs. Nat Rev Drug Discov 3: 673-683, 2004.

9. Shim JS and Liu JO: Recent advances in drug repositioning for the discovery of new anticancer drugs. Int J Biol Sci 10: 654-663, 2014.

10. Pantziarka P, Verbaanderd C, Sukhatme V, Rica Capistrano I, Crispino S, Gyawali B, Rooman I, Van Nuffel AM, Meheus L, Sukhatme VP and Bouche G: ReDO_DB: The repurposing drugs in oncology database. Ecancermedicalscience 12: 886, 2018.

11. Xue H, Li J, Xie H and Wang Y: Review of drug repositioning approaches and resources. Int J Biol Sci 14: 1232-1244, 2018.

12. Organization WH: WHO Model Lists of Essential Medicines, $2019,2019$.

13. Woodrow CJ, Haynes RK and Krishna S: Artemisinins. Postgrad Med J 81: 71-78, 2005.

14. White NJ: Anaemia and malaria. Malar J 17: 371, 2018.

15. Gunjan S, Sharma T, Yadav K, Chauhan BS, Singh SK, Siddiqi MI and Tripathi R: Artemisinin derivatives and synthetic trioxane trigger apoptotic cell death in asexual stages of plasmodium. Front Cell Infect Microbiol 8: 256, 2018.

16. Jeong DE, Song HJ, Lim S, Lee SJ, Lim JE, Nam DH, Joo KM, Jeong BC, Jeon SS, Choi HY and Lee HW: Repurposing the anti-malarial drug artesunate as a novel therapeutic agent for metastatic renal cell carcinoma due to its attenuation of tumor growth, metastasis, and angiogenesis. Oncotarget 6: 33046-33064, 2015.

17. Slezakova S and Ruda-Kucerova J: Anticancer activity of artemisinin and its derivatives. Anticancer Res 37: 5995-6003, 2017.

18. Jiang F, Zhou JY, Zhang D, Liu MH and Chen YG: Artesunate induces apoptosis and autophagy in HCT116 colon cancer cells, and autophagy inhibition enhances the artesunate-induced apoptosis. Int J Mol Med 42: 1295-1304, 2018.

19. Dell'Eva R, Pfeffer U, Vené R, Anfosso L, Forlani A, Albini A and Efferth T: Inhibition of angiogenesis in vivo and growth of Kaposi's sarcoma xenograft tumors by the anti-malarial artesunate. Biochem Pharmacol 68: 2359-2366, 2004.

20. Zheng L and Pan J: The Anti-malarial drug artesunate blocks Wnt/ $\beta$-catenin pathway and inhibits growth, migration and invasion of uveal melanoma cells. Curr Cancer Drug Targets 18: 988-998, 2018.

21. Patyar S,PatyarRR,MedhiB and Khanduja KL: Chemopreventive effect of artesunate in 1,2-dimethylhydrazine-induced rat colon carcinogenesis. J Adv Pharm Technol Res 8: 102-107, 2017.

22. von Hagens C, Walter-Sack I, Goeckenjan M, StorchHagenlocher B, Sertel S, Elsässer M, Remppis BA, Munzinger J, Edler L, Efferth T, et al: Long-term add-on therapy (compassionate use) with oral artesunate in patients with metastatic breast cancer after participating in a phase I study (ARTIC M33/2). Phytomedicine 54: 140-148, 2019.

23. Chen X, Zhang XL, Zhang GH and Gao YF: Artesunate promotes Th1 differentiation from CD4+ T cells to enhance cell apoptosis in ovarian cancer via miR-142. Braz J Med Biol Res 52: e7992, 2019. 
24. Wang Z, Wang C, Wu Z, Xue J, Shen B, Zuo W, Wang Z and Wang SL: Artesunate suppresses the growth of prostatic cancer cells through inhibiting androgen receptor. Biol Pharm Bull 40: 479-485, 2017.

25. Chauhan AK, Min KJ and Kwon TK: RIP1-dependent reactive oxygen species production executes artesunate-induced cell death in renal carcinoma Caki cells. Mol Cell Biochem 435: 15-24, 2017.

26. Tong Y, Liu Y, Zheng H, Zheng L, Liu W, Wu J, Ou R, Zhang G, Li F, Hu M, et al: Artemisinin and its derivatives can significantly inhibit lung tumorigenesis and tumor metastasis through Wnt/ $\beta$-catenin signaling. Oncotarget 7: 31413-31428, 2016

27. Beccafico S, Morozzi G, Marchetti MC, Riccardi C, Sidoni A, Donato R and Sorci G: Artesunate induces ROS- and p38 MAPK-mediated apoptosis and counteracts tumor growth in vivo in embryonal rhabdomyosarcoma cells. Carcinogenesis 36: 1071-1083, 2015.

28. Crespo-Ortiz MP and Wei MQ: Antitumor activity of artemisinin and its derivatives: From a well-known antimalarial agent to a potential anticancer drug. J Biomed Biotechnol 2012: 247597, 2012.

29. Xia X, Fan X, Zhao M and Zhu P: The relationship between ferroptosis and tumors: A novel landscape for therapeutic approach. Curr Gene Ther 19: 117-124, 2019.

30. $\mathrm{Li} \mathrm{Z}, \mathrm{Li} \mathrm{Q}, \mathrm{Wu}$ J, Wang M and Yu J: Artemisinin and its derivatives as a repurposing anticancer agent: What Else Do We Need to Do? Molecules 21: pii: E1331, 2016.

31. Zhou Y, Li W and Xiao Y: Profiling of multiple targets of artemisinin activated by hemin in cancer cell proteome. ACS Chem Biol 11: 882-888, 2016.

32. Ooko E, Saeed ME, Kadioglu O, Sarvi S, Colak M, Elmasaoudi K, Janah R, Greten HJ and Efferth T: Artemisinin derivatives induce iron-dependent cell death (ferroptosis) in tumor cells. Phytomedicine 22: 1045-1054, 2015.

33. Aletaha D, Neogi T, Silman AJ, Funovits J, Felson DT, Bingham CO III, Birnbaum NS, Burmester GR, Bykerk VP, Cohen MD, et al: 2010 Rheumatoid arthritis classification criteria: An American College of Rheumatology/European League Against Rheumatism collaborative initiative. Arthritis Rheum 62: 2569-2581, 2010

34. Wu B, Yang X and Yan M: Synthesis and Structure-activity relationship study of antimicrobial auranofin against ESKAPE pathogens. J Med Chem 62: 7751-7768, 2019.

35. Emery P and Suarez-Almazor M: Rheumatoid arthritis. Clin Evid: 1349-1371, 2003.

36. Roder C and Thomson MJ: Auranofin: Repurposing an old drug for a golden new age. Drugs R D 15: 13-20, 2015.

37. Perez MVR, Roife D, Dai B, Pratt M, Dobrowolski R, Kang Y, Li X, Augustine JJ, Zielinski R, Priebe W and Fleming JB: Antineoplastic effects of auranofin in human pancreatic adenocarcinoma preclinical models. Surgery Open Science 1: 56-63, 2019.

38. Pessetto ZY, Weir SJ, Sethi G, Broward MA and Godwin AK: Drug repurposing for gastrointestinal stromal tumor. Mol Cancer Ther 12: 1299-1309, 2013.

39. Li H, Hu J, Wu S, Wang L, Cao X, Zhang X, Dai B, Cao M, Shao R, Zhang R, et al: Auranofin-mediated inhibition of $\mathrm{PI} 3 \mathrm{~K} / \mathrm{AKT} / \mathrm{mTOR}$ axis and anticancer activity in non-small cell lung cancer cells. Oncotarget 7: 3548-3558, 2016.

40. Xiaobo C, Majidi M, Feng M, Shao R, Wang J, Zhao Y, Baladandayuthapani V, Song J, Fang B, Ji L, et al: TUSC2(FUS1)-erlotinib induced vulnerabilities in epidermal growth factor Receptor(EGFR) wildtype non-small cell lung cancer(NSCLC) targeted by the repurposed drug auranofin. Sci Rep 6: 35741, 2016.

41. Mellemkjaer L, Linet MS, Gridley G, Frisch M, Møller H and Olsen JH: Rheumatoid arthritis and cancer risk. Eur J Cancer 32A: 1753-1757, 1996.

42. Porta C, Paglino C and Mosca A: Targeting PI3K/Akt/mTOR signaling in cancer. Front Oncol 4: 64, 2014.

43. Nitulescu GM, Van De Venter M, Nitulescu G, Ungurianu A, Juzenas P, Peng Q, Olaru OT, Grădinaru D, Tsatsakis A, Tsoukalas D, et al: The Akt pathway in oncology therapy and beyond (Review). Int J Oncol 53: 2319-2331, 2018.

44. El Rashedy AA and Aboul-Enein HY: Benzimidazole derivatives as potential anticancer agents. Mini Rev Med Chem 13: 399-407, 2013

45. Tahlan S, Kumar S, Kakkar S and Narasimhan B: Benzimidazole scaffolds as promising antiproliferative agents: A review. BMC Chem 13: 66, 2019.
46. Herd RP, Miller TB and Gabel AA: A field evaluation of pro-benzimidazole, benzimidazole, and non-benzimidazole anthelmintics in horses. J Am Vet Med Assoc 179: 686-691, 1981.

47. Bansal Y, Kaur M and Bansal G: Antimicrobial potential of benzimidazole derived molecules. Mini Rev Med Chem 19: 624-646, 2019

48. Králová V, Hanušová V, Staňková P, Knoppová K, Čáňová K and Skálová L: Antiproliferative effect of benzimidazole anthelmintics albendazole, ricobendazole, and flubendazole in intestinal cancer cell lines. Anticancer Drugs 24: 911-919, 2013.

49. Dayan AD: Albendazole, mebendazole and praziquantel. Review of non-clinical toxicity and pharmacokinetics. Acta Trop 86: 141-159, 2003.

50. Pourgholami MH, Woon L, Almajd R, Akhter J, Bowery P and Morris DL: In vitro and in vivo suppression of growth of hepatocellular carcinoma cells by albendazole. Cancer Lett 165: 43-49, 2001.

51. Khalilzadeh A, Wangoo KT, Morris DL and Pourgholami MH: Epothilone-paclitaxel resistant leukemic cells CEM/dEpoB300 are sensitive to albendazole: Involvement of apoptotic pathways. Biochem Pharmacol 74: 407-414, 2007.

52. Chu SW, Badar S, Morris DL and Pourgholami MH: Potent inhibition of tubulin polymerisation and proliferation of paclitaxel-resistant 1A9PTX22 human ovarian cancer cells by albendazole. Anticancer Res 29: 3791-3796, 2009.

53. Teruel M, Dercole J and Catalano R: Evaluation of potential embryo toxicity of albendazole sulphoxide in CF1 mice. Biocell 35: 29-33, 2011.

54. Pourgholami MH, Yan Cai Z, Lu Y, Wang L and Morris DL: Albendazole: A potent inhibitor of vascular endothelial growth factor and malignant ascites formation in OVCAR-3 tumor-bearing nude mice. Clin Cancer Res 12: 1928-1935, 2006.

55. Wagil M, Bialk-Bielinska A, Puckowski A, Wychodnik K, Maszkowska J, Mulkiewicz E, Kumirska J, Stepnowski P and Stolte S: Toxicity of anthelmintic drugs (fenbendazole and flubendazole) to aquatic organisms. Environ Sci Pollut Res Int 22: 2566-2573, 2015

56. Canova K, Rozkydalova L and Rudolf E: Anthelmintic flubendazole and its potential use in anticancer therapy. Acta Medica (Hradec Kralove) 60: 5-11, 2017.

57. Hou ZJ, Luo X, Zhang W, Peng F, Cui B, Wu SJ, Zheng FM, $\mathrm{Xu} \mathrm{J}, \mathrm{Xu} \mathrm{LZ}$, Long ZJ, et al: Flubendazole, FDA-approved anthelmintic, targets breast cancer stem-like cells. Oncotarget 6 : 6326-6340, 2015.

58. Spagnuolo PA, Hu J, Hurren R, Wang X, Gronda M, Sukhai MA, Di Meo A, Boss J, Ashali I, Beheshti Zavareh R, et al: The antihelmintic flubendazole inhibits microtubule function through a mechanism distinct from Vinca alkaloids and displays preclinical activity in leukemia and myeloma. Blood 115: 4824-4833, 2010.

59. Michaelis M, Agha B, Rothweiler F, Löschmann N, Voges Y, Mittelbronn M, Starzetz T, Harter PN, Abhari BA, Fulda S, et al: Identification of flubendazole as potential anti-neuroblastoma compound in a large cell line screen. Sci Rep 5: 8202, 2015.

60. Canova K, Rozkydalova L, Vokurkova D and Rudolf E: Flubendazole induces mitotic catastrophe and apoptosis in melanoma cells. Toxicol In Vitro 46: 313-322, 2018.

61. Bai RY, Staedtke V, Aprhys CM, Gallia GL and Riggins GJ: Antiparasitic mebendazole shows survival benefit in 2 preclinical models of glioblastoma multiforme. Neuro Oncol 13: 974-982, 2011.

62. Mukhopadhyay T, Sasaki J, Ramesh R and Roth JA: Mebendazole elicits a potent antitumor effect on human cancer cell lines both in vitro and in vivo. Clin Cancer Res 8: 2963-2969, 2002.

63. Sasaki J, Ramesh R, Chada S, Gomyo Y, Roth JA and Mukhopadhyay T: The anthelmintic drug mebendazole induces mitotic arrest and apoptosis by depolymerizing tubulin in non-small cell lung cancer cells. Mol Cancer Ther 1: 1201-1209, 2002.

64. Nygren P, Fryknas M, Agerup B and Larsson R: Repositioning of the anthelmintic drug mebendazole for the treatment for colon cancer. J Cancer Res Clin Oncol 139: 2133-2140, 2013.

65. Doudican NA, Byron SA, Pollock PM and Orlow SJ: XIAP downregulation accompanies mebendazole growth inhibition in melanoma xenografts. Anticancer Drugs 24: 181-188, 2013.

66. De Witt M, Gamble A, Hanson D, Markowitz D, Powell C, Al Dimassi S, Atlas M, Boockvar J, Ruggieri R and Symons M: Repurposing mebendazole as a replacement for vincristine for the treatment of brain tumors. Mol Med 23: 50-56, 2017. 
67. Jin UH, Kim SB and Safe S: Omeprazole inhibits pancreatic cancer cell invasion through a nongenomic aryl hydrocarbon receptor pathway. Chem Res Toxicol 28: 907-918, 2015.

68. Zhang JL, Liu M, Yang Q, Lin SY, Shan HB, Wang HY and Xu GL: Effects of omeprazole in improving concurrent chemoradiotherapy efficacy in rectal cancer. World J Gastroenterol 23: 2575-2584, 2017.

69. Fako VE, Wu X, Pflug B, Liu JY and Zhang JT: Repositioning proton pump inhibitors as anticancer drugs by targeting the thioesterase domain of human fatty acid synthase. J Med Chem 58: 778-784, 2015

70. Haladyj E, Sikora M, Felis-Giemza A and Olesinska M Antimalarials-are they effective and safe in rheumatic diseases? Reumatologia 56: 164-173, 2018.

71. Wallace DJJUU, Waltham: Antimalarial drugs in the treatment of rheumatic disease, 2014.

72. Bondeson J and Sundler R: Antimalarial drugs inhibit phospholipase A2 activation and induction of interleukin 1beta and tumor necrosis factor alpha in macrophages: Implications for their mode of action in rheumatoid arthritis. Gen Pharmacol 30 357-366, 1998

73. Chou AC and Fitch CD: Heme polymerase: Modulation by chloroquine treatment of a rodent malaria. Life Sci 51: 2073-2078, 1992.

74. Untaroiu AM, Carey MA, Guler JL and Papin JA: Leveraging the effects of chloroquine on resistant malaria parasites for combination therapies. BMC Bioinformatics 20: 186, 2019.

75. Verbaanderd C, Maes H, Schaaf MB, Sukhatme VP, Pantziarka P, Sukhatme V, Agostinis P and Bouche G: Repurposing drugs in oncology (ReDO)-chloroquine and hydroxychloroquine as anti-cancer agents. Ecancermedicalscience 11: 781, 2017.

76. Mulcahy Levy JM, Zahedi S, Griesinger AM, Morin A, Davies KD, Aisner DL, Kleinschmidt-DeMasters BK, Fitzwalter BE, Goodall ML, Thorburn J, et al: Autophagy inhibition overcomes multiple mechanisms of resistance to BRAF inhibition in brain tumors. Elife 6: pii: e19671, 2017.

77. Egawa Y, Saigo C, Kito Y, Moriki T and Takeuchi T: Therapeutic potential of CPI-613 for targeting tumorous mitochondrial energy metabolism and inhibiting autophagy in clear cell sarcoma. PLoS One 13: e0198940, 2018.

78. Liu L, Han C, Yu H, Zhu W, Cui H, Zheng L, Zhang C and Yue L: Chloroquine inhibits cell growth in human A549 lung cancer cells by blocking autophagy and inducing mitochondrialmediated apoptosis. Oncol Rep 39: 2807-2816, 2018.

79. Ho M, Patel A, Hanley C, Murphy A, McSweeney T, Zhang L, McCann A, O'Gorman P and Bianchi G: Exploiting autophagy in multiple myeloma. J Cancer Metastasis Treat 5: 70, 2019.

80. King MA, Ganley IG and Flemington V: Inhibition of cholesterol metabolism underlies synergy between mTOR pathway inhibition and chloroquine in bladder cancer cells. Oncogene 35 : 4518-4528, 2016.

81. Weyerhauser P, Kantelhardt SR and Kim EL: Re-purposing chloroquine for glioblastoma: Potential merits and confounding variables. Front Oncol 8: 335, 2018

82.Kim J, Yip ML, Shen X, Li H, Hsin LY, Labarge S, Heinrich EL, Lee W, Lu J and Vaidehi N: Identification of anti-malarial compounds as novel antagonists to chemokine receptor CXCR4 in pancreatic cancer cells. PLoS One 7: e31004, 2012

83. Mereddy G and Ronayne CJ: Repurposing antimalarial drug mefloquine for cancer Treatment. Transl Med (Sunnyvale) 8: 99 , 2018.

84. Ahmed U, Jones $\mathrm{H}$ and Adams CE: Chlorpromazine for psychosis-induced aggression or agitation. Schizophr Bull 37: 890-891, 2011.

85. Heinrich JC, Donakonda S, Haupt VJ, Lennig P, Zhang Y and Schroeder M: New HSP27 inhibitors efficiently suppress drug resistance development in cancer cells. Oncotarget 7 68156-68169, 2016

86. Gil-Ad I, Shtaif B, Levkovitz Y, Dayag M, Zeldich E and Weizman A: Characterization of phenothiazine-induced apoptosis in neuroblastoma and glioma cell lines: Clinical relevance and possible application for brain-derived tumors. J Mol Neurosci 22: 189-198, 2004

87. Shin SY, Kim CG, Kim SH, Kim YS, Lim Y and Lee YH Chlorpromazine activates $\mathrm{p} 21 \mathrm{Waf} 1 / \mathrm{Cipl}$ gene transcription via early growth response-1 (Egr-1) in C6 glioma cells. Exp Mol Med 42: 395-405, 2010.

88. Cuomo F, Altucci L and Cobellis G: Autophagy function and dysfunction: Potential drugs as Anti-cancer therapy. Cancers (Basel) 11: pii: E1465, 2019.
89. Shin SY, Lee KS, Choi YK, Lim HJ, Lee HG, Lim Y and Lee YH: The antipsychotic agent chlorpromazine induces autophagic cell death by inhibiting the Akt/mTOR pathway in human U-87MG glioma cells. Carcinogenesis 34: 2080-2089, 2013.

90. Ishii N, Maier D, Merlo A, Tada M, Sawamura Y, Diserens AC and Van Meir EG: Frequent co-alterations of TP53, p16/CDKN2A, p14ARF, PTEN tumor suppressor genes in human glioma cell lines. Brain Pathol 9: 469-479, 1999.

91. Michalak K, Wesolowska O, Motohashi N, Molnar J and Hendrich $\mathrm{AB}$ : Interactions of phenothiazines with lipid bilayer and their role in multidrug resistance reversal. Curr Drug Targets 7: 1095-1105, 2006.

92.Zhelev Z, Ohba H, Bakalova R, Hadjimitova V, Ishikawa M, Shinohara Y and Baba Y: Phenothiazines suppress proliferation and induce apoptosis in cultured leukemic cells without any influence on the viability of normal lymphocytes. Phenothiazines and leukemia. Cancer Chemother Pharmacol 53: 267-275, 2004

93. Yde CW, Clausen MP, Bennetzen MV, Lykkesfeldt AE, Mouritsen OG and Guerra B: The antipsychotic drug chlorpromazine enhances the cytotoxic effect of tamoxifen in tamoxifen-sensitive and tamoxifen-resistant human breast cancer cells. Anticancer Drugs 20: 723-735, 2009.

94. Lee WY, Lee WT, Cheng CH, Chen KC, Chou CM, Chung CH, Sun MS, Cheng HW, Ho MN and Lin CW: Repositioning antipsychotic chlorpromazine for treating colorectal cancer by inhibiting sirtuin 1. Oncotarget 6: 27580-27595, 2015.

95. Chen MH, Yang WL, Lin KT, Liu CH, Liu YW, Huang KW, Chang PM, Lai JM, Hsu CN, Chao KM, et al: Gene expression-based chemical genomics identifies potential therapeutic drugs in hepatocellular carcinoma. PLoS One 6: e27186, 2011

96. Lee MS, Johansen L, Zhang Y, Wilson A, Keegan M, Avery W, Elliott P, Borisy AA and Keith CT: The novel combination of chlorpromazine and pentamidine exerts synergistic antiproliferative effects through dual mitotic action. Cancer Res 67: 11359-11367, 2007.

97. Cottingham C, Percival S, Birky T and Wang Q: Tricyclic antidepressants exhibit variable pharmacological profiles at the alpha(2A) adrenergic receptor. Biochem Biophys Res Commun 451: 461-466, 2014.

98. Benkelfat C, Murphy DL, Zohar J, Hill JL, Grover G and Insel TR: Clomipramine in obsessive-compulsive disorder. Further evidence for a serotonergic mechanism of action. Arch Gen Psychiatry 46: 23-28, 1989.

99. Levkovitz Y, Arnest G, Mendlovic S, Treves I and Fennig S: The effect of Ondansetron on memory in schizophrenic patients. Brain Res Bull 65: 291-295, 2005.

100. Rundle-Thiele D, Head R, Cosgrove L and Martin JH Repurposing some older drugs that cross the blood-brain barrier and have potential anticancer activity to provide new treatment options for glioblastoma. Br J Clin Pharmacol 81: 199-209, 2016

101. Higgins SC and Pilkington GJ: The in vitro effects of tricyclic drugs and dexamethasone on cellular respiration of malignant glioma. Anticancer Res 30: 391-397, 2010.

102. Tzadok S, Beery E, Israeli M, Uziel O, Lahav M, Fenig E, Gil-Ad I, Weizman A and Nordenberg J: In vitro novel combinations of psychotropics and anti-cancer modalities in U87 human glioblastoma cells. Int J Oncol 37: 1043-1051, 2010.

103. Xia Z, Bergstrand A, DePierre JW and Nässberger L: The antidepressants imipramine, clomipramine, and citalopram induce apoptosis in human acute myeloid leukemia HL-60 cells via caspase-3 activation. J Biochem Mol Toxicol 13. 338-347, 1999.

104. Daley E, Wilkie D, Loesch A, Hargreaves IP, Kendall DA, Pilkington GJ and Bates TE: Chlorimipramine: A novel anticancer agent with a mitochondrial target. Biochem Biophys Res Commun 328: 623-632, 2005.

105. Bilir A, Erguven M, Oktem G, Ozdemir A, Uslu A, Aktas E and Bonavida B: Potentiation of cytotoxicity by combination of imatinib and chlorimipramine in glioma. Int $\mathrm{J}$ Oncol 32: 829-839, 2008

106. Merry S, Hamilton TG, Flanigan P, Freshney RI and Kaye SB: Circumvention of pleiotropic drug resistance in subcutaneous tumours in vivo with verapamil and clomipramine. Eur J Cancer 27: 31-34, 1991.

107. Lu HA: Diabetes Insipidus. Adv Exp Med Biol 969: 213-225, 2017. 
108. Agerso H, Seiding Larsen L, Riis A, Lövgren U, Karlsson MO and Senderovitz T: Pharmacokinetics and renal excretion of desmopressin after intravenous administration to healthy subjects and renally impaired patients. Br J Clin Pharmacol 58: 352-358, 2004.

109. Deen PM, van Balkom BW and Kamsteeg EJ: Routing of the aquaporin-2 water channel in health and disease. Eur J Cell Biol 79: 523-530, 2000.

110. Hamilton KL and Devor DC: Basolateral membrane K+ channels in renal epithelial cells. Am J Physiol Renal Physiol 302: F1069-F1081, 2012.

111. Mannucci PM: Desmopressin (DDAVP) in the treatment of bleeding disorders: The first 20 years. Blood 90: 2515-2521, 1997.

112. Andersson KE and Van Kerrebroeck P: Pharmacotherapy for Nocturia. Curr Urol Rep 19: 8, 2018.

113. North WG: Gene regulation of vasopressin and vasopressin receptors in cancer. Exp Physiol 85 Spec No: 27S-40S, 2000.

114. Alonso DF, Skilton G, Farias EF, Bal de Kier Joffe E and Gomez DE: Antimetastatic effect of desmopressin in a mouse mammary tumor model. Breast Cancer Res Treat 57: 271-275, 1999.

115. Giron S, Tejera AM, Ripoll GV, Gomez DE and Alonso DF: Desmopressin inhibits lung and lymph node metastasis in a mouse mammary carcinoma model of surgical manipulation. J Surg Oncol 81: 38-44, 2002

116. Ripoll GV, Garona J, Hermo GA, Gomez DE and Alonso DF: Effects of the synthetic vasopressin analog desmopressin in a mouse model of colon cancer. Anticancer Res 30: 5049-5054, 2010.

117. Ripoll GV, Farina HG, Yoshiji H, Gomez DE and Alonso DF: Desmopressin reduces melanoma lung metastasis in transgenic mice overexpressing tissue inhibitor of metalloproteinases-1. In Vivo 20: 881-885, 2006.

118. Hermo GA, Torres P, Ripoll GV, Scursoni AM, Gomez DE, Alonso DF and Gobello C: Perioperative desmopressin prolongs survival in surgically treated bitches with mammary gland tumours: A pilot study. Vet J 178: 103-108, 2008.

119. Ripoll GV, Garona J, Pifano M, Farina HG, Gomez DE and Alonso DF: Reduction of tumor angiogenesis induced by desmopressin in a breast cancer model. Breast Cancer Res Treat 142: 9-18, 2013

120. Garona J, Pifano M, Orlando UD, Pastrian MB, Iannucci NB, Ortega HH, Podesta EJ, Gomez DE, Ripoll GV and Alonso DF: The novel desmopressin analogue [V4Q5]dDAVP inhibits angiogenesis, tumour growth and metastases in vasopressin type 2 receptor-expressing breast cancer models. Int J Oncol 46: 2335-2345, 2015.

121. Weinberg RS, Grecco MO, Ferro GS, Seigelshifer DJ, Perroni NV, Terrier FJ, Sánchez-Luceros A, Maronna E, Sánchez-Marull R, Frahm I, et al: A phase II dose-escalation trial of perioperative desmopressin (1-desamino-8-d-arginine vasopressin) in breast cancer patients. Springerplus 4: 428, 2015.

122. Sasaki H, Klotz LH, Sugar LM, Kiss A and Venkateswaran V: A combination of desmopressin and docetaxel inhibit cell proliferation and invasion mediated by urokinase-type plasminogen activator (uPA) in human prostate cancer cells. Biochem Biophys Res Commun 464: 848-854, 2015.

123. Bass R, Roberto D, Wang DZ, Cantu FP, Mohamadi RM, Kelley SO, Klotz L and Venkateswaran V: Combining desmopressin and docetaxel for the treatment of castration-resistant prostate cancer in an orthotopic model. Anticancer Res 39: 113-118, 2019

124. Rose A, Andre N, Rozados VR, Mainetti LE, Menacho Márquez M, Rico MJ, Schaiquevich P, Villarroel M, Gregianin L, Graupera JM, et al: Highlights from the 1st Latin American meeting on metronomic chemotherapy and drug repositioning in oncology, 27-28 May, 2016, Rosario, Argentina. Ecancermedicalscience 10: 672, 2016.

125. Hollman A: Drugs for atrial fibrillation. Digoxin comes from Digitalis lanata. BMJ 312: 912, 1996.

126. Ravi Kumar A and Kurup PA: Digoxin and membrane sodium potassium ATPase inhibition in cardiovascular disease. Indian Heart J 52: 315-318, 2000.

127. Sperelakis $\mathrm{N}$ and Ohya Y: Electrophysiology of vascular smooth muscle. In: Physiology and Pathophysiology of the Heart Springer, pp773-811, 1989.

128. Menger L, Vacchelli E, Kepp O, Eggermont A, Tartour E, Zitvogel L, Kroemer G and Galluzzi L: Trial watch: Cardiac glycosides and cancer therapy. Oncoimmunology 2: e23082, 2013.
129. Biggar RJ, Wohlfahrt J, Oudin A, Hjuler T and Melbye M: Digoxin use and the risk of breast cancer in women. J Clin Oncol 29: 2165-2170, 2011.

130. Platz EA, Yegnasubramanian S, Liu JO, Chong CR, Shim JS, Kenfield SA, Stampfer MJ, Willett WC, Giovannucci E and Nelson WG: A novel two-stage, transdisciplinary study identifies digoxin as a possible drug for prostate cancer treatment. Cancer Discov 1: 68-77, 2011.

131. Lin J, Zhan T, Duffy D, Hoffman-Censits J, Kilpatrick D, Trabulsi EJ, Lallas CD, Chervoneva I, Limentani K, Kennedy B, et al: A pilot phase II Study of digoxin in patients with recurrent prostate cancer as evident by a rising PSA. Am J Cancer Ther Pharmacol 2: 21-32, 2014.

132. Biggar RJ: Molecular pathways: Digoxin use and estrogen-sensitive cancers-risks and possible therapeutic implications. Clin Cancer Res 18: 2133-2137, 2012.

133. Zhang H, Qian DZ, Tan YS, Lee K, Gao P, Ren YR, Rey S, Hammers H, Chang D, Pili R, et al: Digoxin and other cardiac glycosides inhibit HIF-1alpha synthesis and block tumor growth. Proc Natl Acad Sci USA 105: 19579-19586, 2008

134. Kometiani P, Liu L and Askari A: Digitalis-induced signaling by $\mathrm{Na}+/ \mathrm{K}+-\mathrm{ATP}$ ase in human breast cancer cells. Mol Pharmacol 67: 929-936, 2005.

135. Frankel AE, Eskiocak U, Gill JG, Yuan S, Ramesh V, Froehlich TW, Ahn C and Morrison SJ: Digoxin plus trametinib therapy achieves disease control in BRAF Wild-type metastatic melanoma patients. Neoplasia 19: 255-260, 2017.

136. Xia M, Huang R, Sakamuru S, Alcorta D, Cho MH, Lee DH, Park DM, Kelley MJ, Sommer J and Austin CP: Identification of repurposed small molecule drugs for chordoma therapy. Cancer Biol Ther 14: 638-647, 2013.

137. Heldal AT, Skurtveit S, Lobmaier PPK, Vederhus JK and Bramness JG: Use of drugs for alcohol use disorder in Norway 2004-16. Tidsskr Nor Laegeforen: 138, 2018 doi: 10.4045/tidsskr.18.0383.

138. Huang J, Campian JL, Gujar AD, Tran DD, Lockhart AC, DeWees TA, Tsien CI and Kim AH: A phase I study to repurpose disulfiram in combination with temozolomide to treat newly diagnosed glioblastoma after chemoradiotherapy. J Neurooncol 128: 259-266, 2016.

139. Jiao Y, Hannafon BN and Ding WQ: Disulfiram's anticancer activity: Evidence and mechanisms. Anticancer Agents Med Chem 16: 1378-1384, 2016

140. Liu P, Wang Z, Brown S, Kannappan V, Tawari PE, Jiang W, Irache JM, Tang JZ, Armesilla AL, Darling JL, et al: Liposome encapsulated Disulfiram inhibits NFkB pathway and targets breast cancer stem cells in vitro and in vivo. Oncotarget 5: $7471-7485,2014$

141. Kona FR, Buac D and M Burger A: Disulfiram, and disulfiram derivatives as novel potential anticancer drugs targeting the ubiquitin-proteasome system in both preclinical and clinical studies. Curr Cancer Drug Targets 11: 338-346, 2011.

142. Kuo CF, Luo SF, See LC, Chou IJ, Fang YF and Yu KH: Increased risk of cancer among gout patients: A nationwide population study. Joint Bone Spine 79: 375-378, 2012.

143. Triscott J, Lee C, Hu K, Fotovati A, Berns R, Pambid M, Luk M, Kast RE, Kong E, Toyota E, et al: Disulfiram, a drug widely used to control alcoholism, suppresses the self-renewal of glioblastoma and over-rides resistance to temozolomide. Oncotarget 3: 1112-1123, 2012

144. Cvek B: TNF-alpha could be responsible for disulfiram-mediated hepatotoxicity. J Hepatol 49: 865-866, 2008.

145. Ekinci E, Rohondia S, Khan R and Dou QP: Repurposing disulfiram as an Anti-cancer agent: Updated review on literature and patents. Recent Pat Anticancer Drug Discov 14: 113-132, 2019.

146. Schott B, Londos-Gagliardi D, Ries C, Huet S and Robert J: Pharmacological and molecular characterization of intrinsic and acquired doxorubicin resistance in murine tumor cell lines. J Cancer Res Clin Oncol 119: 527-532, 1993.

147. Skrott Z, Mistrik M, Andersen KK, Friis S, Majera D, Gursky J, Ozdian T, Bartkova J, Turi Z, Moudry P, et al: Alcohol-abuse drug disulfiram targets cancer via p97 segregase adaptor NPL4. Nature 552: 194-199, 2017.

148. Cong J, Wang Y, Zhang X, Zhang N, Liu L, Soukup K, Michelakos T, Hong T, DeLeo A, Cai L, et al: A novel chemoradiation targeting stem and nonstem pancreatic cancer cells by repurposing disulfiram. Cancer Lett 409: 9-19, 2017.

149. Triscott J, Rose Pambid M and Dunn SE: Concise review: Bullseye: Targeting cancer stem cells to improve the treatment of gliomas by repurposing disulfiram. Stem Cells 33: 1042-1046, 2015. 
150. Verma S, Stewart DJ, Maroun JA and Nair RC: A randomized phase II study of cisplatin alone versus cisplatin plus disulfiram. Am J Clin Oncol 13: 119-124, 1990.

151. Schweizer MT, Lin J, Blackford A, Bardia A, King S, Armstrong AJ, Rudek MA, Yegnasubramanian $S$ and Carducci MA: Pharmacodynamic study of disulfiram in men with non-metastatic recurrent prostate cancer. Prostate Cancer Prostatic Dis 16: 357-361, 2013.

152. Peyriere H, Makinson A, Marchandin H and Reynes J: Doxycycline in the management of sexually transmitted infections. J Antimicrobial Chemother 73: 553-563, 2018.

153. Polikanov YS, Aleksashin NA, Beckert B and Wilson DN: The mechanisms of action of ribosome-targeting peptide antibiotics. Front Mol Biosci 5: 48, 2018.

154. Gilbertson-Beadling S, Powers EA, Stamp-Cole M, Scott PS, Wallace TL, Copeland J, Petzold G, Mitchell M, Ledbetter S and Poorman R: The tetracycline analogs minocycline and doxycycline inhibit angiogenesis in vitro by a non-metalloproteinase-dependent mechanism. Cancer Chemother Pharmacol 36: 418-424, 1995.

155. Yamazaki M, Akahane T, Buck T, Yoshiji H, Gomez DE, Schoeffner DJ, Okajima E, Harris SR, Bunce OR, Thorgeirsson SS and Thorgeirsson UP: Long-term exposure to elevated levels of circulating TIMP-1 but not mammary TIMP-1 suppresses growth of mammary carcinomas in transgenic mice. Carcinogenesis 25: 1735-1746, 2004

156. Gomez DE, Yoshiji H, Kim JC and Thorgeirsson UP: Ulex europaeus I lectin induces activation of matrix-metalloproteinase-2 in endothelial cells. Biochem Biophys Res Commun 216 177-182, 1995.

157. Lamb R, Ozsvari B, Lisanti CL, Tanowitz HB, Howell A, Martinez-Outschoorn UE, Sotgia F and Lisanti MP: Antibiotics that target mitochondria effectively eradicate cancer stem cells, across multiple tumor types: Treating cancer like an infectious disease. Oncotarget 6: 4569-4584, 2015.

158. Scatena C, Roncella M, Di Paolo A, Aretini P, Menicagli M, Fanelli G, Marini C, Mazzanti CM, Ghilli M, Sotgia F, et al: Doxycycline, an inhibitor of mitochondrial biogenesis, effectively reduces cancer stem cells (CSCs) in early breast cancer patients: A clinical pilot study. Front Oncol 8: 452, 2018.

159. Pulvino M, Chen L, Oleksyn D, Li J, Compitello G, Rossi R, Spence S, Balakrishnan V, Jordan C, Poligone B, et al: Inhibition of COP9-signalosome (CSN) deneddylating activity and tumor growth of diffuse large B-cell lymphomas by doxycycline. Oncotarget 6: 14796-14813, 2015.

160. Son K, Fujioka S, Iida T, Furukawa K, Fujita T, Yamada H, Chiao PJ and Yanaga K: Doxycycline induces apoptosis in PANC-1 pancreatic cancer cells. Anticancer Res 29: 3995-4003, 2009.

161. Duivenvoorden WC, Popović SV, Lhoták S, Seidlitz E, Hirte HW, Tozer RG and Singh G: Doxycycline decreases tumor burden in a bone metastasis model of human breast cancer. Cancer Res 62 1588-1591, 2002.

162. Wan L, Dong H, Xu H, Ma J, Zhu Y, Lu Y, Wang J, Zhang T, Li T, Xie J, et al: Aspirin, lysine, mifepristone and doxycycline combined can effectively and safely prevent and treat cancer metastasis: Prevent seeds from gemmating on soil. Oncotarget 6: 35157-35172, 2015

163. Qin Y, Zhang Q, Lee S, Zhong WL, Liu YR, Liu HJ, Zhao D, Chen S, Xiao T, Meng J, et al: Doxycycline reverses epithelial-to-mesenchymal transition and suppresses the proliferation and metastasis of lung cancer cells. Oncotarget 6: 40667-40679, 2015.

164. Davis AJ, Chen BP and Chen DJ: DNA-PK: A dynamic enzyme in a versatile DSB repair pathway. DNA Repair (Amst) 17: 21-29, 2014

165. Lamb R, Fiorillo M, Chadwick A, Ozsvari B, Reeves KJ, Smith DL, Clarke RB, Howell SJ, Cappello AR, Martinez-Outschoorn UE, et al: Doxycycline down-regulates DNA-PK and radiosensitizes tumor initiating cells: Implications for more effective radiation therapy. Oncotarget 6: 14005-14025, 2015.

166. Shimomura A, Takasaki A, Nomura R, Hayashi N and Senda T: Identification of DNA-dependent protein kinase catalytic subunit as a novel interaction partner of lymphocyte enhancer factor 1. Med Mol Morphol 46: 14-19, 2013.

167. Alexander-Savino CV, Hayden MS, Richardson C, Zhao J and Poligone B: Doxycycline is an NF-kB inhibitor that induces apoptotic cell death in malignant T-cells. Oncotarget 7: 75954-75967, 2016
168. Xu N, Wang Q, Jiang S, Wang Q, Hu W, Zhou S, Zhao L, Xie L, Chen J, Wellstein A and Lai EY: Fenofibrate improves vascular endothelial function and contractility in diabetic mice. Redox Biol 20: 87-97, 2019.

169. Li T, Zhang Q, Zhang J, Yang G, Shao Z, Luo J, Fan M, Ni C, $\mathrm{Wu} \mathrm{Z}$ and $\mathrm{Hu} \mathrm{X}$ : Fenofibrate induces apoptosis of triple-negative breast cancer cells via activation of NF-kB pathway. BMC Cancer 14: 96, 2014.

170. Shigeto T, Yokoyama Y, Xin B and Mizunuma H: Peroxisome proliferator-activated receptor alpha and gamma ligands inhibit the growth of human ovarian cancer. Oncol Rep 18: 833-840, 2007.

171. Liu H, Zang C, Fenner MH, Liu D, Possinger K, Koeffler HP and Elstner E: Growth inhibition and apoptosis in human Philadelphia chromosome-positive lymphoblastic leukemia cell lines by treatment with the dual PPARalpha/gamma ligand TZD18. Blood 107: 3683-3692, 2006.

172. Zhu Y, Dean AE, Horikoshi N, Heer C, Spitz DR and Gius D: Emerging evidence for targeting mitochondrial metabolic dysfunction in cancer therapy. J Clin Invest 128: 3682-3691, 2018.

173. Jan CI, Tsai MH, Chiu CF, Huang YP, Liu CJ and Chang NW: Fenofibrate suppresses oral tumorigenesis via reprogramming metabolic processes: Potential drug repurposing for oral cancer. Int J Biol Sci 12: 786-798, 2016.

174. Luo F, Li Y, Yuan F and Zuo J: Hexokinase II promotes the Warburg effect by phosphorylating alpha subunit of pyruvate dehydrogenase. Chin J Cancer Res 31: 521-532, 2019.

175. Feron O: Pyruvate into lactate and back: From the Warburg effect to symbiotic energy fuel exchange in cancer cells Radiother Oncol 92: 329-333, 2009.

176. Pedersen PL: Voltage dependent anion channels (VDACs): A brief introduction with a focus on the outer mitochondrial compartment's roles together with hexokinase-2 in the 'Warburg effect' in cancer. J Bioenerg Biomembr 40: 123-126, 2008.

177. Nielsen MH, Pedersen FS and Kjems J: Molecular strategies to inhibit HIV-1 replication. Retrovirology 2: 10, 2005.

178. Jensen K, Bikas A, Patel A, Kushchayeva Y, Costello J, McDaniel D, Burman K and Vasko V: Nelfinavir inhibits proliferation and induces DNA damage in thyroid cancer cells. Endocr Relat Cancer 24: 147-156, 2017.

179. Wilson JM, Fokas E, Dutton SJ, Patel N, Hawkins MA, Eccles C, Chu KY, Durrant L, Abraham AG, Partridge M, et al: ARCII: A phase II trial of the HIV protease inhibitor Nelfinavir in combination with chemoradiation for locally advanced inoperable pancreatic cancer. Radiother Oncol 119: 306-311, 2016.

180. Hoover AC, Milhem MM, Anderson CM, Sun W, Smith BJ, Hoffman HT and Buatti JM: Efficacy of nelfinavir as monotherapy in refractory adenoid cystic carcinoma: Results of a phase II clinical trial. Head Neck 37: 722-726, 2015.

181. Goda JS, Pachpor T, Basu T, Chopra S and Gota V: Targeting the AKT pathway: Repositioning HIV protease inhibitors as radiosensitizers. Indian J Med Res 143: 145-159, 2016.

182. Jiang W, Mikochik PJ, Ra JH, Lei H, Flaherty KT, Winkler JD and Spitz FR: HIV protease inhibitor nelfinavir inhibits growth of human melanoma cells by induction of cell cycle arrest. Cancer Res 67: 1221-1227, 2007.

183. Srirangam A, Mitra R, Wang M, Gorski JC, Badve S, Baldridge L, Hamilton J, Kishimoto H, Hawes J, Li L, et al: Effects of HIV protease inhibitor ritonavir on Akt-regulated cell proliferation in breast cancer. Clin Cancer Res 12: 1883-1896, 2006.

184. Mahoney E, Maddocks K, Flynn J, Jones J, Cole SL, Zhang X, Byrd JC and Johnson AJ: Identification of endoplasmic reticulum stress-inducing agents by antagonizing autophagy: A new potential strategy for identification of anti-cancer therapeutics in B-cell malignancies. Leuk Lymphoma 54: 2685-2692, 2013.

185. Pore N, Gupta AK, Cerniglia GJ and Maity A: HIV protease inhibitors decrease VEGF/HIF-1alpha expression and angiogenesis in glioblastoma cells. Neoplasia 8: 889-895, 2006.

186. Hampson L, Kitchener HC and Hampson IN: Specific HIV protease inhibitors inhibit the ability of HPV16 E6 to degrade p53 and selectively kill E6-dependent cervical carcinoma cells in vitro. Antivir Ther 11: 813-825, 2006.

187. Yang Y, Ikezoe T, Nishioka C, Bandobashi K, Takeuchi T, Adachi Y, Kobayashi M, Takeuchi S, Koeffler HP and Taguchi H: NFV, an HIV-1 protease inhibitor, induces growth arrest, reduced Akt signalling, apoptosis and docetaxel sensitisation in NSCLC cell lines. Br J Cancer 95: 1653-1662, 2006. 
188. Pajonk F, Himmelsbach J, Riess K, Sommer A and McBride WH: The human immunodeficiency virus (HIV)-1 protease inhibitor saquinavir inhibits proteasome function and causes apoptosis and radiosensitization in non-HIV-associated human cancer cells. Cancer Res 62: 5230-5235, 2002.

189. Yang Y, Ikezoe T, Takeuchi T, Adachi Y, Ohtsuki Y, Takeuchi S, Koeffler HP and Taguchi H: HIV-1 protease inhibitor induces growth arrest and apoptosis of human prostate cancer LNCaP cells in vitro and in vivo in conjunction with blockade of androgen receptor STAT3 and AKT signaling. Cancer Sci 96: 425-433, 2005.

190. Koltai T: Nelfinavir and other protease inhibitors in cancer: Mechanisms involved in anticancer activity. F1000Res 4: 9, 2015.

191. Bruning A, Vogel M, Burger P, Rahmeh M, Gingelmaier A, Friese K, Lenhard M and Burges A: Nelfinavir induces TRAIL receptor upregulation in ovarian cancer cells. Biochem Biophys Res Commun 377: 1309-1314, 2008.

192. Gupta V, Samuleson CG, Su S and Chen TC: Nelfinavir potentiation of imatinib cytotoxicity in meningioma cells via survivin inhibition. Neurosurg Focus 23: E9, 2007.

193. Xie L, Evangelidis T, Xie L and Bourne PE: Drug discovery using chemical systems biology: Weak inhibition of multiple kinases may contribute to the anti-cancer effect of nelfinavir. PLoS Comput Biol 7: e1002037, 2011.

194. Lenhard JM, Croom DK, Weiel JE and Winegar DA: HIV protease inhibitors stimulate hepatic triglyceride synthesis. Arterioscler Thromb Vasc Biol 20: 2625-2629, 2000

195. McBrayer SK, Cheng JC, Singhal S, Krett NL, Rosen ST and Shanmugam M: Multiple myeloma exhibits novel dependence on GLUT4, GLUT8, and GLUT11: Implications for glucose transporter-directed therapy. Blood 119: 4686-4697, 2012.

196. Laurent N, de Bouard S, Guillamo JS, Christov C, Zini R, Jouault H, Andre P, Lotteau V and Peschanski M: Effects of the proteasome inhibitor ritonavir on glioma growth in vitro and in vivo. Mol Cancer Ther 3: 129-136, 2004.

197. Kast RE: The role of interleukin-18 in glioblastoma pathology implies therapeutic potential of two old drugs-disulfiram and ritonavir. Chin J Cancer 34: 161-165, 2015.

198. Ikezoe T, Saito T, Bandobashi K, Yang Y, Koeffler HP and Taguchi H: HIV-1 protease inhibitor induces growth arrest and apoptosis of human multiple myeloma cells via inactivation of signal transducer and activator of transcription 3 and extracellular signal-regulated kinase 1/2. Mol Cancer Ther 3: 473-479, 2004

199. Kast RE, Karpel-Massler G and Halatsch ME: CUSP9* treatment protocol for recurrent glioblastoma: Aprepitant, artesunate, auranofin, captopril, celecoxib, disulfiram, itraconazole, ritonavir, sertraline augmenting continuous low dose temozolomide. Oncotarget 5: 8052-8082, 2014.

200. Mendez-Lopez M, Sutter T, Driessen C and Besse L: HIV protease inhibitors for the treatment of multiple myeloma. Clin Adv Hematol Oncol 17: 615-623, 2019.

201. Ondieki G, Nyagblordzro M, Kikete S, Liang R, Wang L and $\mathrm{He} \mathrm{X}$ : Cytochrome P450 and P-Glycoprotein-mediated interactions involving african herbs indicated for common noncommunicable diseases. Evid Based Complement Alternat Med 2017: 2582463, 2017.

202.Perrotti D, Jamieson C, Goldman J and Skorski T: Chronic myeloid leukemia: Mechanisms of blastic transformation. J Clin Invest 120: 2254-2264, 2010.

203. Jabbour E, Parikh SA, Kantarjian H and Cortes J: Chronic myeloid leukemia: Mechanisms of resistance and treatment. Hematol Oncol Clin North Am 25: 981-995, v, 2011.

204.Bixby D and Talpaz M: Mechanisms of resistance to tyrosine kinase inhibitors in chronic myeloid leukemia and recent therapeutic strategies to overcome resistance. Hematology Am Soc Hematol Educ Program: 461-476, 2009 doi: 10.1182/asheducation-2009.1.461.

205. Xu HL, Wang ZJ, Liang XM, Li X, Shi Z, Zhou N and Bao JK In silico identification of novel kinase inhibitors targeting wild-type and T315I mutant ABL1 from FDA-approved drugs. Mol Biosyst 10: 1524-1537, 2014.

206. Ahluwalia MS, Patton C, Stevens G, Tekautz T, Angelov L, Vogelbaum MA, Weil RJ, Chao S, Elson P, Suh JH, et al: Phase II trial of ritonavir/lopinavir in patients with progressive or recurrent high-grade gliomas. J Neurooncol 102: 317-321, 2011.

207. Rathbun RC and Liedtke MD: Antiretroviral drug interactions: Overview of interactions involving new and investigational agents and the role of therapeutic drug monitoring for management. Pharmaceutics 3: 745-781, 2011.
208. Kast RE: Ritonavir and disulfiram may be synergistic in lowering active interleukin-18 levels in acute pancreatitis, and thereby hasten recovery. JOP 9: 350-353, 2008.

209. Piliero PJ: Interaction between ritonavir and statins. Am J Med 112: 510-511, 2002.

210. Maertens JA: History of the development of azole derivatives. Clin Microbiol Infect 10 (Suppl 1): S1-S10, 2004.

211. Vanden Bossche H, Marichal P, Le Jeune L, Coene MC, Gorrens $\mathrm{J}$ and Cools W: Effects of itraconazole on cytochrome P-450-dependent sterol 14 alpha-demethylation and reduction of 3-ketosteroids in Cryptococcus neoformans. Antimicrob Agents Chemother 37: 2101-2105, 1993.

212. Chong CR, Xu J, Lu J, Bhat S, Sullivan DJ Jr and Liu JO: Inhibition of angiogenesis by the antifungal drug itraconazole. ACS Chem Biol 2: 263-270, 2007.

213. Nacev BA, Grassi P, Dell A, Haslam SM and Liu JO: The antifungal drug itraconazole inhibits vascular endothelial growth factor receptor 2 (VEGFR2) glycosylation, trafficking, and signaling in endothelial cells. J Biol Chem 286: 44045-44056, 2011.

214. Aftab BT, Dobromilskaya I, Liu JO and Rudin CM: Itraconazole inhibits angiogenesis and tumor growth in non-small cell lung cancer. Cancer Res 71: 6764-6772, 2011.

215. Xu J, Dang Y, Ren YR and Liu JO: Cholesterol trafficking is required for mTOR activation in endothelial cells. Proc Natl Acad Sci USA 107: 4764-4769, 2010

216. Kim J, Tang JY, Gong R, Kim J, Lee JJ, Clemons KV, Chong CR, Chang KS, Fereshteh M, Gardner D, et al: Itraconazole, a commonly used antifungal that inhibits Hedgehog pathway activity and cancer growth. Cancer Cell 17: 388-399, 2010.

217. Liu R, Li J, Zhang T, Zou L, Chen Y, Wang K, Lei Y, Yuan K, $\mathrm{Li}$ Y, Lan J, et al: Itraconazole suppresses the growth of glioblastoma through induction of autophagy: Involvement of abnormal cholesterol trafficking. Autophagy 10: 1241-1255, 2014.

218. You M, Varona-Santos J, Singh S, Robbins DJ, Savaraj N and Nguyen DM: Targeting of the Hedgehog signal transduction pathway suppresses survival of malignant pleural mesothelioma cells in vitro. J Thorac Cardiovasc Surg 147: 508-516, 2014.

219. Takara K, Tanigawara Y, Komada F, Nishiguchi K, Sakaeda T and Okumura K: Cellular pharmacokinetic aspects of reversal effect of itraconazole on P-glycoprotein-mediated resistance of anticancer drugs. Biol Pharm Bull 22: 1355-1359, 1999.

220. Antonarakis ES, Heath EI, Smith DC, Rathkopf D, Blackford AL Danila DC, King S, Frost A, Ajiboye AS, Zhao M, et al: Repurposing itraconazole as a treatment for advanced prostate cancer: A noncomparative randomized phase II trial in men with metastatic castration-resistant prostate cancer. Oncologist 18: $163-173,2013$

221. Rudin CM, Brahmer JR, Juergens RA, Hann CL, Ettinger DS, Sebree R, Smith R, Aftab BT, Huang P and Liu JO: Phase 2 study of pemetrexed and itraconazole as second-line therapy for metastatic nonsquamous non-small-cell lung cancer. J Thorac Oncol 8: 619-623, 2013

222. Pounds R, Leonard S, Dawson C and Kehoe S: Repurposing itraconazole for the treatment of cancer. Oncol Lett 14: 2587-2597, 2017.

223. Ademuyiwa F, Zhao Q, Perkins S, Gebregziabher N, Jones DR, Sledge LGVW and Miller K: A pilot trial of itraconazole pharmacokinetics in patients with metastatic breast cancer. J Clin Oncol 29: e13565, 2011

224. Tsubamoto H, Sonoda T, Yamasaki M and Inoue K: Impact of combination chemotherapy with itraconazole on survival for patients with recurrent or persistent ovarian clear cell carcinoma. Anticancer Res 34: 2007-2014, 2014.

225. Ringshausen I, Feuerstacke Y, Krainz P, den Hollander J, Hermann K, Buck A, Peschel C and Meyer Zum Bueschenfelde C: Antifungal therapy with itraconazole impairs the anti-lymphoma effects of rituximab by inhibiting recruitment of CD20 to cell surface lipid rafts. Cancer Res 70: 4292-4296, 2010.

226. Juarez M, Schcolnik-Cabrera A and Dueñas-Gonzalez A: The multitargeted drug ivermectin: From an antiparasitic agent to a repositioned cancer drug. Am J Cancer Res 8: 317-331, 2018.

227. Papich MG: Saunders handbook of veterinary drugs. Elsevier, 2007.

228. Triggle DJ and Taylor JB: Comprehensive Medicinal Chemistry II. Elsevier, 2006.

229. Intuyod K, Hahnvajanawong C, Pinlaor P and Pinlaor S: Anti-parasitic drug ivermectin exhibits potent anticancer activity against gemcitabine-resistant cholangiocarcinoma in vitro. Anticancer Res 39: 4837-4843, 2019. 
230. Jiang L, Wang $\mathrm{P}$, Sun $\mathrm{YJ}$ and $\mathrm{Wu} \mathrm{YJ}$ : Ivermectin reverses the drug resistance in cancer cells through EGFR/ERK/Akt/NF- $\mathrm{B}$ pathway. J Exp Clin Cancer Res 38: 265, 2019.

231. Sun D, Li X, He Y, Li W, Wang Y, Wang H, Jiang S and Xin Y: YAP1 enhances cell proliferation, migration, and invasion of gastric cancer in vitro and in vivo. Oncotarget 7: 81062-81076, 2016.

232. Kobayashi Y, Banno K, Kunitomi H, Tominaga E and Aoki D: Current state and outlook for drug repositioning anticipated in the field of ovarian cancer. J Gynecol Oncol 30: e10, 2019.

233. Kodama M, Kodama T, Newberg JY, Katayama H, Kobayashi M, Hanash SM, Yoshihara K, Wei Z, Tien JC, Rangel R, et al: In vivo loss-of-function screens identify KPNB1 as a new druggable oncogene in epithelial ovarian cancer. Proc Natl Acad Sci USA 114: E7301-E7310, 2017.

234. Melotti A, Mas C, Kuciak M, Lorente-Trigos A, Borges I and Ruiz I Altaba A: The river blindness drug Ivermectin and related macrocyclic lactones inhibit WNT-TCF pathway responses in human cancer. EMBO Mol Med 6: 1263-1278, 2014.

235. Kwon YJ, Petrie K, Leibovitch BA, Zeng L, Mezei M, Howell L, Gil V, Christova R, Bansal N, Yang S, et al: Selective Inhibition of SIN3 Corepressor with Avermectins as a novel therapeutic strategy in Triple-Negative breast cancer. Mol Cancer Ther 14 1824-1836, 2015.

236. Breedveld FC and Dayer JM: Leflunomide: Mode of action in the treatment of rheumatoid arthritis. Ann Rheum Dis 59: 841-849, 2000.

237. Schiff MH, Strand V, Oed C and Loew-Friedrich I: Leflunomide: Efficacy and safety in clinical trials for the treatment of rheumatoid arthritis. Drugs Today (Barc) 36: 383-394, 2000

238. Baumann P, Mandl-Weber S, Völkl A, Adam C, Bumeder I, Oduncu F and Schmidmaier R: Dihydroorotate dehydrogenase inhibitor A771726 (leflunomide) induces apoptosis and diminishes proliferation of multiple myeloma cells. Mol Cancer Ther 8: 366-375, 2009.

239. Hail N Jr, Chen P and Bushman LR: Teriflunomide (leflunomide) promotes cytostatic, antioxidant, and apoptotic effects in transformed prostate epithelial cells: Evidence supporting a role for teriflunomide in prostate cancer chemoprevention. Neoplasia 12: 464-475, 2010.

240. Cook MR,Pinchot SN,Jaskula-SztulR,Luo J,Kunnimalaiyaan M and Chen H: Identification of a novel Raf-1 pathway activator that inhibits gastrointestinal carcinoid cell growth. Mol Cancer Ther 9: 429-437, 2010

241. Zhu S, Yan X, Xiang Z, Ding HF and Cui H: Leflunomide reduces proliferation and induces apoptosis in neuroblastoma cells in vitro and in vivo. PLoS One 8: e71555, 2013.

242. Hanson K, Robinson SD, Al-Yousuf K, Hendry AE, Sexton DW, Sherwood V and Wheeler GN: Correction: The anti-rheumatic drug, leflunomide, synergizes with MEK inhibition to suppress melanoma growth. Oncotarget 9: 36645, 2018.

243. Gupta R, Bhatia J and Gupta SK: Risk of hepatotoxicity with add-on leflunomide in rheumatoid arthritis patients. Arzneimittelforschung 61: 312-316, 2011

244. Chu $\mathrm{M}$ and Zhang C: Inhibition of angiogenesis by leflunomide via targeting the soluble ephrin-A1/EphA2 system in bladder cancer. Sci Rep 8: 1539, 2018.

245. Zhang $\mathrm{C}$ and Chu M: Leflunomide: A promising drug with good antitumor potential. Biochem Biophys Res Commun 496: 726-730, 2018.

246. Belli H, Ural C and Akbudak M: Borderline personality disorder: Bipolarity, mood stabilizers and atypical antipsychotics in treatment. J Clin Med Res 4: 301-308, 2012.

247. Taylor C, Fricker AD, Devi LA and Gomes I: Mechanisms of action of antidepressants: From neurotransmitter systems to signaling pathways. Cell Signal 17: 549-557, 2005.

248. Lenox RH and Hahn CG: Overview of the mechanism of action of lithium in the brain: Fifty-year update. J Clin Psychiatry 61 (Suppl 9): S5-S15, 2000.

249. Muneer A: Wnt and GSK3 signaling pathways in bipolar disorder: Clinical and therapeutic implications. Clin Psychopharmaco Neurosci 15: 100-114, 2017.

250. Li B, Thrasher JB and Terranova P: Glycogen synthase kinase-3: A potential preventive target for prostate cancer management. Urol Oncol 33: 456-463, 2015

251. Rashid MS, Mazur T Ji W, Liu ST and Taylor WR: Analysis of the role of GSK3 in the mitotic checkpoint. Sci Rep 8: 14259, 2018.

252. Kamarudin MNA and Parhar I: Emerging therapeutic potential of anti-psychotic drugs in the management of human glioma: A comprehensive review. Oncotarget 10: 3952-3977, 2019.
253. Nowicki MO, Dmitrieva N, Stein AM, Cutter JL, Godlewski J, Saeki Y, Nita M, Berens ME, Sander LM, Newton HB, et al: Lithium inhibits invasion of glioma cells; Possible involvement of glycogen synthase kinase-3. Neuro Oncol 10: 690-699, 2008.

254. Sun A, Shanmugam I, Song J, Terranova PF, Thrasher JB and Li B: Lithium suppresses cell proliferation by interrupting E2F-DNA interaction and subsequently reducing S-phase gene expression in prostate cancer. Prostate 67: 976-988, 2007.

255. Azimian-Zavareh V, Hossein G and Janzamin E: Effect of lithium chloride and antineoplastic drugs on survival and cell cycle of androgen-dependent prostate cancer LNCap cells. Indian J Pharmacol 44: 714-721, 2012.

256. Maeng YS, Lee R, Lee B, Choi SI and Kim EK: Lithium inhibits tumor lymphangiogenesis and metastasis through the inhibition of TGFBIp expression in cancer cells. Sci Rep 6: 20739, 2016.

257. Pottegård A, Hallas J, Jensen BL, Madsen K and Friis S: Long-term lithium use and risk of renal and upper urinary tract cancers. J Am Soc Nephrol 27: 249-255, 2016.

258. Pottegård A, Ennis ZN, Hallas J, Jensen BL, Madsen K and Friis S: Long-term use of lithium and risk of colorectal adenocarcinoma: A nationwide case-control study. Br J Cancer 114: 571-575, 2016.

259. Elmaci I and Altinoz MA: A Metabolic inhibitory cocktail for grave cancers: Metformin, pioglitazone and lithium combination in treatment of pancreatic cancer and glioblastoma multiforme. Biochem Genet 54: 573-618, 2016.

260. Taylor OG, Brzozowski JS and Skelding KA: Glioblastoma multiforme: An overview of emerging therapeutic targets. Front Oncol 9: 963, 2019

261. Sleire L, Førde HE, Netland IA, Leiss L, Skeie BS and Enger PØ: Drug repurposing in cancer. Pharmacol Res 124: 74-91, 2017.

262. Bailey CJ: Metformin: Historical overview. Diabetologia 60: 1566-1576, 2017.

263. Wheaton WW, Weinberg SE, Hamanaka RB, Soberanes S, Sullivan LB, Anso E, Glasauer A, Dufour E, Mutlu GM, Budigner GS and Chandel NS: Metformin inhibits mitochondrial complex I of cancer cells to reduce tumorigenesis. Elife 3: e02242, 2014

264. Viollet B, Guigas B, Sanz Garcia N, Leclerc J, Foretz M and Andreelli F: Cellular and molecular mechanisms of metformin An overview. Clin Sci (Lond) 122: 253-270, 2012.

265. Stephenne X, Foretz M, Taleux N, van der Zon GC, Sokal E, Hue L, Viollet B and Guigas B: Metformin activates AMP-activated protein kinase in primary human hepatocytes by decreasing cellular energy status. Diabetologia 54: 3101-3110, 2011.

266. Negrotto L, Farez MF and Correale J: Immunologic effects of metformin and pioglitazone treatment on metabolic syndrome and multiple sclerosis. JAMA Neurol 73: 520-528, 2016.

267. Evans JM, Donnelly LA, Emslie-Smith AM, Alessi DR and Morris AD: Metformin and reduced risk of cancer in diabetic patients. BMJ 330: 1304-1305, 2005.

268. Kim HJ, Lee S, Chun KH, Jeon JY, Han SJ, Kim DJ, Kim YS, Woo JT, Nam MS, Baik SH, et al: Metformin reduces the risk of cancer in patients with type 2 diabetes: An analysis based on the Korean National diabetes program cohort. Medicine (Baltimore) 97: e0036, 2018.

269. Zi F, Zi H, Li Y, He J, Shi Q and Cai Z: Metformin and cancer: An existing drug for cancer prevention and therapy. Oncol Lett 15: 683-690,2018.

270. Yu H, Zhong X, Gao P, Shi J, Wu Z, Guo Z, Wang Z and Song Y: The potential effect of metformin on cancer: An umbrella review. Front Endocrinol (Lausanne) 10: 617, 2019.

271. Saraei P, Asadi I, Kakar MA and Moradi-Kor N: The beneficial effects of metformin on cancer prevention and therapy: A comprehensive review of recent advances. Cancer Manag Res 11: 3295-3313, 2019.

272. Gandini S, Puntoni M, Heckman-Stoddard BM, Dunn BK, Ford L, DeCensi A and Szabo E: Metformin and cancer risk and mortality: A systematic review and meta-analysis taking into account biases and confounders. Cancer Prev Res (Phila) 7: 867-885, 2014

273. Suissa S and Azoulay L: Metformin and cancer: Mounting evidence against an association. Diabetes Care 37: 1786-1788, 2014.

274. Tsilidis KK, Capothanassi D, Allen NE, Rizos EC, Lopez DS, van Veldhoven K, Sacerdote C, Ashby D, Vineis P, Tzoulaki I and Ioannidis JP: Metformin does not affect cancer risk: A cohort study in the U.K. Clinical Practice Research Datalink analyzed like an intention-to-treat trial. Diabetes Care 37: 2522-2532, 2014. 
275. Preston MA, Riis AH, Ehrenstein V, Breau RH, Batista JL, Olumi AF, Mucci LA, Adami HO and Sørensen HT: Metformin use and prostate cancer risk. Eur Urol 66: 1012-1020, 2014.

276. Dalva-Aydemir S, Bajpai R, Martinez M, Adekola KU, Kandela I, Wei C, Singhal S, Koblinski JE, Raje NS, Rosen ST and Shanmugam M: Targeting the metabolic plasticity of multiple myeloma with FDA-approved ritonavir and metformin. Clin Cancer Res 21: 1161-1171, 2015.

277. Del Barco S, Vazquez-Martin A, Cufi S, Oliveras-Ferraros C, Bosch-Barrera J, Joven J, Martin-Castillo B and Menendez JA: Metformin: Multi-faceted protection against cancer. Oncotarget 2: 896-917, 2011.

278. Pollak MN: Investigating metformin for cancer prevention and treatment: The end of the beginning. Cancer Discov 2: 778-790, 2012

279. Pollak M: The insulin and insulin-like growth factor receptor family in neoplasia: An update. Nat Rev Cancer 12: 159-169, 2012.

280. Foretz M, Guigas B, Bertrand L, Pollak M and Viollet B: Metformin: From mechanisms of action to therapies. Cell Metab 20: 953-966, 2014.

281. Moiseeva O, Deschenês-Simard X, Pollak M and Ferbeyre G: Metformin, aging and cancer. Aging (Albany NY) 5: 330-331, 2013.

282. Pearce EL, Walsh MC, Cejas PJ, Harms GM, Shen H, Wang LS Jones RG and Choi Y: Enhancing CD8 T-cell memory by modulating fatty acid metabolism. Nature 460: 103-107, 2009.

283. Kim J, Yang G, Kim Y, Kim J and Ha J: AMPK activators: Mechanisms of action and physiological activities. Exp Mol Med 48: e224, 2016.

284. Birsoy K, Sabatini DM and Possemato R: Untuning the tumor metabolic machine: Targeting cancer metabolism: A bedside lesson. Nat Med 18: 1022-1023, 2012.

285. Buzzai M, Jones RG, Amaravadi RK, Lum JJ, DeBerardinis RJ, Zhao F, Viollet B and Thompson CB: Systemic treatment with the antidiabetic drug metformin selectively impairs p53-deficient tumor cell growth. Cancer Res 67: 6745-6752, 2007.

286. Ben Sahra I, Le Marchand-Brustel Y, Tanti JF and Bost F: Metformin in cancer therapy: A new perspective for an old antidiabetic drug? Mol Cancer Ther 9: 1092-1099, 2010.

287. Haq R and Fisher DE: Improving apoptotic responses to targeted therapy. Oncotarget 4: 1331, 2013 .

288. Zakikhani M, Dowling R, Fantus IG, Sonenberg N and Pollak M: Metformin is an AMP kinase-dependent growth inhibitor for breast cancer cells. Cancer Res 66: 10269-10273, 2006.

289. Schulten HJ: Pleiotropic effects of metformin on cancer. Int J Mol Sci 19: pii: E2850, 2018.

290. Choi YK and Park KG: Metabolic roles of AMPK and metformin in cancer cells. Mol Cells 36: 279-287, 2013.

291. Matsushita M and Kawaguchi M: Immunomodulatory effects of drugs for effective cancer immunotherapy. J Oncol 2018 8653489, 2018.

292. Chae YK, Arya A, Malecek MK, Shin DS, Carneiro B, Chandra S, Kaplan J, Kalyan A, Altman JK, Platanias L and Giles F: Repurposing metformin for cancer treatment: Current clinical studies. Oncotarget 7: 40767-40780, 2016.

293. Goodwin PJ, Parulekar WR, Gelmon KA, Shepherd LE, Ligibel JA, Hershman DL, Rastogi P, Mayer IA, Hobday TJ, Lemieux $\mathrm{J}$, et al: Effect of metformin vs placebo on and metabolic factors in NCIC CTG MA.32. J Natl Cancer Inst 107: pii: djv006, 2015

294.Heckman-Stoddard BM, DeCensi A, Sahasrabuddhe VV and Ford LG: Repurposing metformin for the prevention of cancer and cancer recurrence. Diabetologia 60: 1639-1647, 2017.

295. Laranjo-González M, Devleesschauwer B, Jansen F, Dorny P, Dupuy C, Requena-Méndez A and Allepuz A: Epidemiology and economic impact of bovine cysticercosis and taeniosis caused by Taenia saginata in northeastern Spain (Catalonia). Parasit Vectors 11: 376, 2018.

296. Chen W, Mook RA Jr, Premont RT and Wang J: Niclosamide: Beyond an antihelminthic drug. Cell Signal 41: 89-96, 2018

297. Satoh K, Zhang L, Zhang Y, Chelluri R, Boufraqech M, Nilubol N, Patel D, Shen M and Kebebew E: Identification of niclosamide as a novel anticancer agent for adrenocortical carcinoma. Clin Cancer Res 22: 3458-3466, 2016.

298. Fonseca BD, Diering GH, Bidinosti MA, Dalal K, Alain T, Balgi AD, Forestieri R, Nodwell M, Rajadurai CV, Gunaratnam C, et al: Structure-activity analysis of niclosamide reveals potential role for cytoplasmic $\mathrm{pH}$ in control of mammalian target of rapamycin complex 1 (mTORC1) signaling. J Biol Chem 287: 17530-17545, 2012.
299. Balgi AD, Diering GH, Donohue E, Lam KK, Fonseca BD, Zimmerman C, Numata $M$ and Roberge $M$ : Regulation of mTORC1 signaling by pH. PLoS One 6: e21549, 2011.

300. Wang AM, Ku HH, Liang YC, Chen YC, Hwu YM and Yeh TS: The autonomous notch signal pathway is activated by baicalin and baicalein but is suppressed by niclosamide in K562 cells. J Cell Biochem 106: 682-692, 2009.

301. Karakas D, Cevatemre B, Aztopal N, Ari F, Yilmaz VT and Ulukaya E: Addition of niclosamide to palladium(II) saccharinate complex of terpyridine results in enhanced cytotoxic activity inducing apoptosis on cancer stem cells of breast cancer. Bioorg Med Chem 23: 5580-5586, 2015.

302.Liu J, Chen X, Ward T, Pegram M and Shen K: Combined niclosamide with cisplatin inhibits epithelial-mesenchymal transition and tumor growth in cisplatin-resistant triple-negative breast cancer. Tumour Biol 37: 9825-9835, 2016

303. Osada T, Chen M, Yang XY, Spasojevic I, Vandeusen JB, Hsu D, Clary BM, Clay TM, Chen W, Morse MA and Lyerly HK: Antihelminth compound niclosamide downregulates Wnt signaling and elicits antitumor responses in tumors with activating APC mutations. Cancer Res 71: 4172-4182, 2011.

304. Sack U, Walther W, Scudiero D, Selby M, Kobelt D, Lemm M, Fichtner I, Schlag PM, Shoemaker RH and Stein U: Novel effect of antihelminthic Niclosamide on S100A4-mediated metastatic progression in colon cancer. J Natl Cancer Inst 103: 1018-1036, 2011.

305. Suliman MA, Zhang Z, Na H, Ribeiro AL, Zhang Y, Niang B, Hamid AS, Zhang H, Xu L and Zuo Y: Niclosamide inhibits colon cancer progression through downregulation of the Notch pathway and upregulation of the tumor suppressor miR-200 family. Int J Mol Med 38: 776-784, 2016.

306. Arend RC, Londoño-Joshi AI, Gangrade A, Katre AA, Kurpad C, Li Y, Samant RS, Li PK, Landen CN, Yang ES, et al: Niclosamide and its analogs are potent inhibitors of Wnt/ß-catenin, mTOR and STAT3 signaling in ovarian cancer. Oncotarget 7: 86803-86815, 2016.

307. Wieland A, Trageser D, Gogolok S, Reinartz R, Höfer H, Keller M, Leinhaas A, Schelle R, Normann S, Klaas L, et al: Anticancer effects of niclosamide in human glioblastoma. Clin Cancer Res 19: 4124-4136, 2013.

308. Medina Enriquez MM, Félix AJ, Ciudad CJ and Noé V: Cancer immunotherapy using PolyPurine reverse hoogsteen hairpins targeting the PD-1/PD-L1 pathway in human tumor cells. PLoS One 13: e0206818, 2018.

309. Cardozo AJ, Gómez DE and Argibay PF: Transcriptional characterization of Wnt and Notch signaling pathways in neuronal differentiation of human adipose tissue-derived stem cells. J Mol Neurosci 44: 186-194, 2011.

310. Jin Y, Lu Z, Ding K, Li J, Du X, Chen C, Sun X, Wu Y, Zhou J and Pan J: Antineoplastic mechanisms of niclosamide in acute myelogenous leukemia stem cells: Inactivation of the NF-kappaB pathway and generation of reactive oxygen species. Cancer Res 70: 2516-2527, 2010.

311. Lopes GL, Vattimo EF and Castro Junior G: Identifying activating mutations in the EGFR gene: Prognostic and therapeutic implications in non-small cell lung cancer. J Bras Pneumol 41: 365-375, 2015 (In English, Portuguese).

312. Li R, Hu Z, Sun SY, Chen ZG, Owonikoko TK, Sica GL, Ramalingam SS, Curran WJ, Khuri FR and Deng X: Niclosamide overcomes acquired resistance to erlotinib through suppression of STAT3 in non-small cell lung cancer. Mol Cancer Ther 12: 2200-2212, 2013.

313. You S, Li R, Park D, Xie M, Sica GL, Cao Y, Xiao ZQ and Deng X: Disruption of STAT3 by niclosamide reverses radioresistance of human lung cancer. Mol Cancer Ther 13: 606-616, 2014.

314. Lee SL, Son AR, Ahn J and Song JY: Niclosamide enhances ROS-mediated cell death through c-Jun activation. Biomed Pharmacother 68: 619-624, 2014.

315. Kim MO, Choe MH, Yoon YN, Ahn J, Yoo M, Jung KY, An S, Hwang SG, Oh JS and Kim JS: Antihelminthic drug niclosamide inhibits CIP2A and reactivates tumor suppressor protein phosphatase $2 \mathrm{~A}$ in non-small cell lung cancer cells. Biochem Pharmacol 144: 78-89, 2017.

316. Liao Z, Nan G, Yan Z, Zeng L, Deng Y, Ye J, Zhang Z, Qiao M, Li R, Denduluri S, et al: The anthelmintic drug niclosamide inhibits the proliferative activity of human osteosarcoma cells by targeting multiple signal pathways. Curr Cancer Drug Targets 15: 726-738, 2015 . 
317. Yo YT, Lin YW, Wang YC, Balch C, Huang RL, Chan MW, Sytwu HK, Chen CK, Chang CC, Nephew KP, et al: Growth inhibition of ovarian tumor-initiating cells by niclosamide. Mol Cancer Ther 11: 1703-1712, 2012.

318. King ML, Lindberg ME, Stodden GR, Okuda H, Ebers SD, Johnson A, Montag A, Lengyel E, MacLean Ii JA and Hayashi K: WNT7A/ $\beta$-catenin signaling induces FGF1 and influences sensitivity to niclosamide in ovarian cancer. Oncogene 34 3452-3462, 2015

319. Rodriguez-Vida A, Galazi M, Rudman S, Chowdhury S and Sternberg CN: Enzalutamide for the treatment of metastatic castration-resistant prostate cancer. Drug Des Devel Ther 9: $3325-3339,2015$

320. Aboukameel A, Muqbil I, Baloglu E, Senapedis W, Landesman Y, Argueta C, Kauffman M, Chang H, Kashyap T, Shacham S, et al Down-regulation of AR splice variants through XPO1 suppression contributes to the inhibition of prostate cancer progression. Oncotarget 9: 35327-35342, 2018.

321. Liu C, Armstrong CM, Lou W, Lombard AP, Cucchiara V, Gu X, Yang JC, Nadiminty N, Pan CX, Evans CP and Gao AC: Niclosamide and bicalutamide combination treatment overcomes enzalutamide- and Bicalutamide-resistant prostate cancer. Mol Cancer Ther 16: 1521-1530, 2017.

322.Ippolito JE, Brandenburg MW, Ge X, Crowley JR, Kirmess KM, Som A, D'Avignon DA, Arbeit JM, Achilefu S, Yarasheski KE and Milbrandt J: Extracellular pH modulates neuroendocrine prostate cancer cell metabolism and susceptibility to the mitochondrial inhibitor niclosamide. PLoS One 11: e0159675, 2016

323. Yu X, Liu F, Zeng L, He F, Zhang R, Yan S, Zeng Z, Shu Y, Zhao C, Wu X, et al: Niclosamide exhibits potent anticancer activity and synergizes with sorafenib in human renal cell cancer cells. Cell Physiol Biochem 47: 957-971, 2018.

324. Chen L, Wang L, Shen H, Lin H and Li D: Anthelminthic drug niclosamide sensitizes the responsiveness of cervical cancer cells to paclitaxel via oxidative stress-mediated mTOR inhibition. Biochem Biophys Res Commun 484: 416-421, 2017.

325. Chang WL, Hsu LC, Leu WJ, Chen CS and Guh JH: Repurposing of nitroxoline as a potential anticancer agent against human prostate cancer: A crucial role on AMPK/mTOR signaling pathway and the interplay with Chk2 activation. Oncotarget 6: 39806-39820, 2015.

326. Mirković B, Renko M, Turk S, Sosič I, Jevnikar Z, Obermajer N Turk D, Gobec S and Kos J: Novel mechanism of cathepsin B inhibition by antibiotic nitroxoline and related compounds. ChemMedChem 6: 1351-1356, 2011.

327. Zhang QI, Wang S, Yang D, Pan K, Li L and Yuan S: Preclinical pharmacodynamic evaluation of antibiotic nitroxoline for anticancer drug repurposing. Oncol Lett 11: 3265-3272, 2016.

328. Mao H, Du Y, Zhang Z, Cao B, Zhao J, Zhou H and Mao X: Nitroxoline shows antimyeloma activity by targeting the TRIM25/p53 axle. Anticancer Drugs 28: 376-383, 2017.

329. Meek IL, Van de Laar MA and E Vonkeman H: Non-steroida Anti-inflammatory drugs: An overview of cardiovascular risks Pharmaceuticals (Basel) 3: 2146-2162, 2010

330. Tóth L, Muszbek L and Komáromi I: Mechanism of the irreversible inhibition of human cyclooxygenase-1 by aspirin as predicted by QM/MM calculations. J Mol Graph Model 40 99-109, 2013.

331. Zhang Z, Chen F and Shang L: Advances in antitumor effects of NSAIDs. Cancer Manag Res 10: 4631-4640, 2018.

332. Chan AT, Ogino S and Fuchs CS: Aspirin and the risk of colorectal cancer in relation to the expression of COX-2. N Engl J Med 356: 2131-2142, 2007

333. Mohammed A, Yarla NS, Madka V and Rao CV: Clinically relevant Anti-inflammatory agents for chemoprevention of colorectal cancer: New perspectives. Int J Mol Sci 19: pii: E2332, 2018.

334. Cole BF, Logan RF, Halabi S, Benamouzig R, Sandler RS, Grainge MJ, Chaussade S and Baron JA: Aspirin for the chemoprevention of colorectal adenomas: Meta-analysis of the randomized trials. J Natl Cancer Inst 101: 256-266, 2009.

335. Qiao Y, Yang T, Gan Y, Li W, Wang C, Gong Y and Lu Z: Associations between aspirin use and the risk of cancers: A meta-analysis of observational studies. BMC Cancer 18: 288 , 2018.

336. Gaist D, García-Rodríguez LA, Sørensen HT, Hallas J and Friis S: Use of low-dose aspirin and non-aspirin nonsteroidal anti-inflammatory drugs and risk of glioma: A case-control study. Br J Cancer 108: 1189-1194, 2013.
337. Fink SP, Dawson DM, Zhang Y, Kresak A, Lawrence EG, Yang P, Chen Y, Barnholtz-Sloan JS, Willis JE, Kopelovich L and Markowitz SD: Sulindac reversal of 15-PGDH-mediated resistance to colon tumor chemoprevention with NSAIDs. Carcinogenesis 36: 291-298, 2015.

338. Umar A, Steele VE, Menter DG and Hawk ET: Mechanisms of nonsteroidal anti-inflammatory drugs in cancer prevention. Semin Oncol 43: 65-77, 2016.

339. Balta MG, Loos BG and Nicu EA: Emerging concepts in the resolution of periodontal inflammation: A role for resolvin E1. Front Immunol 8: 1682, 2017.

340. Umar A, Boisseau M, Yusup A, Upur H, Bégaud B and Moore N: Interactions between aspirin and COX-2 inhibitors or NSAIDs in a rat thrombosis model. Fundam Clin Pharmacol 18: 559-563, 2004.

341. Stark LA, Reid K, Sansom OJ, Din FV, Guichard S, Mayer I, Jodrell DI, Clarke AR and Dunlop MG: Aspirin activates the NF-kappaB signalling pathway and induces apoptosis in intestinal neoplasia in two in vivo models of human colorectal cancer. Carcinogenesis 28: 968-976, 2007.

342. Rayburn ER, Ezell SJ and Zhang R: Anti-inflammatory agents for cancer therapy. Mol Cell Pharmacol 1: 29-43, 2009.

343. McNicol E, Strassels S, Goudas L, Lau J and Carr D: Nonsteroidal anti-inflammatory drugs, alone or combined with opioids, for cancer pain: A systematic review. J Clin Oncol 22: 1975-1992, 2004.

344. Thun MJ, Henley SJ and Patrono C: Nonsteroidal anti-inflammatory drugs as anticancer agents: Mechanistic, pharmacologic, and clinical issues. J Natl Cancer Inst 94: 252-266, 2002.

345. Hall JJ, Bolina M, Chatterley T and Jamali F: Interaction between Low-dose methotrexate and nonsteroidal Anti-inflammatory drugs, penicillins, and proton pump inhibitors. Ann Pharmacother 51: 163-178, 2017

346.Zarghi A and Arfaei S: Selective COX-2 inhibitors: A review of their structure-activity relationships. Iran J Pharm Res 10: 655-683, 2011.

347. Solomon SD, McMurray JJ, Pfeffer MA, Wittes J, Fowler R, Finn P, Anderson WF, Zauber A, Hawk E and Bertagnolli M; Adenoma Prevention with Celecoxib (APC) Study Investigators: Cardiovascular risk associated with celecoxib in a clinical trial for colorectal adenoma prevention. N Engl J Med 352: 1071-1080, 2005.

348. Wang J, Cho NL, Zauber AG, Hsu M, Dawson D, Srivastava A, Mitchell-Richards KA, Markowitz SD and Bertagnolli MM: Chemopreventive efficacy of the Cyclooxygenase-2 (Cox-2) inhibitor, celecoxib, is predicted by adenoma expression of Cox-2 and 15-PGDH. Cancer Epidemiol Biomarkers Prev 27: 728-736, 2018.

349. Bowers LW, Maximo IX, Brenner AJ, Beeram M, Hursting SD, Price RS, Tekmal RR, Jolly CA and deGraffenried LA: NSAID use reduces breast cancer recurrence in overweight and obese women: Role of prostaglandin-aromatase interactions. Cancer Res 74: 4446-4457, 2014

350. Huang C, Chen Y, Liu H, Yang J, Song X, Zhao J, He N, Zhou CJ, Wang Y, Huang C and Dong Q: Celecoxib targets breast cancer stem cells by inhibiting the synthesis of prostaglandin $\mathrm{E}_{2}$ and down-regulating the Wnt pathway activity. Oncotarget 8: 115254-115269, 2017.

351. Yeh CT, Yao CJ, Yan JL, Chuang SE, Lee LM, Chen CM, Yeh CF, Li CH and Lai GM: Apoptotic cell death and inhibition of Wnt/ $\beta$-catenin signaling pathway in human colon cancer cells by an active fraction (HS7) from taiwanofungus camphoratus. Evid Based Complement Alternat Med 2011: 750230, 2011

352. Yang Y and Gao L: Celecoxib alleviates memory deficits by downregulation of COX-2 expression and upregulation of the BDNF-TrkB signaling pathway in a diabetic rat model. J Mol Neurosci 62: 188-198, 2017.

353. Li J, Hao Q, Cao W, Vadgama JV and Wu Y: Celecoxib in breast cancer prevention and therapy. Cancer Manag Res 10: 4653-4667, 2018.

354. Yu C, Li WB, Liu JB, Lu JW and Feng JF: Autophagy: Novel applications of nonsteroidal anti-inflammatory drugs for primary cancer. Cancer Med 7: 471-484, 2018

355. Toloczko-Iwaniuk N, Dziemiańczyk-Pakieła D, Nowaszewska BK, Celińska-Janowicz K and Miltyk W: Celecoxib in cancer therapy and prevention-review. Curr Drug Targets 20: 302-315, 2019.

356. Leidgens V, Seliger C, Jachnik B, Welz T, Leukel P, Vollmann-Zwerenz A, Bogdahn U, Kreutz M, Grauer OM and Hau P: Ibuprofen and diclofenac restrict migration and proliferation of human glioma cells by distinct molecular mechanisms. PLoS One 10: e0140613, 2015. 
357. Barbarić M, Kralj M, Marjanović M, Husnjak I, Pavelić K, Filipović-Grcić J, Zorc D and Zorc B: Synthesis and in vitro antitumor effect of diclofenac and fenoprofen thiolated and nonthiolated polyaspartamide-drug conjugates. Eur J Med Chem 42: 20-29, 2007.

358. Arisan ED, Ergül Z, Bozdağ G, Rencüzoğulları Ö, ÇokerGürkan A, Obakan-Yerlikaya P, Coşkun D and Palavan-Ünsal N: Diclofenac induced apoptosis via altering PI3K/Akt/MAPK signaling axis in HCT 116 more efficiently compared to SW480 colon cancer cells. Mol Biol Rep 45: 2175-2184, 2018.

359. Fosslien E: Biochemistry of cyclooxygenase (COX)-2 inhibitors and molecular pathology of COX-2 in neoplasia. Crit Rev Clin Lab Sci 37: 431-502, 2000.

360.Lau L, Hansford LM, Cheng LS, Hang M, Baruchel S, Kaplan DR and Irwin MS: Cyclooxygenase inhibitors modulate the p53/HDM2 pathway and enhance chemotherapy-induced apoptosis in neuroblastoma. Oncogene 26: 1920-1931, 2007.

361. Andrews P, Zhao X, Allen J, Li F and Chang M: A comparison of the effectiveness of selected non-steroidal anti-inflammatory drugs and their derivatives against cancer cells in vitro. Cancer Chemother Pharmacol 61: 203-214, 2008.

362. Bombardo M, Malagola E, Chen R, Rudnicka A, Graf R and Sonda S: Ibuprofen and diclofenac treatments reduce proliferation of pancreatic acinar cells upon inflammatory injury and mitogenic stimulation. Br J Pharmacol 175: 335-347, 2018.

363. Samal SK, Routray S, Veeramachaneni GK, Dash R and Botlagunta M: Ketorolac salt is a newly discovered DDX3 inhibitor to treat oral cancer. Sci Rep 5: 9982, 2015.

364. Retsky M, Rogers R, Demicheli R, Hrushesky WJ, Gukas I, Vaidya JS, Baum M, Forget P, Dekock M and Pachmann K: NSAID analgesic ketorolac used perioperatively may suppress early breast cancer relapse: Particular relevance to triple negative subgroup. Breast Cancer Res Treat 134: 881-888, 2012.

365. Hudson LG, Cook LS, Grimes MM, Muller CY, Adams SF and Wandinger-Ness A: Dual actions of ketorolac in metastatic ovarian cancer. Cancers (Basel) 11: pii: E1049, 2019.

366. Chaudhary SC, Waseem M, Rana M, Xu H, Kopelovich L, Elmets CA and Athar M: Naproxen inhibits UVB-induced basal cell and squamous cell carcinoma development in Ptch $1^{+} /-/ \mathrm{SKH}-1$ hairless mice. Photochem Photobiol 93: 1016-1024, 2017.

367. Campione E, Paternò EJ, Candi E, Falconi M, Costanza G, Diluvio L, Terrinoni A, Bianchi L and Orlandi A: The relevance of piroxicam for the prevention and treatment of nonmelanoma skin cancer and its precursors. Drug Des Devel Ther 9: 5843-5850, 2015.

368. Mackay AR, Gomez DE, Nason AM and Thorgeirsson UP: Studies on the effects of laminin, E-8 fragment of laminin and synthetic laminin peptides PA22-2 and YIGSR on matrix metalloproteinases and tissue inhibitor of metalloproteinase expression. Lab Invest 70: 800-806, 1994.

369. Philipp-Dormston WG: Field cancerization: From molecular basis to selective field-directed management of actinic keratosis. Curr Probl Dermatol 46: 115-121, 2015.

370. Khodaie F, Khazaei-Poul Y and Moini-Zanjani T: Antiproliferative effects of piroxicam and nimesulide on A431 human squamous carcinoma cell line. Int J Cancer Manag 10: e7565, 2017.

371. Campione E, Diluvio L, Paterno EJ and Chimenti S: Topical treatment of actinic keratoses with piroxicam $1 \%$ gel: A preliminary open-label study utilizing a new clinical score. Am J Clin Dermatol 11: 45-50, 2010.

372. Palmerini E, Fan K, Yang K, Risio M, Edelmann W, Lipkin M and Biasco G: Piroxicam increases colon tumorigenesis and promotes apoptosis in Mlh1 +/-/Apc1638(N/+) mice. Anticancer Res 27: 3807-3812, 2007.

373. Scheper MA, Nikitakis NG, Chaisuparat R, Montaner S and Sauk JJ: Sulindac induces apoptosis and inhibits tumor growth in vivo in head and neck squamous cell carcinoma. Neoplasia 9: 192-199, 2007.

374. Giardiello FM, Yang VW, Hylind LM, Krush AJ, Petersen GM, Trimbath JD, Piantadosi S, Garrett E, Geiman DE, Hubbard W, et al: Primary chemoprevention of familial adenomatous polyposis with sulindac. N Engl J Med 346: 1054-1059, 2002

375. Takayama T, Katsuki S, Takahashi Y, Ohi M, Nojiri S, Sakamaki S, Kato J, Kogawa K, Miyake H and Niitsu Y: Aberrant crypt foci of the colon as precursors of adenoma and cancer. N Engl J Med 339: 1277-1284, 1998.

376. Ferguson JE III and Carson CC III: Phosphodiesterase type 5 inhibitors as a treatment for erectile dysfunction: Current information and new horizons. Arab J Urol 11: 222-229, 2013.
377. Phosphodiesterase type 5 (PDE5) Inhibitors. In: LiverTox: Clinical and research information on drug-induced liver injury, Bethesda (MD), 2012.

378. Sandner P, Tinel H, Stelte-Ludwig B, Huetter J, Neuser D, Bischoff $E$ and Ulbrich E: PDE5 inhibitors in treatment of benign prostatic syndrome. Urologe A 46: 1189-1192, 2007 (In German).

379. Burnett AL: The role of nitric oxide in erectile dysfunction: Implications for medical therapy. J Clin Hypertens (Greenwich) 8 (12 Suppl 4): S53-S62, 2006.

380. Barone I, Giordano C, Bonofiglio D, Ando S and Catalano S: Phosphodiesterase type 5 and cancers: Progress and challenges. Oncotarget 8: 99179-99202, 2017.

381. Das A, Xi L and Kukreja RC: Protein kinase G-dependent cardioprotective mechanism of phosphodiesterase-5 inhibition involves phosphorylation of ERK and GSK3beta. J Biol Chem 283: 29572-29585, 2008.

382. Goble RR and Frangoulis MA: Lymphangioma circumscriptum of the eyelids and conjunctiva. Br J Ophthalmol 74: 574-575, 1990.

383. Serafini P, Meckel K, Kelso M, Noonan K, Califano J, Koch W, Dolcetti L, Bronte V and Borrello I: Phosphodiesterase-5 inhibition augments endogenous antitumor immunity by reducing myeloid-derived suppressor cell function. J Exp Med 203: 2691-2702, 2006

384. Whitehead CM, Earle KA, Fetter J, Xu S, Hartman T, Chan DC, Zhao TL, Piazza G, Klein-Szanto AJ, Pamukcu R, et al: Exisulind-induced apoptosis in a non-small cell lung cancer orthotopic lung tumor model augments docetaxel treatment and contributes to increased survival. Mol Cancer Ther 2: 479-488, 2003.

385. Pusztai L, Zhen JH, Arun B, Rivera E, Whitehead C, Thompson WJ, Nealy KM, Gibbs A, Symmans WF, Esteva FJ, et al: Phase I and II study of exisulind in combination with capecitabine in patients with metastatic breast cancer. J Clin Oncol 21: 3454-3461, 2003.

386. Das A, Durrant D, Mitchell C, Mayton E, Hoke NN, Salloum FN, Park MA, Qureshi I, Lee R, Dent P and Kukreja RC: Sildenafil increases chemotherapeutic efficacy of doxorubicin in prostate cancer and ameliorates cardiac dysfunction. Proc Natl Acad Sci USA 107: 18202-18207, 2010.

387. Di X, Gennings C, Bear HD, Graham LJ, Sheth CM, White KL Jr and Gewirtz DA: Influence of the phosphodiesterase-5 inhibitor sildenafil, on sensitivity to chemotherapy in breast tumor cells. Breast Cancer Res Treat 124: 349-360, 2010

388. Liu N, Mei L, Fan X, Tang C, Ji X, Hu X, Shi W, Qian Y, Hussain $\mathrm{M}, \mathrm{Wu}$ J, et al: Phosphodiesterase 5/protein kinase G signal governs stemness of prostate cancer stem cells through Hippo pathway. Cancer Lett 378: 38-50, 2016.

389. Wang C: Phosphodiesterase-5 inhibitors and benign prostatic hyperplasia. Curr Opin Urol 20: 49-54, 2010.

390. Tiwari AK and Chen ZS: Repurposing phosphodiesterase-5 inhibitors as chemoadjuvants. Front Pharmacol 4: 82, 2013.

391. Chan DC, Earle KA, Zhao TL, Helfrich B, Zeng C, Baron A, Whitehead CM, Piazza G, Pamukcu R, Thompson WJ, et al: Exisulind in combination with docetaxel inhibits growth and metastasis of human lung cancer and prolongs survival in athymic nude rats with orthotopic lung tumors. Clin Cancer Res 8: 904-912, 2002.

392. Bunn PA Jr, Chan DC, Earle K, Zhao TL, Helfrich B, Kelly K, Piazza G, Whitehead CM, Pamukcu R, Thompson W and Alila H: Preclinical and clinical studies of docetaxel and exisulind in the treatment of human lung cancer. Semin Oncol 29 (1 Suppl 4): S87-S94, 2002.

393. Li Q and Shu Y: Pharmacological modulation of cytotoxicity and cellular uptake of anti-cancer drugs by PDE5 inhibitors in lung cancer cells. Pharm Res 31: 86-96, 2014.

394. Li WQ, Qureshi AA, Robinson KC and Han J: Sildenafil use and increased risk of incident melanoma in US men: A prospective cohort study. JAMA Intern Med 174: 964-970, 2014.

395. Marino N, Collins JW, Shen C, Caplen NJ, Merchant AS, Gökmen-Polar Y, Goswami CP, Hoshino T, Qian Y, Sledge GW Jr and Steeg PS: Identification and validation of genes with expression patterns inverse to multiple metastasis suppressor genes in breast cancer cell lines. Clin Exp Metastasis 31: 771-786, 2014.

396. Tinsley HN, Gary BD, Keeton AB, Zhang W, Abadi AH, Reynolds RC and Piazza GA: Sulindac sulfide selectively inhibits growth and induces apoptosis of human breast tumor cells by phosphodiesterase 5 inhibition, elevation of cyclic GMP, and activation of protein kinase G. Mol Cancer Ther 8: 3331-3340, 2009. 
397. Tinsley HN, Gary BD, Keeton AB, Lu W, Li Y and Piazza GA: Inhibition of PDE5 by sulindac sulfide selectively induces apoptosis and attenuates oncogenic Wnt/ $\beta$-catenin-mediated transcription in human breast tumor cells. Cancer Prev Res (Phila) 4: 1275-1284, 2011.

398. Thompson HJ, Jiang C, Lu J, Mehta RG, Piazza GA, Paranka NS, Pamukcu R and Ahnen DJ: Sulfone metabolite of sulindac inhibits mammary carcinogenesis. Cancer Res 57: 267-271, 1997.

399. Rice PL, Goldberg RJ, Ray EC, Driggers LJ and Ahnen DJ: Inhibition of extracellular signal-regulated kinase $1 / 2$ phosphorylation and induction of apoptosis by sulindac metabolites. Cancer Res 61: 1541-1547, 2001

400. Mei XL, Yang Y, Zhang YJ, Li Y, Zhao JM, Qiu JG, Zhang WJ, Jiang QW, Xue YQ, Zheng DW, et al: Sildenafil inhibits the growth of human colorectal cancer in vitro and in vivo. Am J Cancer Res 5: 3311-3324, 2015.

401. Islam BN, Sharman SK, Hou Y, Bridges AE, Singh N, Kim S, Kolhe R, Trillo-Tinoco J, Rodriguez PC, Berger FG, et al: Sildenafil suppresses inflammation-driven colorectal cancer in mice. Cancer Prev Res (Phila) 10: 377-388, 2017.

402. Giordano D, Giorgi M, Sette C, Biagioni S and Augusti-Tocco G: cAMP-dependent induction of PDE5 expression in murine neuroblastoma cell differentiation. FEBS Lett 446: 218-222, 1999.

403. Pantziarka P, Sukhatme V, Crispino S, Bouche G, Meheus L and Sukhatme VP: Repurposing drugs in oncology (ReDO)-selective PDE5 inhibitors as anti-cancer agents. Ecancermedicalscience 12: 824, 2018.

404. Roberts JL, Booth L, Conley A, Cruickshanks N, Malkin M, Kukreja RC, Grant S, Poklepovic A and Dent P: PDE5 inhibitors enhance the lethality of standard of care chemotherapy in pediatric CNS tumor cells. Cancer Biol Ther 15: 758-767, 2014.

405. Black KL, Yin D, Ong JM, Hu J, Konda BM, Wang X, Ko MK Bayan JA, Sacapano MR, Espinoza A, et al: PDE5 inhibitors enhance tumor permeability and efficacy of chemotherapy in a rat brain tumor model. Brain Res 1230: 290-302, 2008

406.Hu J, Ljubimova JY, Inoue S, Konda B, Patil R, Ding H, Espinoza A, Wawrowsky KA, Patil C, Ljubimov AV and Black KL: Phosphodiesterase type 5 inhibitors increase Herceptin transport and treatment efficacy in mouse metastatic brain tumor models. PLoS One 5: e10108, 2010

407. Wang R, Chen W, Zhang Q, Liu Y, Qiao X, Meng K and Mao Y: Phosphodiesterase type 5 inhibitor Tadalafil increases Rituximab treatment efficacy in a mouse brain lymphoma model. J Neurooncol 122: 35-42, 2015.

408. Sponziello M, Verrienti A, Rosignolo F, De Rose RF Pecce V, Maggisano V, Durante C, Bulotta S, Damante G, Giacomelli L, et al: PDE5 expression in human thyroid tumors and effects of PDE5 inhibitors on growth and migration of cancer cells. Endocrine 50: 434-441, 2015.

409. Loeb S, Folkvaljon Y, Lambe M, Robinson D, Garmo H, Ingvar $\mathrm{C}$ and Stattin P: Use of phosphodiesterase type 5 inhibitors for erectile dysfunction and risk of malignant melanoma. JAMA 313: 2449-2455, 2015.

410. Matthews A, Langan SM, Douglas IJ, Smeeth L and Bhaskaran K: Phosphodiesterase type 5 inhibitors and risk of malignant melanoma: Matched cohort study using primary care data from the UK clinical practice research datalink. PLoS Med 13: e1002037, 2016

411. Wang J, Shen Y, Wang J, Xue Y, Liao L, Thapa S and Ji K: Relation of phosphodiesterase type 5 inhibitors and malignan melanoma: A meta-analysis and systematic review. Oncotarget 8 : 46461-46467, 2017.

412. Lee JK, Nam DH and Lee J: Repurposing antipsychotics as glioblastoma therapeutics: Potentials and challenges. Oncol Lett 11: 1281-1286, 2016.

413. Jia H, Ren W, Feng Y, Wei T, Guo M, Guo J, Zhao J, Song X, Wang M, Zhao T, et al: The enhanced antitumour response of pimozide combined with the IDO inhibitor LMT in melanoma. Int J Oncol 53: 949-960, 2018.

414. Cai N, Zhou W, Ye LL, Chen J, Liang QN, Chang G and Chen JJ: The STAT3 inhibitor pimozide impedes cell proliferation and induces ROS generation in human osteosarcoma by suppressing catalase expression. Am J Transl Res 9: 3853-3866, 2017.

415. Nelson EA, Walker SR, Weisberg E, Bar-Natan M, Barrett R, Gashin LB, Terrell S, Klitgaard JL, Santo L, Addorio MR, et al: The STAT5 inhibitor pimozide decreases survival of chronic myelogenous leukemia cells resistant to kinase inhibitors Blood 117: 3421-3429, 2011.

416. McGrath PC and Neifeld JP: Inhibition of murine neuroblastoma growth by dopamine antagonists. J Surg Res 36: 413-419, 1984.
417. Ren Y, Tao J, Jiang Z, Guo D and Tang J: Pimozide suppresses colorectal cancer via inhibition of Wnt/beta-catenin signaling pathway. Life Sci 209: 267-273, 2018.

418. Strobl JS, Kirkwood KL, Lantz TK, Lewine MA, Peterson VA and Worley JF III: Inhibition of human breast cancer cell proliferation in tissue culture by the neuroleptic agents pimozide and thioridazine. Cancer Res 50: 5399-5405, 1990

419. Chen J, Dexheimer TS, Ai Y, Liang Q, Villamil MA, Inglese J, Maloney DJ, Jadhav A, Simeonov A and Zhuang Z: Selective and cell-active inhibitors of the USP1/UAF1 deubiquitinase complex reverse cisplatin resistance in non-small cell lung cancer cells. Chem Biol 18: 1390-1400, 2011

420. Zhou W, Chen MK, Yu HT, Zhong ZH, Cai N, Chen GZ, Zhang $\mathrm{P}$ and Chen JJ: The antipsychotic drug pimozide inhibits cell growth in prostate cancer through suppression of STAT3 activation. Int J Oncol 48: 322-328, 2016.

421. Goncalves JM, Silva CAB, Rivero ERC and Cordeiro MMR Inhibition of cancer stem cells promoted by Pimozide. Clin Exp Pharmacol Physiol 46: 116-125, 2019.

422. Fako V, Yu Z, Henrich CJ, Ransom T, Budhu AS and Wang XW: Inhibition of wnt $/ \beta$-catenin signaling in hepatocellular carcinoma by an antipsychotic drug pimozide. Int J Biol Sci 12 768-775, 2016.

423. Choi J, Lee YJ, Yoon YJ, Kim CH, Park SJ, Kim SY, Doo Kim N, Cho Han D and Kwon BM: Pimozide suppresses cancer cell migration and tumor metastasis through binding to ARPC2, a subunit of the Arp2/3 complex. Cancer Sci 110: 3788-3801, 2019

424. Dakir EH, Pickard A, Srivastava K, McCrudden CM, Gross SR, Lloyd S, Zhang SD, Margariti A, Morgan R, Rudland PS and El-Tanani M: The anti-psychotic drug pimozide is a novel chemotherapeutic for breast cancer. Oncotarget 9: 34889-34910, 2018.

425. Kim JY, Park Y, Lee BM, Kim HS and Yoon S: P-gp inhibition by the Anti-psychotic drug pimozide increases apoptosis, as well as expression of $\mathrm{pRb}$ and $\mathrm{pH} 2 \mathrm{AX}$ in Highly Drug-resistant KBV20C cells. Anticancer Res 38: 5685-5692, 2018.

426. Chen JJ, Zhang LN, Cai N, Zhang Z and Ji K: Antipsychotic agent pimozide promotes reversible proliferative suppression by inducing cellular quiescence in liver cancer. Oncol Rep 42: $1101-1109,2019$

427. Clarke GL, Bhattacherjee A, Tague SE, Hasan W and Smith PG: ß-adrenoceptor blockers increase cardiac sympathetic innervation by inhibiting autoreceptor suppression of axon growth J Neurosci 30: 12446-12454, 2010.

428. Sica D, Frishman WH and Manowitz N: Pharmacokinetics of propranolol after single and multiple dosing with sustained release propranolol or propranolol CR (innopran XL), a new chronotherapeutic formulation. Heart Dis 5: 176-181, 2003.

429. Ge J, Zheng J, Zhang L, Yuan W and Zhao H: Oral propranolol combined with topical timolol for compound infantile hemangiomas: A retrospective study. Sci Rep 6: 19765, 2016.

430. Rotter A and de Oliveira ZNP: Infantile hemangioma: Pathogenesis and mechanisms of action of propranolol. J Dtsch Dermatol Ges 15: 1185-1190, 2017.

431. de Lorenzo MS, Ripoll GV, Yoshiji H, Yamazaki M, Thorgeirsson UP, Alonso DF and Gomez DE: Altered tumor angiogenesis and metastasis of B16 melanoma in transgenic mice overexpressing tissue inhibitor of metalloproteinases-1. In Vivo 17: 45-50, 2003.

432. Storch CH and Hoeger PH: Propranolol for infantile haemangiomas: Insights into the molecular mechanisms of action. Br J Dermatol 163: 269-274, 2010.

433. Wagner MJ, Cranmer LD, Loggers ET and Pollack SM: Propranolol for the treatment of vascular sarcomas. J Exp Pharmacol 10: 51-58, 2018

434. De Giorgi V, Grazzini M, Benemei S, Marchionni N, Botteri E, Pennacchioli E, Geppetti P and Gandini S: Propranolol for Off-label treatment of patients with melanoma: Results from a cohort study. JAMA Oncol 4: e172908, 2018.

435. Barron TI, Connolly RM, Sharp L, Bennett K and Visvanathan K Beta blockers and breast cancer mortality: A population-based study. J Clin Oncol 29: 2635-2644, 2011

436. Szewczyk M, Richter C, Briese V and Richter DU: A retrospective in vitro study of the impact of anti-diabetics and cardioselective pharmaceuticals on breast cancer. Anticancer Res 32: 2133-2138, 2012.

437. Zhang D, Ma Q, Shen S and Hu H: Inhibition of pancreatic cancer cell proliferation by propranolol occurs through apoptosis induction: The study of beta-adrenoceptor antagonist's anticancer effect in pancreatic cancer cell. Pancreas 38: 94-100, 2009. 
438. Annabi B, Lachambre MP, Plouffe K, Moumdjian R and Beliveau R: Propranolol adrenergic blockade inhibits human brain endothelial cells tubulogenesis and matrix metalloproteinase-9 secretion. Pharmacol Res 60: 438-445, 2009.

439. Sminia P, Kuipers G, Geldof A, Lafleur V and Slotman B: COX-2 inhibitors act as radiosensitizer in tumor treatment. Biomed Pharmacother 59 (Suppl 2): S272-S275, 2005.

440.Geoerger B, Gaspar N, Opolon P, Morizet J, Devanz P, Lecluse Y, Valent A, Lacroix L, Grill J and Vassal G: EGFR tyrosine kinase inhibition radiosensitizes and induces apoptosis in malignant glioma and childhood ependymoma xenografts. Int J Cancer 123: 209-216, 2008.

441.Zimmermann M, Zouhair A, Azria D and Ozsahin M: The epidermal growth factor receptor (EGFR) in head and neck cancer: Its role and treatment implications. Radiat Oncol 1: 11, 2006.

442. Rico M, Baglioni M, Bondarenko M, Laluce NC, Rozados V, André N, Carré M, Scharovsky OG and Menacho Márquez M: Metformin and propranolol combination prevents cancer progression and metastasis in different breast cancer models. Oncotarget 8: 2874-2889, 2017.

443. Montoya A, Amaya CN, Belmont A, Diab N, Trevino R, Villanueva G, Rains S, Sanchez LA, Badri N, Otoukesh S, et al: Use of non-selective $\beta$-blockers is associated with decreased tumor proliferative indices in early stage breast cancer. Oncotarget 8: 6446-6460, 2017.

444. Pantziarka P, Bryan BA, Crispino S and Dickerson EB: Propranolol and breast cancer-a work in progress. Ecancermedicalscience 12: ed82, 2018

445. Gomez DE, Hartzler JL, Corbitt RH, Nason AM and Thorgeirsson UP: Immunomagnetic separation as a final purification step of liver endothelial cells. In Vitro Cell Dev Biol Anim 29: 451-455, 1993

446.Liao JQ, Su XQ, Peng XC, Shi HS, Zhang HL and Yang L: Antitumor effect by combination of recombinant endostatin adenovirus with carboplatin. Sichuan Da Xue Xue Bao Yi Xue Ban 41: 386-389, 2010 (In Chinese).

447. Pasquier E, Street J, Pouchy C, Carre M, Gifford AJ, Murray J, Norris MD, Trahair T, Andre N and Kavallaris M: $\beta$-blockers increase response to chemotherapy via direct antitumour and anti-angiogenic mechanisms in neuroblastoma. Br J Cancer 108: 2485-2494, 2013.

448. Shah SM, Carey IM, Owen CG, Harris T, Dewilde S and Cook DG: Does $\beta$-adrenoceptor blocker therapy improve cancer survival? Findings from a population-based retrospective cohort study. Br J Clin Pharmacol 72: 157-161, 2011.

449. Forbes A, Anoopkumar-Dukie S, Chess-Williams R and McDermott C: Relative cytotoxic potencies and cell death mechanisms of alpha1-adrenoceptor antagonists in prostate cancer cell lines. Prostate 76: 757-766, 2016.

450. Miller RG, Mitchell JD and Moore DH: Riluzole for amyotrophic lateral sclerosis (ALS)/motor neuron disease (MND). Cochrane Database Syst Rev: CD001447, 2012.

451. Song JH, Huang CS, Nagata K, Yeh JZ and Narahashi T: Differential action of riluzole on tetrodotoxin-sensitive and tetrodotoxin-resistant sodium channels. J Pharmacol Exp Ther 282: 707-714, 1997.

452. Lewerenz J, Hewett SJ, Huang Y, Lambros M, Gout PW, Kalivas PW, Massie A, Smolders I, Methner A, Pergande M, et al: The cystine/glutamate antiporter system $\mathrm{x}(\mathrm{c})(-)$ in health and disease: From molecular mechanisms to novel therapeutic opportunities. Antioxid Redox Signal 18: 522-555, 2013.

453. Bridges RJ, Natale NR and Patel SA: System xc ${ }^{-}$cystine/glutamate antiporter: An update on molecular pharmacology and roles within the CNS. Br J Pharmacol 165: 20-34, 2012.

454. Sperling S, Aung T, Martin S, Rohde V and Ninkovic M: Riluzole: A potential therapeutic intervention in human brain tumor stem-like cells. Oncotarget 8: 96697-96709, 2017.

455. Seidlitz EP, Sharma MK, Saikali Z, Ghert M and Singh G: Cancer cell lines release glutamate into the extracellular environment. Clin Exp Metastasis 26: 781-787, 2009.

456. Sattler R, Tyler B, Hoover B, Coddington LT, Recinos V, Hwang L, Brem $\mathrm{H}$ and Rothstein JD: Increased expression of glutamate transporter GLT-1 in peritumoral tissue associated with prolonged survival and decreases in tumor growth in a rat model of experimental malignant glioma. J Neurosurg 119: 878-886, 2013.

457. Shin SS, Jeong BS, Wall BA, Li J, Shan NL, Wen Y, Goydos JS and Chen S: Participation of XCT in melanoma cell proliferation in vitro and tumorigenesis in vivo. Oncogenesis 7: 86, 2018.
458. Wadosky KM, Shourideh M, Goodrich DW and Koochekpour S: Riluzole induces AR degradation via endoplasmic reticulum stress pathway in androgen-dependent and Castration-resistant prostate cancer cells. Prostate 79: 140-150, 2019.

459. Yip D, Le MN, Chan JL, Lee JH, Mehnert JA, Yudd A, Kempf J, Shih WJ, Chen S and Goydos JS: A phase 0 trial of riluzole in patients with resectable stage III and IV melanoma. Clin Cancer Res 15: 3896-3902, 2009.

460. Fumagalli E, Funicello M, Rauen T, Gobbi M and Mennini T: Riluzole enhances the activity of glutamate transporters GLAST, GLT1 and EAAC1. Eur J Pharmacol 578: 171-176, 2008

461. Chen Y, Hu S, Mu L, Zhao B, Wang M, Yang N, Bao G, Zhu C and $\mathrm{Wu} \mathrm{X}$ : Slc7a11 modulated by POU2F1 is involved in pigmentation in rabbit. Int J Mol Sci 20: pii: E2493, 2019.

462. Florell SR, Bowen AR, Hanks AN, Murphy KJ and Grossman D: Proliferation, apoptosis, and survivin expression in a spectrum of melanocytic nevi. J Cutan Pathol 32: 45-49, 2005.

463. Wall BA, Wangari-Talbot J, Shin SS, Schiff D, Sierra J, Yu LJ, Khan A, Haffty B, Goydos JS and Chen S: Disruption of GRM1-mediated signalling using riluzole results in DNA damage in melanoma cells. Pigment Cell Melanoma Res 27: 263-274, 2014

464. Lee HJ, Wall BA, Wangari-Talbot J, Shin SS, Rosenberg S, Chan JL, Namkoong J, Goydos JS and Chen S: Glutamatergic pathway targeting in melanoma: Single-agent and combinatorial therapies. Clin Cancer Res 17: 7080-7092, 2011.

465. Yu LJ, Wall BA and Chen S: The current management of brain metastasis in melanoma: A focus on riluzole. Expert Rev Neurother 15: 779-792, 2015.

466. Davies JT, Delfino SF, Feinberg CE, Johnson MF, Nappi VL, Olinger JT, Schwab AP and Swanson HI: Current and emerging uses of statins in clinical therapeutics: A review. Lipid Insights 9: $13-29,2016$

467. WilleyJZandElkindMS:3-Hydroxy-3-methylglutaryl-coenzyme A reductase inhibitors in the treatment of central nervous system diseases. Arch Neurol 67: 1062-1067, 2010.

468. Ricco N, Flor A, Wolfgeher D, Efimova EV, Ramamurthy A, Appelbe OK, Brinkman J, Truman AW, Spiotto MT and Kron SJ: Mevalonate pathway activity as a determinant of radiation sensitivity in head and neck cancer. Mol Oncol 13: 1927-1943, 2019.

469. Zodda D, Giammona R and Schifilliti S: Treatment strategy for dyslipidemia in cardiovascular disease prevention: Focus on old and new drugs. Pharmacy (Basel) 6: pii: E10, 2018.

470. Efimova EV, Ricco N, Labay E, Mauceri HJ, Flor AC, Ramamurthy A, Sutton HG, Weichselbaum RR and Kron SJ: HMG-CoA reductase inhibition delays DNA repair and promotes senescence after tumor irradiation. Mol Cancer Ther 17: 407-418, 2018

471. Waller DD, Park J and Tsantrizos YS: Inhibition of farnesyl pyrophosphate (FPP) and/or geranylgeranyl pyrophosphate (GGPP) biosynthesis and its implication in the treatment of cancers. Crit Rev Biochem Mol Biol 54: 41-60, 2019.

472. Jeong A, Suazo KF, Wood WG, Distefano MD and Li L: Isoprenoids and protein prenylation: Implications in the pathogenesis and therapeutic intervention of Alzheimer's disease. Crit Rev Biochem Mol Biol 53: 279-310, 2018.

473. Alonso DF, Farina HG, Skilton G, Gabri MR, De Lorenzo MS and Gomez DE: Reduction of mouse mammary tumor formation and metastasis by lovastatin, an inhibitor of the mevalonate pathway of cholesterol synthesis. Breast Cancer Res Treat 50: 83-93, 1998.

474. Cardama GA, Gonzalez N, Maggio J, Menna PL and Gomez DE: Rho GTPases as therapeutic targets in cancer (Review). Int J Oncol 51: 1025-1034, 2017.

475. Farina HG, Bublik DR, Alonso DF and Gomez DE: Lovastatin alters cytoskeleton organization and inhibits experimental metastasis of mammary carcinoma cells. Clin Exp Metastasis 19: 551-559, 2002

476. Liao JK and Laufs U: Pleiotropic effects of statins. Annu Rev Pharmacol Toxicol 45: 89-118, 2005.

477. Menna PL, Parera RL, Cardama GA, Alonso DF, Gomez DE and Farina HG: Enhanced cytostatic activity of statins in mouse mammary carcinoma cells overexpressing $\beta 2$-chimaerin. Mol Med Rep 2: 97-102, 2009.

478. Jakobisiak M and Golab J: Potential antitumor effects of statins (Review). Int J Oncol 23: 1055-1069, 2003.

479. Undela K, Shah CS and Mothe RK: Statin use and risk of cancer: An overview of meta-analyses. World J Meta-Anal 5: 41-53, 2017. 
480. Hu YB, Hu ED and Fu RQ: Statin use and cancer incidence in patients with type 2 diabetes mellitus: A network Meta-analysis. Gastroenterol Res Pract 2018: 8620682, 2018.

481. Singh PP and Singh S: Statins are associated with reduced risk of gastric cancer: A systematic review and meta-analysis. Ann Oncol 24: 1721-1730, 2013.

482. Thomas T, Loke Y and Beales ILP: Systematic review and Meta-analysis: Use of statins is associated with a reduced incidence of oesophageal adenocarcinoma. J Gastrointest Cancer 49: 442-454, 2018.

483. Pascual S, Herrera I and Irurzun J: New advances in hepatocellular carcinoma. World J Hepatol 8: 421-438, 2016.

484. Desai P, Chlebowski R, Cauley JA, Manson JE, Wu C, Martin LW, Jay A, Bock C, Cote M, Petrucelli N, et al: Prospective analysis of association between statin use and breast cancer risk in the women's health initiative. Cancer Epidemiol Biomarkers Prev 22: 1868-1876, 2013.

485. Jacobs EJ, Newton CC, Thun MJ and Gapstur SM: Long-term use of cholesterol-lowering drugs and cancer incidence in a large United States cohort. Cancer Res 71: 1763-1771, 2011.

486. Boudreau DM, Yu O and Johnson J: Statin use and cancer risk: A comprehensive review. Expert Opin Drug Saf 9: 603-621, 2010.

487. Roix JJ, Harrison SD, Rainbolt EA, Meshaw KR, McMurry AS, Cheung $\mathrm{P}$ and Saha S: Systematic repurposing screening in xenograft models identifies approved drugs with novel anti-cancer activity. PLoS One 9: e101708, 2014.

488. Vargesson N: Thalidomide-induced teratogenesis: History and mechanisms. Birth Defects Res C Embryo Today 105: 140-156, 2015.

489. Therapontos C, Erskine L, Gardner ER, Figg WD and Vargesson N: Thalidomide induces limb defects by preventing angiogenic outgrowth during early limb formation. Proc Natl Acad Sci USA 106: 8573-8578, 2009.

490. Shi Q and Chen L: Cereblon: A protein crucial to the multiple functions of immunomodulatory drugs as well as cell metabolism and disease generation. J Immunol Res 2017: 9130608 , 2017.

491. D'Amato RJ, Loughnan MS, Flynn E and Folkman J: Thalidomide is an inhibitor of angiogenesis. Proc Natl Acad Sci USA 91: 4082-4085, 1994

492. Singhal S, Mehta J, Desikan R, Ayers D, Roberson P, Eddlemon P, Munshi N, Anaissie E, Wilson C, Dhodapkar M, et al: Antitumor activity of thalidomide in refractory multiple myeloma. N Engl J Med 341: 1565-1571, 1999.

493. Sissung TM, Thordardottir S, Gardner ER and Figg WD: Current status of thalidomide and CC-5013 in the treatment of metastatic prostate cancer. Anticancer Agents Med Chem 9: 1058-1069, 2009

494. Mercurio A, Adriani G, Catalano A, Carocci A, Rao L, Lentini G, Cavalluzzi MM, Franchini C, Vacca A and Corbo F: A Mini-review on thalidomide: Chemistry, mechanisms of action, therapeutic potential and anti-angiogenic properties in multiple myeloma. Curr Med Chem 24: 2736-2744, 2017.

495. Aragon-Ching JB, Li H, Gardner ER and Figg WD: Thalidomide analogues as anticancer drugs. Recent Pat Anticancer Drug Discov 2: 167-174, 2007.

496. Zeldis JB, Knight R, Hussein M, Chopra R and Muller G: A review of the history, properties, and use of the immunomodulatory compound lenalidomide. Ann N Y Acad Sci 1222: 76-82, 2011

497. Palumbo A, Dimopoulos M, San Miguel J, Harousseau JL Attal M, Hussein M, Knop S, Ludwig H, von Lilienfeld-Toal M and Sonneveld P: Lenalidomide in combination with dexamethasone for the treatment of relapsed or refractory multiple myeloma. Blood Rev 23: 87-93, 2009.

498. Holstein SA, Suman VJ and McCarthy PL: Update on the role of lenalidomide in patients with multiple myeloma. Ther Adv Hematol 9: 175-190, 2018.

499. Fan WJ, Fan ZQ, Yang MJ, Pan YZ and Bai H: Molecular mechanism of CRBN in the activity of lenalidomid eagainst Myeloma-review. Zhongguo Shi Yan Xue Ye Xue Za Zhi 26 : 1240-1243, 2018 (In Chinese).

500. Ying L, YinHui T, Yunliang $\mathrm{Z}$ and Sun H: Lenalidomide and the risk of serious infection in patients with multiple myeloma: A systematic review and meta-analysis. Oncotarget 8: 46593-46600, 2017.

501. Bringhen S, Offidani M, Palmieri S, Pisani F, Rizzi R, Spada S, Evangelista A, Di Renzo N, Musto P, Marcatti M, et al: Early mortality in myeloma patients treated with first-generation novel agents thalidomide, lenalidomide, bortezomib at diagnosis: A pooled analysis. Crit Rev Oncol Hematol 130: 27-35, 2018.
502. Sherbet GV: Therapeutic potential of thalidomide and its analogues in the treatment of cancer. Anticancer Res 35: 5767-5772, 2015.

503. Cipriani A, Reid K, Young AH, Macritchie K and Geddes J: Valproic acid, valproate and divalproex in the maintenance treatment of bipolar disorder. Cochrane Database Syst Rev: CD003196, 2013.

504. Owens MJ and Nemeroff CB: Pharmacology of valproate. Psychopharmacol Bull 37 (Suppl 2): S17-S24, 2003.

505. Annunziato AT and Hansen JC: Role of histone acetylation in the assembly and modulation of chromatin structures. Gene Expr 9: 37-61, 2000.

506. Legube $\mathrm{G}$ and Trouche D: Regulating histone acetyltransferases and deacetylases. EMBO Rep 4: 944-947, 2003.

507. Eckschlager T, Plch J, Stiborova M and Hrabeta J: Histone deacetylase inhibitors as anticancer drugs. Int J Mol Sci 18: pii: E1414, 2017.

508. Mauger TF, Kuennen RA, Smith RH and Sawyer W: Acanthamoeba and Stenotrophomonas maltophilia keratitis with fungal keratitis in the contralateral eye. Clin Ophthalmol 4: 1207-1209, 2010.

509. Chen HP, Zhao YT and Zhao TC: Histone deacetylases and mechanisms of regulation of gene expression. Crit Rev Oncog 20: 35-47, 2015.

510. Eberharter A and Becker PB: Histone acetylation: A switch between repressive and permissive chromatin. Second in review series on chromatin dynamics. EMBO Rep 3: 224-229, 2002.

511. Glozak MA and Seto E: Histone deacetylases and cancer. Oncogene 26: 5420-5432, 2007.

512. Moschos MM, Dettoraki M, Androudi S, Kalogeropoulos D, Lavaris A, Garmpis N, Damaskos C, Garmpi A and Tsatsos M: The role of histone deacetylase inhibitors in uveal melanoma: Current evidence. Anticancer Res 38: 3817-3824, 2018.

513. Ji MM, Wang L, Zhan Q, Xue W, Zhao Y, Zhao X, Xu PP, Shen Y, Liu H, Janin A, et al: Induction of autophagy by valproic acid enhanced lymphoma cell chemosensitivity through HDAC-independent and IP3-mediated PRKAA activation. Autophagy 11: 2160-2171, 2015.

514. Sanaei M, Kavoosi F and Mansoori O: Effect of valproic acid in comparison with vorinostat on cell growth inhibition and apoptosis induction in the human colon cancer SW48 cells in vitro. Exp Oncol 40: 95-100, 2018.

515. Chou YW, Chaturvedi NK, Ouyang S, Lin FF, Kaushik D, Wang J, Kim I and Lin MF: Histone deacetylase inhibitor valproic acid suppresses the growth and increases the androgen responsiveness of prostate cancer cells. Cancer Lett 311: 177-186, 2011

516. Witt D, Burfeind P, von Hardenberg S, Opitz L, Salinas-Riester G, Bremmer F, Schweyer S, Thelen P, Neesen J and Kaulfuss S: Valproic acid inhibits the proliferation of cancer cells by re-expressing cyclin D2. Carcinogenesis 34: 1115-1124, 2013.

517. Gan CP, Hamid S, Hor SY, Zain RB, Ismail SM, Wan Mustafa WM, Teo SH, Saunders N and Cheong SC: Valproic acid: Growth inhibition of head and neck cancer by induction of terminal differentiation and senescence. Head Neck 34: 344-353, 2012.

518. Tran LNK, Kichenadasse G, Butler LM, Centenera MM, Morel KL, Ormsby RJ, Michael MZ, Lower KM and Sykes PJ: The combination of metformin and valproic acid induces synergistic apoptosis in the presence of $\mathrm{p} 53$ and androgen signaling in prostate cancer. Mol Cancer Ther 16: 2689-2700, 2017.

519. Cerna T, Hrabeta J, Eckschlager T, Frei E, Schmeiser HH, Arlt VM and Stiborová M: The histone deacetylase inhibitor valproic acid exerts a synergistic cytotoxicity with the DNA-damaging drug ellipticine in neuroblastoma cells. Int J Mol Sci 19: pii: E164, 2018.

520. Liu S, Liang B, Jia H, Jiao Y, Pang Z and Huang Y: Evaluation of cell death pathways initiated by antitumor drugs melatonin and valproic acid in bladder cancer cells. FEBS Open Bio 7: 798-810, 2017

521. Terranova-Barberio M, Roca MS, Zotti AI, Leone A, Bruzzese F, Vitagliano C, Scogliamiglio G, Russo D, D'Angelo G, Franco R, et al: Valproic acid potentiates the anticancer activity of capecitabine in vitro and in vivo in breast cancer models via induction of thymidine phosphorylase expression. Oncotarget 7: 7715-7731, 2016.

522. Tung EW and Winn LM: Valproic acid increases formation of reactive oxygen species and induces apoptosis in postimplantation embryos: A role for oxidative stress in valproic acid-induced neural tube defects. Mol Pharmacol 80: 979-987, 2011. 
523. Abdelaleem M, Ezzat H, Osama M, Megahed A, Alaa W, Gaber A, Shafei A and Refaat A: Prospects for repurposing CNS drugs for cancer treatment. Oncol Rev 13: 411, 2019.

524. Yu W, Wang P, Ma H, Zhang G, Yulin Z, Lu B, Wang H and Dong M: Suppression of T-type Ca2+ channels inhibited human laryngeal squamous cell carcinoma cell proliferation running title: Roles of T-type $\mathrm{Ca} 2+$ channels in LSCC cell proliferation. Clin Lab 60: 621-628, 2014.

525. Sun YH, Gao X, Tang YJ, Xu CL and Wang LH: Androgens induce increases in intracellular calcium via a $\mathrm{G}$ protein-coupled receptor in LNCaP prostate cancer cells. J Androl 27: 671-678, 2006.

526. Jensen RL and Wurster RD: Calcium channel antagonists inhibit growth of subcutaneous xenograft meningiomas in nude mice. Surg Neurol 55: 275-283, 2001.

527. Ragel BT, Asher AL, Selden $\mathrm{N}$ and MacDonald JD: Self-assessment in neurological surgery: The SANS wired white paper. Neurosurgery 59: 759-766, 2006.

528. Hajighasemi $F$ and Mirshafiey A: Effect of verapamil on vascular endothelial growth factor production in immunocompetent cells. Eur Respiratory J 46: PA4011, 2015.

529. Taylor JM and Simpson RU: Inhibition of cancer cell growth by calcium channel antagonists in the athymic mouse. Cancer Res 52: 2413-2418, 1992

530. Yoshida J, Ishibashi T and Nishio M: Antiproliferative effect of $\mathrm{Ca} 2+$ channel blockers on human epidermoid carcinoma A431 cells. Eur J Pharmacol 472: 23-31, 2003.

531. Wilson LE, D'Aloisio AA, Sandler DP and Taylor JA: Long-term use of calcium channel blocking drugs and breast cancer risk in a prospective cohort of US and Puerto Rican women. Breast Cancer Res 18: 61, 2016.

532. Mason RP: Calcium channel blockers, apoptosis and cancer: Is there a biologic relationship? J Am Coll Cardiol 34: 1857-1866, 1999

533. Zhao L, Zhao Y, Schwarz B, Mysliwietz J, Hartig R, Camaj P, Bao Q, Jauch KW, Guba M, Ellwart JW, et al: Verapamil inhibits tumor progression of chemotherapy-resistant pancreatic cancer side population cells. Int J Oncol 49: 99-110, 2016.

534. Furuya N, Yu J, Byfield M, Pattingre S and Levine B: The evolutionarily conserved domain of Beclin 1 is required for Vps34 binding, autophagy and tumor suppressor function. Autophagy 1: 46-52, 2005 .

535. Kania E, Pajak B, O'Prey J, Sierra Gonzalez P, Litwiniuk A, Urbańska K, Ryan KM and Orzechowski A: Verapamil treatment induces cytoprotective autophagy by modulating cellular metabolism. FEBS J 284: 1370-1387, 2017.

536. Strigun A, Noor F, Pironti A, Niklas J, Yang TH and Heinzle E: Metabolic flux analysis gives an insight on verapamil induced changes in central metabolism of HL-1 cells. J Biotechnol 155: 299-307, 2011

537. Granchi C and Minutolo F: Anticancer agents that counteract tumor glycolysis. ChemMedChem 7: 1318-1350, 2012.

538. Huang D, Lan H, Liu F, Wang S, Chen X, Jin K and Mou X: Anti-angiogenesis or pro-angiogenesis for cancer treatment: Focus on drug distribution. Int J Clin Exp Med 8: 8369-8376, 2015.

539. Galeano E, Rojas JJ and Martinez A: Pharmacological developments obtained from marine natural products and current pipeline perspective. Nat Prod Commun 6: 287-300, 2011.

540. De Clercq E: The history of antiretrovirals: Key discoveries over the past 25 years. Rev Med Virol 19: 287-299, 2009.

541. Falchetti A, Franchi A, Bordi C, Mavilia C, Masi L, Cioppi F, Recenti R, Picariello L, Marini F, Del Monte F, et al: Azidothymidine induces apoptosis and inhibits cell growth and telomerase activity of human parathyroid cancer cells in culture. J Bone Miner Res 20: 410-418, 2005.

542. Armando RG, Mengual Gomez DL, Maggio J, Sanmartin MC and Gomez DE: Telomeropathies: Etiology, diagnosis, treatment and follow-up. Ethical and legal considerations. Clin Genet 96: $3-16,2019$.

543. Mason M, Schuller A and Skordalakes E: Telomerase structure function. Curr Opin Struct Biol 21: 92-100, 2011.

544. Kim NW, Piatyszek MA, Prowse KR, Harley CB, West MD, Ho PL, Coviello GM, Wright WE, Weinrich SL and Shay JW: Specific association of human telomerase activity with immortal cells and cancer. Science 266: 2011-2015, 1994

545. Gomez D, Kassim A and Olivero O: Preferential incorporation of 3'-azido-2',3'-dideoxythymidine (azt) in telomeric sequences of cho cells. Int J Oncol 7: 1057-1060, 1995.

546. Gomez DE, Armando RG and Alonso DF: AZT as a telomerase inhibitor. Front Oncol 2: 113, 2012
547. Beltz L, Moran R, Elsawy O, Sadler J and Jurgenson J: The effects of telomerase inhibitors on lymphocyte function. Anticancer Res 19: 3205-3211, 1999.

548. Multani AS, Furlong C and Pathak S: Reduction of telomeric signals in murine melanoma and human breast cancer cell lines treated with 3'-azido-2'-3'-dideoxythymidine. Int J Oncol 13: 923-925, 1998.

549. Melana SM, Holland JF and Pogo BG: Inhibition of cell growth and telomerase activity of breast cancer cells in vitro by 3'-azido-3'-deoxythymidine. Clin Cancer Res 4: 693-696, 1998.

550. Jeng KS, Sheen IS and Jeng WJ: Azidothymidine treatment of hepatocellular carcinoma in rats: An in vivo study of telomerase inhibition. Hepatogastroenterology 58: 2091-2096, 2011.

551. Murakami J, Nagai N, Shigemasa K and Ohama K: Inhibition of telomerase activity and cell proliferation by a reverse transcriptase inhibitor in gynaecological cancer cell lines. Eur J Cancer 35: 1027-1034, 1999.

552. Johnston JS, Johnson A, Gan Y, Wientjes MG and Au JL: Synergy between 3'-azido-3'-deoxythymidine and paclitaxel in human pharynx FaDu cells. Pharm Res 20: 957-961, 2003.

553. Brown T, Sigurdson E, Rogatko A and Broccoli D: Telomerase inhibition using azidothymidine in the HT-29 colon cancer cell line. Ann Surg Oncol 10: 910-915, 2003.

554. Tejera AM, Alonso DF, Gomez DE and Olivero OA: Chronic in vitro exposure to 3'-azido-2',3'-dideoxythymidine induces senescence and apoptosis and reduces tumorigenicity of metastatic mouse mammary tumor cells. Breast Cancer Res Treat 65: 93-99, 2001.

555. Faraj A, El Alaoui AM, Gosselin G, Imbach JL, Morrow C and Sommadossi JP: Effects of beta-L-3'-azido-3'-deoxythymidine 5'-triphosphate on host and viral DNA polymerases. Antiviral Res 47: 97-102, 2000.

556. Armando RG, Gomez DM and Gomez DE: AZT exerts its antitumoral effect by telomeric and non-telomeric effects in a mammary adenocarcinoma model. Oncol Rep 36: 2731-2736, 2016.

557. Gomez DL, Farina HG and Gomez DE: Telomerase regulation: A key to inhibition? (Review). Int J Oncol 43: 1351-1356, 2013.

558. Song L, Ding S, Ge Z, Zhu X, Qiu C, Wang Y, Lai E, Yang W, Sun Y, Chow SA and Yu L: Nucleoside/nucleotide reverse transcriptase inhibitors attenuate angiogenesis and lymphangiogenesis by impairing receptor tyrosine kinases signalling in endothelial cells. Br J Pharmacol 175: 1241-1259, 2018.

559. Datta A, Bellon M, Sinha-Datta U, Bazarbachi A, Lepelletier Y, Canioni D, Waldmann TA, Hermine O and Nicot C: Persistent inhibition of telomerase reprograms adult T-cell leukemia to p53-dependent senescence. Blood 108: 1021-1029, 2006.

560. Posner MR, Darnowski JW, Weitberg AB, Dudley MN, Corvese D, Cummings FJ, Clark J, Murray C, Clendennin N, Bigley J, et al: High-dose intravenous zidovudine with 5-fluorouracil and leucovorin. A phase I trial. Cancer 70: 2929-2934, 1992.

561. Marchbanks K, Dudley MN, Posner MR and Darnowski J: Pharmacokinetics and pharmacodynamics of high-dose zidovudine administered as a continuous infusion in patients with cancer. Pharmacotherapy 15: 451-457, 1995.

562. Clark J, Sikov W, Cummings F, Browne M, Akerley W, Wanebo H, Weitberg A, Kennedy T, Cole B, Bigley J, et al: Phase II study of 5-fluoruracil leucovorin and azidothymidine in patients with metastatic colorectal cancer. J Cancer Res Clin Oncol 122: 554-558, 1996.

563. Miller KD, Loehrer PJ, Gonin R, Weber G, Ansari R, Pletcher W, McClean J, Spiridonidis CH and Mortimer J: A phase II study of weekly oral methotrexate and zidovudine (AZT) in advanced adenocarcinoma of the pancreas and hepatocellular carcinoma. Invest New Drugs 14: 207-212, 1996.

564. Falcone A, Lencioni M, Brunetti I, Pfanner E, Allegrini G, Antonuzzo A, Andreuccetti M, Malvaldi G, Danesi R, Del Tacca $M$ and Conte PF: Maximum tolerable doses of intravenous zidovudine in combination with 5-fluorouracil and leucovorin in metastatic colorectal cancer patients. Clinical evidence of significant antitumor activity and enhancement of zidovudine-induced DNA single strand breaks in peripheral nuclear blood cells. Ann Oncol 8: 539-545, 1997.

565. Saraswati AP, Relitti N, Brindisi M, Gemma S, Zisterer D, Butini S and Campiani G: Raising the bar in anticancer therapy: Recent advances in, and perspectives on, telomerase inhibitors. Drug Discov Today 24: 1370-1388, 2019.

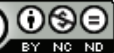

This work is licensed under a Creative Commons Attribution-NonCommercial-NoDerivatives 4.0 International (CC BY-NC-ND 4.0) License. 